Portland State University

PDXScholar

6-1992

\title{
Alzheimer's Disease Caregivers: The Transition from Home Care to Formal Care
}

Marie Theresa Duncan

Portland State University

Follow this and additional works at: https://pdxscholar.library.pdx.edu/open_access_etds

Part of the Health Policy Commons, and the Social Welfare Commons Let us know how access to this document benefits you.

\section{Recommended Citation}

Duncan, Marie Theresa, "Alzheimer's Disease Caregivers: The Transition from Home Care to Formal Care" (1992). Dissertations and Theses. Paper 3228.

https://doi.org/10.15760/etd.3220

This Dissertation is brought to you for free and open access. It has been accepted for inclusion in Dissertations and Theses by an authorized administrator of PDXScholar. Please contact us if we can make this document more accessible: pdxscholar@pdx.edu. 
ALZHEIMER'S DISEASE CAREGIVERS:

THE TRANSITION FROM HOME CARE TO FORMAL CARE

\begin{abstract}
by
MARIE THERESA DUNCAN

A dissertation submitted in partial fulfillment of the requirements for the degree of
\end{abstract}

DOCTOR OF PHILOSOPHY

in

URBAN STUDIES

Portland State University

(c) 1992 
TO THE OFFICE OF GRADUATE STUDIES:

The members of the Committee approve the dissertation of Marie Theresa Duncan presented June 4, 1992.
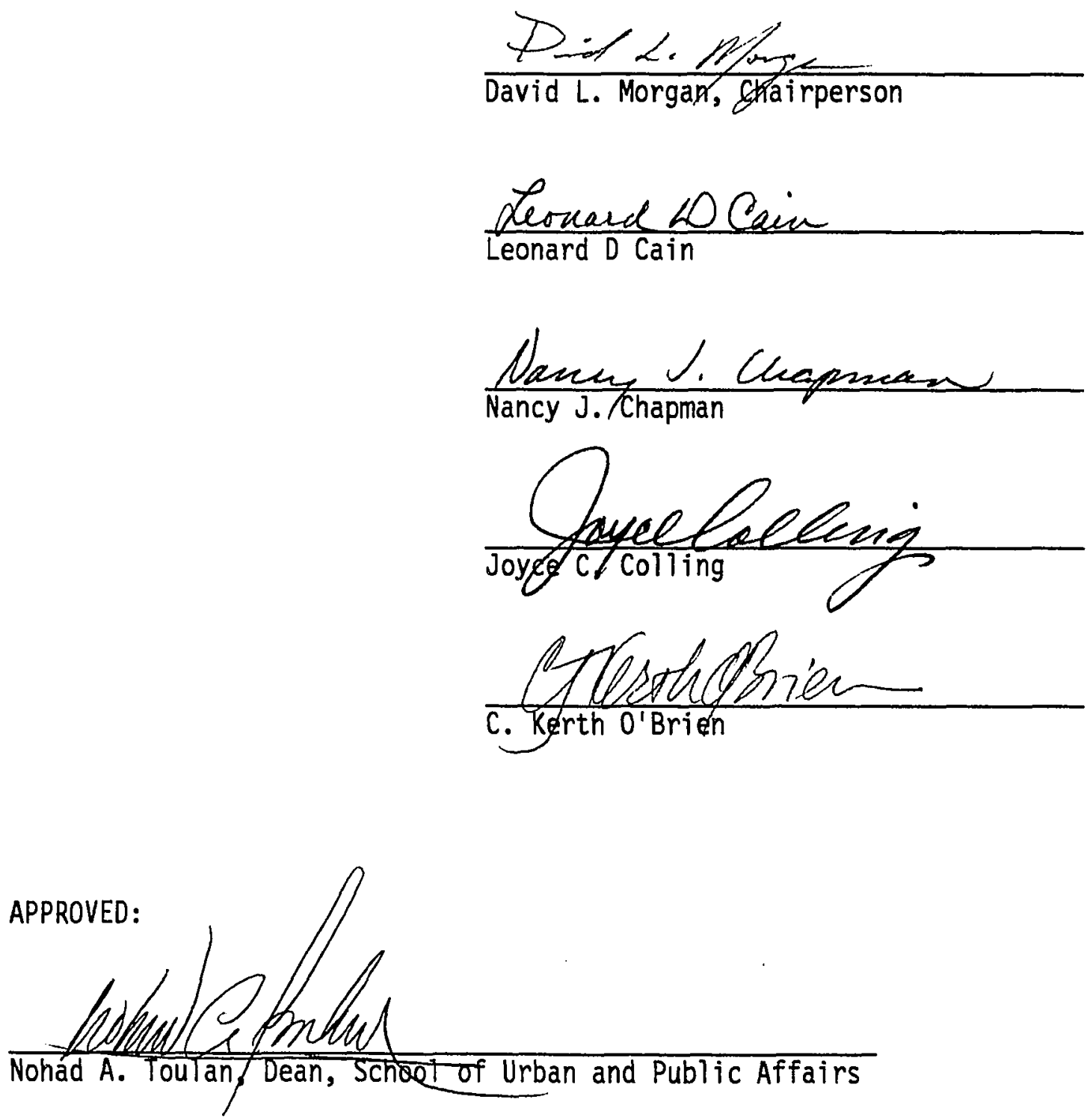

C. will Bowery

C. Will i am Savery, Vice Provost for Graduate Studies and Research 
AN ABSTRACT OF THE DISSERTATION OF Marie Theresa Duncan for the Doctor of Philosophy in Urban Studies presented June 4, 1992.

Title: Alzheimer's Disease Caregivers: The Transition From Home Care to Formal Care

APPROVED BY THE MEMBERS OF THE DISSERTATION COMMITTEE:

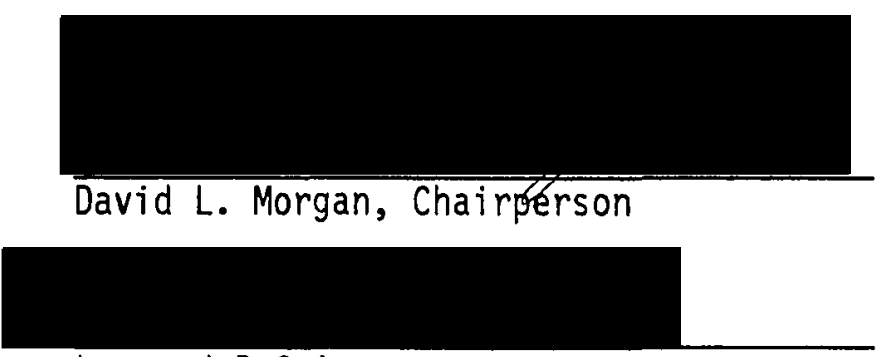

Leonard D Cain

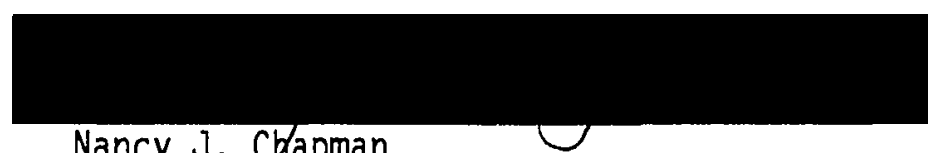

Nancy J. Chapman

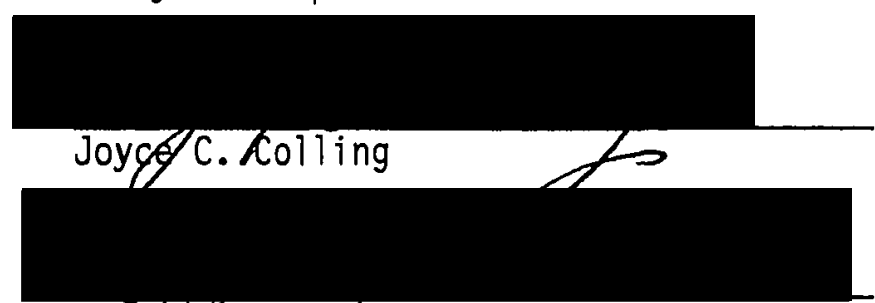

C. Kerth O'Brien

Elderly people with irreversible cognitive declines such as Alzheimer's Disease (AD) make many demands on those who must care for them, whether those caregivers are family members or the paid staff of nursing homes. When family members no longer have the capacity to meet 
these demands, a move to a nursing home or other formal care facility becomes the only solution. Such a shift does not, however, mean the end of family caregiving. Instead, the family's caregiving activities must be integrated with the ongoing efforts of the formal care staff. Currently, relatively little is known about 1) what families experience in making that shift and 2) the relationship between family caregivers and paid staff in formal care settings.

Recognizing this as a time of transition for these family caregivers, three research questions were identified: 1) What do family caregivers to $A D$ individuals experience as they shift their caregiving from home to formal care settings? 2) How does caregiving in formal care differ from caregiving at home?, and 3) How do family caregivers perceive the relationships that develop between families and formal care staff? Specific attention was also paid to the experiences of both spouses and adult children.

A qualitative approach provides an especially usefui methodology. Grounding the study in the world and experiences of caregivers is not only appropriate for increasing knowledge but also practical for exploring new areas.

Two specific bodies of data were investigated. First, transcripts of a series of 30 focus groups with 179 caregivers who were providing care either at home or in formal care settings were analyzed. Second, ten follow-up interviews were done with 12 caregivers who had previously been involved in the focus groups while they were providing care at home and who had since placed their family member in formal care. 
There comes a time to make the decision that results in the transition to formal care. Both spouses and adult children overwhelmingly identified physical exhaustion and often emotional exhaustion as the pervasive common theme. After reaching this state, the caregivers identified turning points that had contributed to the placement decision. While the literature has often pointed to the importance of crises in caregiving decisions, the findings of this study, while not negating this, also call attention to the pivotal nature of events. These kinds of events turn out to be more like turning points than crises.

Caregivers in this study identified five themes that were influential in their decision-making process. In order of their importance to the caregivers, they were: events, the health care system, caregivercare receiver relationship, support, and options and availability. By themselves, these factors did not necessarily predict placement but, in combination, there was a profound effect leading to placement. Themes of family and surviving remained consistent throughout all phases of the transition to formal care.

A male spouse caregiver was more likely to make a decision for placement following a turning point event that centered on an incontinence problem, while a female spouse caregiver was more often moved to action by an $A D$ safety issue. The health care system was usually a negative influence and served to delay the placement decision. Within the caregiver-care receiver relationship, the influence of past experiences and perceptions was extremely powerful, but support did not receive the degree of influence that the caregiving literature has 
suggested. Finally, even if a family had its care receiver's name on a waiting list, it was rare that an opening was available at the time of need.

A real paradox happens at the time of the placement process. Caregivers are "trying to hold on while letting go." Immediately, family caregivers noted shifts in three major areas: control, involvement and personal reorganization. They noted an intense "roller coaster" effect. Most often their first mention was of guilt. Caregivers found the new experience of confronting a unit of $A D$ residents an overwhelming beginning experience.

In reflecting on the evolving process of participating in formal care, caregivers frequently noted the development of a caregiving relationship with staff. The individuals whom the family caregivers mentioned most often were the aides. Even though a complex organizational environment exists in a nursing home, family caregivers expect sensitive and professional behavior toward not only the resident but also toward themselves. Their bottom line was that staff delivered quality care, which they equated with caring about the resident rather than merely taking care of them.

The findings from this study have implications for theory development, family caregivers, formal care staff, and health care policy. 


\section{DEDICATION}

This dissertation is dedicated to my parents, Joseph Edward Grimm and Creta Anderson Grimm. My father was such a strong believer in "getting a good education." He was very influential in my early and continued investment in scholarly knowledge. Although he is no longer living, I am sure he would be pleased with my attainment of this latest goal.

My mother served a dual roie in influencing this process. First, she was a powerful role model for working hard and reaching goals. Second, through her difficult journey with a brain tumor, she helped me understand how families experience cognitive impairment. This disease robbed her of her past and both of us of our future. However, we both benefitted from this experience. I am grateful to have had such a special care-receiver teacher and sense that my gentle caregiving and love was adequate reciprocity. Thus, it is with heartfelt respect, appreciation, and love I dedicate this dissertation to Joe and Creta. 


\section{ACKNOWLEDGEMENTS}

The culmination of this research project was possible because of the help and support of several special individuals. First, I sincerely want to thank the members of my committee. Dr. David Morgan was outstanding in his ability to be a critique, mentor and friend. To the other cormittee members: Dr. Leonard Cain, Dr. Nancy Chapman, Dr. Joyce Colling, and Dr. Kerth O'Brien, thank you for the time, energy, and insights you contributed. To all of you I am most respectful of your investment in my professional and personal growth.

In addition, these individuals were important in accomplishing this goal. To Dr. Alice Scannell, thanks for participating in the oral defense when an original committee member was out of town. (I appreciate the amount of time you invested in reading and critiquing for the comparatively short time in the actual defense.) Dr. Margaret Imle, your consultation around the analysis was very much appreciated but your belief in my ability was invaluable. My great appreciation to Yuko Spofford and Bev Rogers for quality assistance with transcripts and to Beverly Dixson for the professional job on the final project. To Tammy Schuman, I am forever indebted for your help with my frantic requests to transfer documents from Macintosh to IBM. To Teri Gerlet, Gretchen Rust, and Teri Woo, I sincerely respect the professional job you did with our students this past year while I was so focused on this research. 
I acknowledge the grant from the AARP Andrus Foundation which provided funding for the original data source and to Beta Psi Chapter of Sigma Theta Tau which provided some support for the overall research project.

To the special family caregivers who shared their time and insights with me at such a personal time in their life, I am forever grateful. Without your gift, this research would not have been possible.

Finally, to my family: my husband, Tom, son, T.J., and Aunt Arlene, I will always remember your support, sacrifice and love. 
TABLE OF CONTENTS

PAGE

ACKNOWLEDGEMENTS $\ldots \ldots \ldots \ldots \ldots \ldots \ldots$

LIST OF TABLES $\ldots \ldots \ldots \ldots \ldots \ldots \ldots \ldots$

LIST OF FIGURES $\ldots \ldots \ldots \ldots \ldots \ldots \ldots \ldots$

CHAPTER

I INTRODUCTION $\ldots \ldots \ldots \ldots \ldots \ldots$

Purpose of the Study $\ldots \ldots \ldots \ldots$

Conceptual Direction ............... 5

Transition

Research Questions and Objectives ........11

Methodology .................... 12

Grounded Theory Method

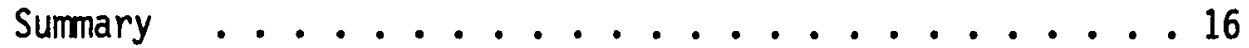

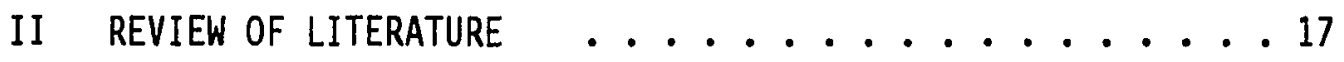

The Elderly . . . . . . . . . . . . 17

Families and Family Caregiving ......... 19

Why Give Care

Caregiving Burden

Dementia . . . . . . . . . . . . . 24

Formal Care . . . . . . . . . . . . . 27

Dementia, Family Caregivers and Formal Care . . . . . 29

Division of Labor and Formal Care

Surmary ...................... 37 
PAGE

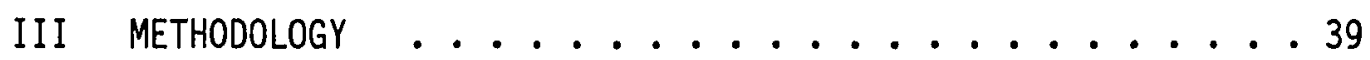

Data Collection and Analysis .......... 40

Focus Groups

Individual Interviews

IV REACHING THE END: DECISIONS .......... 53

Findings $\ldots \ldots \ldots \ldots \ldots$

Event

Health Care System (HCS)

Caregiver-Care Receiver Relationship

Support

Options and Availability

Summary

$\checkmark$ MAKING THE TRANSITION: PLACEMENT $\ldots \ldots \ldots 76$

Findings $\ldots \ldots \ldots \ldots \ldots$

Control

Involvement

Personal Reorganization

vi THE MOVE BEYOND $\ldots \ldots \ldots \ldots \ldots$

Caregiver-Staff Relationship . . . . . . . 87

Aides

Factors Influencing the Nature of the Formal

Caregiving Relationship ........... 91

Monitoring

Trust

Staff Behaviors

Family Behaviors

Family Caregiver Evaluation of Quality

of Care .................... 99

Quality of Care

VII DISCUSSION . . . . . . . . . . 107

Spouse-adult Child . . . . . . . . . . 107 


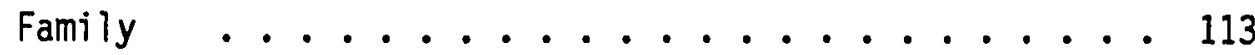

Extended Family

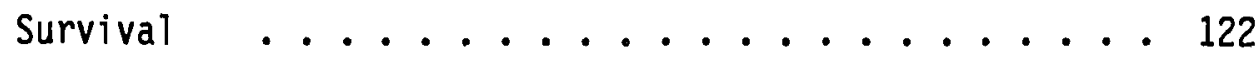

Individualized Experience .......... 126

VIII CONCLUSIONS AND RECOMMENDATIONS . . . . . . . 132

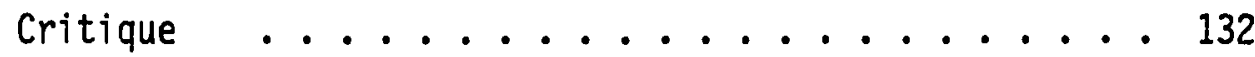

Evaluation of Bridges' Model

Limitations

What Was Learned

Recommendations .................. 146

Theory Development

Institutional Policy

Clinical Practice and Formal Care

Family Caregivers' Behaviors

Future Research

REFERENCES .................. 153

APPENDIX

A FOCUS GROUP INTERVIEW . . . . . . . . . 161

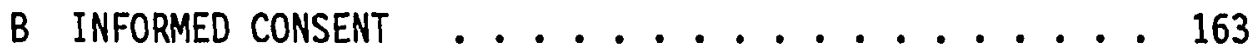

C FOLLOW-UP INTERVIEW GUIDE $\ldots \ldots 165$ 


\section{LIST OF TABLES}

TABLE

PAGE

I Focus Group Participants .............. 41

II Positive and Negative Mentions of Formal Care Staff by Family Caregivers in Group Interviews $(N=179) \ldots 90$ 


\section{LIST OF FIGURES}

\section{FIGURE}

1. Follow-up Interview Guide ..................... 48

2. Caregiver-Care Receiver Relationship Before and After

Placement ................. . 88

3. Bridges' Model of Transitions Applied Caregiving . . 137 


\section{CHAPTER I}

\section{INTRODUCTION}

It is widely known and accepted that families take care of an older family member during illness. The hope for most families is to be able to provide the necessary care at home. Recently, there has been considerable research directed toward helping families accomplish this task. However, there are times this is not a manageable goal. Cognitive impairment in the care receiver is often a significant contributor to the move to formal care. The overwhelming difficulty of providing 24-hour care contributes to more than three-fourths of Alzheimer's Disease (AD) caregivers placement (Stephens, Kinney, and Ogrocki, 1991)

This study investigates the experience of family caregivers to Alzheimer's Disease care receivers as they make the decision which ends their ability to provide caregiving at home and shifts the setting to formal care.

The cause of Alzheimer's is unknown, but the devastation of the progressive and irreversible brain damage leaves the individual completely dependent and very vulnerable to institutionalization. Also, $A D$ is the fourth leading cause of death among older adults (Blieszner and Shifflett, 1990). The significance of this situation is noted in the fact that $A D$ and other forms of cognitive impairment are the major 
causes of nursing home placement and at least 50 percent of residents in nursing homes suffer from some type of dementing illness (National Institute of Health, 1981). Because of the often gradual change in the individual's behavior and ability to function, family members find themselves involved in a caregiver's role. After a period of time that varies widely, family members find it necessary to seek professional help and resources. This shift from caregiving at home to a formal care setting results in major changes for the older individual, the family caregivers and the extended family.

The family's response to providing care to our aging population has been well documented (Bengtson, 1989; Brody, 1985; Lerner, Somers, Reid, Chiriboga and Tierney, 1991; Shanas, 1979b, 1980; Treas, 1977). In the past decade there has been considerable research on family caregiving at home (Barusch, 1988; Cantor, 1980; Gwyther and George, 1986; Horowitz, 1985a; Miller, 1986; Zarit, Reever and Bach-Peterson, 1980). It has been recognized that family caregiving continues after the move to formal care (George and Gwyther, 1986; Stephens, et a1. 1991). Although research on families and formal care can be found, very little organized attention has been given to experiences of family members of institutionalized dementia patients (Bowers, 1988; Pratt, Schmall and Wright 1987a; Pratt, Schmal1, Wright and Hare, 1987b). The need for research on the family has been identified as an important area in Alzheimer's Disease (Ory, Williams, Emr, Lebowitz, Rabins, Salloway, Sluss-Radbaugh, Wolff and Zarit, 1985).

In the past, institutions, specifically nursing homes, have been viewed by the public as places that smell bad, are warehouses, and where 
care is often inadequate if not abusive. Families who institutionalized their family members often felt society judged them guilty of abandonment. In $A D$ however, while the physical and mental status of the care receivers and often the caregiver deteriorate, the family ties do not (Bengtson, 1978). The working team prior to institutionalization has been the caregiver and the care receiver. The caregiver has had to negotiate this course in often unclear circumstances involving a disease process, medications, new services and the health care delivery system. Once the shift to formal care is made, the caregiver-care receiver dyad changes to a triad with the addition of formal care staff. Now the course is still undefined and vague, but caregivers must chart it within the confines of a formal institutional setting. They may be required to do more than they want or may feel cut out of care they desire to give.

In general, early research shows that technical tasks involving physical care are provideú by staff and nontechnical tasks involving emotional or psychosocial care are more likely to be provided by family (Fauerbach, 1984; Litwak, 1981). Yet, other studies direct attention to the ambiguity that surrounds specific responsibilities of staff and families in relation to patient care (Rubin and Shuttlesworth, 1983; Shuttlesworth, Rubin and Duffy, 1982). Bowers (1988), found that caregivers were more likely to perceive their caregiving by its purpose rather than with a task focus. While research provides increasing knowledge about family caregiving in formal care, a key point remains, the quality of nursing home care appears to benefit when families remain involved with their institutionalized relative (Shuttlesworth et al. 1982). As discussed above, with the gradual deterioration of the elder, 
families find themselves in a caregiver role. In exploring family caregiving it is important to recognize that the individuals who provide direct care most often are the spouse or adult child. Caregivers have been predominantly wives and daughters (Johnson and Catalano, 1983; Brody, 1981), although some husbands do care for their demented wives. As parents age and spouse caretaking takes its toll, adult children are called upon to assume increased multigenerational caregiving demands. Children who find themselves in a caregiver role feel more strain than do spouse caregivers (Johnson and Catalano, 1983). Spouses report poorer physical health and well-being along with more stress symptoms than adult children (George and Gwyther, 1986). If we compare spouse caregivers of dementia patients, Fitting, Rabins, Lucas and Eastham (1986) found women were more distressed than men and the younger wives felt more lonely and more resentful of their role than the older wives. Thus much remains to be discovered and understood about the move from family caregiving at home to formal care. It is also important to explore family caregiving to the institutionalized dementia patient and how it effects the different types of caregivers. Greene and Monahan (1987) point to the increasing interest in the nature of the caregiving relationship and the experience of its participants because of a recognition of its importance at a system level. Recognizing the patient-centered focus in formal care, Pratt et al. (1987b) has described the family caregivers to institutionalized dementia patient as "forgotten clients." 
PURPOSE OF THE STUDY

The purpose of this study is to contribute to the knowledge base about family caregivers' transition from home care to formal care. This study is limited to family caregivers of elderly with Alzheimer's Disease. It is an especially important study since research on family caregiving in formal care settings is in an early stage of development. Exploring the shift from home to formal care will allow for an investigation of the caregiving placement decisions, early formal care adjustments and development of the family-staff relationship. This will provide for a longer-term view of caregiving as on a continuum which can be explored as phases which evolve over time. In this view, institutionalization is not a separate or end event, but reflects a continuation of prior caregiving experiences. This research will also explore the differences and similarities between spouses and adult children in what they do and how they feel about this caregiving transition.

\section{CONCEPTUAL DIRECTION}

This section identifies the basic theoretical concept. The concept of transition provides a direction for the conduct of this study.

\section{Transition}

Transition invariably is related to change. It can be viewed as a period between fairly stable states; or "linking change with experienced time" (Chick and Meleis, 1986, p. 239); as a bridge or a boundary zone between the two more stable states (Levinson, 1978); or an ending, 
neutra1 zone and new beginning (Bridges, 1980); or "a period of moving from one state of certainty to another with an interval of uncertainty and change in between" (Golan, 1981, p. 12). Parkes (1971) writes of psycho-social transition which conceptually is merged from stress, crisis and loss research. Individuals most often resist change. The reactions they experience are often influenced by their prior experiences and the way they perceive what is happening. These reactions span a spectrum from viewing change as a rite of passage, to being considered an individual weakness requiring attention (Silverman, 1982).

Transition contains the elements of process, time span and perception (Chick and Meleis, 1986). Process involves disruption and suggests phases, such as a shift from what was, into confusion, then to a new beginning. The individual's response to the disruption is part of the process element. Time span implies elements of both an ongoing activity yet suggests a bounded phenomenon. Finally, perception offers a clue to the meaning of the transition to the person to whom it is happening. It often is associated with role ambiguity and threatens the individual's self-concept. Golan (1981) classifies transitions by time periods, role shifts and marker events. Time periods refers to the life cycle and movement through chronological stages influenced by biological, psychological or social events. Role shifts implies a change or acquisition to a new social role with its inherent need for adaptation. The incident which triggers the beginning of the change and often shapes the time of change is known as the marker event. Thus, a transition may be viewed as a series of personal experiences and adaptations. 
"The work required in a transition is related to the suddenness of the onset of the condition, the amount or degree of loss to the individual and how much of his life is touched by the situation" (Silverman, 1978, p. 12 ). Transitions can vary by several dimensions which are often presented with dichotomies, such as minor disruption vs. major disruption, temporary vs. permanent, desired vs. undesired, and planned-predicted vs. unplanned-unpredicted (Chick and Meleis, 1986).

Transitions are not experienced in a uniform way, even when the actual situation, such as caregiving, is similar. They do have commonalities of a beginning or entry into, the going through or passage and/or exit. As cited above, specifics about the dimensions would help generate information about the entry. An important part of the passage phase is the meaning the situation has for the individual. As the individual exits, outcome is often spoken of as the level of well being. In summary, transition involves a passage from one state, phase or condition to another. It is a personal process and it results from complex person-environment interactions.

For the purposes of this research, a transition model developed by Bridges (1980) will be applied. Bridges' (1980) perspective is particularly useful because most discussions of transition treat a change or stressful life event as the beginning of transition. Bridges (1980), however, provides a contrasting approach which presents transition as starting with endings, followed by a period of distress and confusion, called the neutral zone, and finishing with a new beginning. By examining the underlying patterns involved, an attempt can be made to better understand the process. He states, ". . . it is 
based on a theory of personal development that views transition as the natural process of disorientation and reorientation that marks the turning points of the path of growth" (p. 5). Bridges (1980) starts the transition process with an ending. He notes that too often we take transition as an end point rather than identifying it as the very point where, upon recognition, one can actually begin anew. In the neutral zone there is confusion and disorganization, a disconnection with the past but not yet an emotional hook-up with the present. The new beginning calls for internal action, not just reaching the point by being a survivor.

Endings. Letting go is a difficult task and one tends to let go of most of the external ties before making the necessary internal ones. As an ambiguous process, this is why one tends to come back to old ways. However, before one can move to the new, one must let go of the old. During this phase, individuals bring previously developed styles which they sometimes recognize and other times don't. Bridges (1980) notes, "One of the reasons that it is so difficult to assess things is that the impact of transition upon us does not necessarily bear any relation to the apparent importance of the event that triggered it off" (p. 19). If individuals reflect on their style, it can be useful to explore what pieces are actually theirs and those that belong to the influence of others, culture, and social dictates. When a transition involves more chan one individual, they obviousiy may come to points of separate and personal transitions. Bridges (1980) identified four aspects of the natural ending experience: disengagement, disidentification, disenchantment and disorientation. 
Disengagement results in a break with the familiar and this helps change the old familiar clues which reinforce the role and past behaviors. Disidentification is the internal capturing of the loss of familiar roles and labels. In disenchantment, the individual discovers, or even begins the transition with some sense their world is now no longer real. This experience is often the initial clue to transition. Disorientation is a time of confusion and emptiness when common things from the past take on an unreal quality. The basic essence to endings is that often this aspect is so difficult one isn't sure of surviving the challenge to self.

Neutral zone. The common descriptors for this time are feelings of emptiness and 10ss. Bridges (1980) notes, "The neutral zone is not an important part of the transition process -- it is only a temporary state of loss to be endured" (p. 112). Common behaviors are often captured by labels of inactivity and ritual. An inner reorganization occurs during this time and the individual must first surrender to the feelings of emptiness and 10ss. It is during this time that self-renewal occurs, a new perspective emerges, and opportunity for insight occurs.

New Beginnings. In Bridges' (1980) model, one comes to the beginning only at the end. Inner, subtle signals will alert the individual that changes are occurring which result in feelings of renewal. "New beginnings are accessible to everyone and everyone has trouble with them" (p. 141). A critical feature of this personal time is to do more than "just hang in there." While an external new beginning may appear early on, the individualized work involved in the inner beginning occurs more slowly. With this hard work, the individual should remember to 
take a time out, be patient with himself and engage any known supports that helps him through this job.

Bridges' (1980) model will be applied to the family caregiving situation in $A D$ and evaluated as to its fit. One of the goals is to assess how apt a conceptual framework it will prove to be. It is recognized as an adequate organizing framework, but will it be able to help further the understanding of the transition to formal care? Do family caregivers experience ambiguity in their decision-making time, and once they have accomplished placement is there a period of disruption and confusion? Is it possible for these caregivers to experience anything closely resembling a new beginning? Thus, will this model help us better understand caregiving in general and placement into formal care in specific?

In summary, this transition model by Bridges (1980) starts with an ending, moves to a neutral zone and is completed with a new beginning. Since one experiences many changes in one's life, these transition excursions are like side trips off the main road only to return to the freeway of life.

A quote from Ralph Waldo Emerson (1965, p. 38) is appropriate: "Not in his goals but in his transitions man is great."

As might be implied above, these family caregivers are at an exceptional level of commitment and intensity when they are involved in this particular transition work. The concept of transition provides a framework for exploring caregiving. Is caregiving on a continuum with only a change in site from home to institution? An individual who makes a placement decision resulting in formal care may describe it as a 
"benchmark-type" experience. Most certainiy, transition into formal care caregiving involves negotiations among family, staff, and the health care organization. Clearer understanding of the concept of transition in relationship to the phenomenology of caregiving is needed. Research questions are presented which address the purpose of this study.

\section{RESEARCH QUESTIONS AND OBJECTIVES}

There are three basic research questions. Associated with each question is a series of objectives that will be pursued to gather data in order to address the question.

1. What do family caregivers to Alzheimer's Disease individuals experience as they shift their caregiving from home to formal care?

1.1 analyze the feelings involved with the shift;

1.2 analyze the discussion of the decision-making process;

1.3 analyze the difference between spouse and adult child.

2. How does caregiving in formal care differ from caregiving at home?

2.1 analyze what family members perceive as their role after they shift to formal care;

2.2 analyze the mention of other family members and their effect on the caregiving process;

2.3 analyze the differences between spouse and adult children.

3. How do family caregivers perceive the relationship that occurs between families and formal care staff? 
3.1 analyze what is involved in dealing with staff;

3.2 analyze their perceptions of staff members and the nursing home organization;

3.3 analyze the differences between spouse and adult children.

Since the goals of this study are largely exploratory and there is not a large developed literature raising these questions to advance our understanding, a qualitative approach is uniquely suited as methodology.

$$
\text { METHODOLOGY }
$$

\section{Grounded Theory Method}

Grounding the study in the world and experiences of the caregivers is not only appropriate for increased knowledge but practical for exploring new areas. Grounded theory was first described by Glaser and Strauss (1967) in their pioneering book, The Discovery of Grounded Theory. A current description of grounded theory refers to the processes involved rather than static conditions where theory is generated from the data $(S t e r n, 1985)$. The researcher works in a matrix where several processes are occurring at once, rather than a linear or step-by-step process. The processes include methods and techniques of observing, identifying, documenting, analyzing, and interpreting or knowing thoughts, beliefs, meanings, values and general characteristics of specific phenomena which the researcher is studying (Leininger, 1985). What is it that makes the phenomenon what it is? Maxwell and Maxwell (1986) have described a five-step process: 
1) collection of empirical data, which can be from interviews, observations, or documents. The data are loosely coded by identifying processes, compared with other data, and assigned to categories by fit;

2) concept formation whereby using the data as a reference, a tentative conceptual framework is generated;

3) coricept development, in which reduction of categories, selective sampling of the existing literature and verification of the properties of the main concepts or variables are undertaken;

4) concept modification and integration where theoretical coding and memoing, i.e., capturing insights and abstractions, contribute to the integration and delineation of the emerging theory; and

5) production of the research report, which integrates literature to explain the new knowledge, is absent of numerical data and incorporates the use of field notes.

In summary, this process is aimed at trying to increase our understanding of the research subjects' world. Because data collection and analysis are conducted concurrently, the focus of the initial research question is often transformed during the process which permits the movement from general to more specific.

Data Sources. For the researcher using the grounded theory method, there are many rich sources of data available. In this study, data will come from caregiver interviews. Caregiver interviews will be approached through focus group discussion and one-on-one interviews. This approach will be elaborated upon later.

In order to address the purpose of this study, two specific bodies of data wi11 be investigated. First, data generated by an existing 
series of 30 focus groups comprised of caregivers who are either providing care at home or in formal care setting will be analyzed. Second, data from ten follow-up interviews conducted with caregivers who were initially involved in the focus group discussion while caregiving at home and who subsequently placed their family member in formal care will also be analyzed.

Focus Groups. Focus groups emerged from marketing techniques and are a relatively new qualitative technique (Krueger, 1988; Morgan, 1988; Morgan and Spanish, 1984). Their major advantage is allowing the researcher to observe individuals in group discussion which concentrates on personal experiences and perspectives. In this study it provides for observation of a naturalistic interaction between individuals who are sharing the caregiving experience. "Focus groups are useful when it comes to investigating what participants think, but they excel at uncovering why participants think as they do" (Morgan, 1988, p. 25). The researcher selects the topic of interest and leads the group discussion. Morgan and Spanish (1984) have described a moderator style which allows for minimal involvement in the actual discussions. In summary, focus groups are valuable for their ability to collect data from group interaction, explore topics, generate hypotheses and answer research questions.

The purpose of the Family Caregivers Project (Morgan, 1989), where the focus group transcripts were generated, was to compare caregiving in formal care with caregiving in the home. Quantitative data collection was designed to test hypotheses from existing literature on home-based caregiving. The principal goal of Morgan's analysis was to take a 
series of quantitative results and search for equivalent qualitative work to provide a point of comparison. Consequently, the work that was initially done based on content analysis where the content areas were the issues that matched the quantitative data collection. The content analyses were used to compare the relative frequency with which various areas were mentioned in the focus groups as opposed to how they were rated in the surveys. No systematic work has been done on the broader issues of caregiving in formal care. Portions of the transcripts dealing with formal care were simply noted in the original project and not otherwise coded or analyzed.

The importance of this study is to provide a qualitative analysis of the focus group data which will explore issues of participation, meaning and feelings in formal caregiving experiences. These issues were not specifically addressed in the original study. This analysis will contribute to our knowledge of feelings, emotions, perceptions and meanings family caregivers experience, especially spouses and adult children. If we are to generate knowledge which contributes to our understanding of family caregiving in formal care settings, we must explore what caregivers do and how they feel in this time of transition. The follow-up interviews allow for an in-depth exploration of the shift from home care to formal care. The data will provide access to perceptions, meanings, and feelings of family caregivers, specifically spouses and adult children, as they share their transition experiences.

It is possible that two extra benefits may result from the proposed design. First, it may be possible that a caregiver will respond to a previous focus group discussion issue, thereby providing potential 
insight into the caregiving continuum. Second, because of potential over-time access it will be possible to explore the question of which factors lead home-based caregivers to the end decision that result in placement of their family member. Most studies can only compare home-based caregivers with formal-care-based caregivers. Increased knowledge in these areas would contribute to our overall knowledge of the family caregiver and formal care.

\section{SUMMARY}

In summary, this qualitative research study involved two major pieces of data, one existing and needing analysis and the other remaining to be collected and analyzed. Spouses and adult children of Alzheimer's Disease care receivers form the study population. The purpose of this research is to generate knowledge about family caregivers' transition from caregiving at home to caregiving in the formal care setting. Specific focus will be placed on the issues faced in making the placement decisions, how caregiving in formal care differs from caregiving at home, and the caregiver's perception of the relationship that occurs between families and formal care. 


\section{CHAPTER II}

\section{REVIEW OF LITERATURE}

This chapter reviews five categories of relevant literature:

the elderly; (2) families and family caregiving; (3) dementia; (4) formal care; and (5) dementia, family caregivers, and formal care.

\section{THE ELDERLY}

Between 1950 and 1980 the 65-plus population in the U.S. doubled in size, reaching 24.9 million. By the year 2000 , this elderly population is projected to be 34.9 million persons and by 2030 will increase to 65.6 million (Ahmed and Smith, 1992). Also, by 2000, persons age 65+ will account for 13 percent of the total population and by 2030 they will rise; it is projected, to 21.8 percent (U.S. Bureau of the Census, 1988). Internal changes are another important factor in this growth rate. With the reduction of mortality from chronic diseases, life expectancy has increased proportionally for the older person. Thus the distribution of the aged population has shifted toward the "old-old" ages. This means between 1980 and 2020 the over age 85 group is expected to triple (Feinstein, Gornick and Greenberg, 1984). As life expectancy increases there is also an increase in the number of individuals who have long-term care needs, including medical as well as personal activities of daily living. Many individuals express concern about their prospective quality of life as they grow old. They are 
concerned about their health as it affects their status, the meaning of life, and most certainly their ability to avoid being burden on their family.

Knowing that the aged have become an increasing proportion of the overall dependency burden has important implications for society and the family. About 80 percent of these adults over 65 have adequate health to live independently, but there are approximately 20 percent, or three to four billion, who need outside help in order to manage (Springer and Brubaker, 1984). According to a report by U.S. Department of Health Education and Welfare (HEW), Federal Council on Aging, only 6.3 percent of the population under 70 is extremely impaired compared to 9.3 percent of those between 75 and 79 and 22.5 percent of those over 85 years. Townsend's recent study in Britain (cited in Bowers, 1987) indicated that three times as many severely impaired individuals are living at home as in all institutional settings combined. The 1975 National Center for Health Statistics report noted that families provide 80 percent of all home health care for older people (Horowitz, 1985a). Shanas (1979b) has projected that for every elderly individual in a nursing home there are two who are similarly disabled in the community being cared for by their families. For most individuals then, aging occurs in a family context. Of all the roles a family performs, perhaps its most seminal role involve care and nurturance (McGoldrick and Carter, 1982). 
FAMILIES AND FAMILY CAREGIVING

It has been argued that parent care has become a normative but stressful experience for individuals and families and that its nature, scope and consequences are not yet fully understood (Brody, 1985). A conservative estimate is that currently over five million people are involved in parent-care at any given time.

There are some demographic changes to consider in the discussion of family support. The declining fertility rate is profoundly affecting the availability of younger family members. This will clearly impact the kin network and its ability to provide support. The older population has also experienced changes in composition. The elderly relative today is likely to be a woman, a widow and very old (Treas, 1977). The old-old population in greatest need for care have children who are now young-old themselves. Women are increasingly working for pay outside the home. Economic changes have affected both the dependency of the elderly and the support the family can ensure. These shifts the demographic structure suggest that it will be the individuals who are engaged in their own aging processes who will be increasingly faced with caring for their parents (Robinson and Thurnher, 1979).

In 1979 a study of noninstitutionalized elderly Stoller and Earl (1983), found that spouses were the major source of help whether they were able to perform their ADL's or were impaired. Recent research by Barusch (1988) revealed spouse caregivers prefer to handle things themselves and are reluctant to seek or accept help. If the spouse was not present or able, adult daughters were the major source of support. For the demented patients, families are the primary caregivers until the 
"burden" just gets to be too great (Zarit et al. 1980; Zarit, Todd and Zarit, 1986). These caregivers include wives and daughters predominantly although some husbands and sons are caregivers.

\section{Why Give Care}

It is important to look at why people become caregivers. Horowitz (1978) cited these family duty reasons: reciprocating for help received in the past, to gain a sense of personal satisfaction, to fill a void in their lives and to avoid nursing homes. In a study of caregiving satisfaction (Worcester and Quayhagen, 1983), over one-third of the study population indicated they assumed responsibility for giving care because the individual was part of the family. Other reasons included love and caring and the fact that there was no one else to give the care. Horowitz (1978) found that children who felt they were basically doing their duty did not mention any satisfaction or indicate successful adjustment to caretaking. However, children with a history of reciprocity and affective interaction adapted better to the caretaking. Thus many individuals do so because of a loving relationship while others simply feel an obligation to care for their elder family members.

An interesting study by Archbold (1982b) looked at caregiving roles. Most literature assumes one type of parent caring role. Through qualitative analysis of her data she suggests the roles of care provider, care manager and care transferrer. The roles are based on whether the services are identified and provided (provider), identified and managed (manager), or transferred to another individual (transferrer). "Parentcarers make changes in parentcaring roles based on ongoing assessments of the costs and benefits of caregiving" (p. 10). The four 
factors which influence the assumption of the care provider or care manager role include socio-economic status (SES), housing arrangement, illness onset and past caregiving experience. SES had the most impact. Archbold (1982b) also noted that women who were working, especially in highly valued society positions, found a salient competing role to parentcaring. More providers (73 percent) shared housing with their parent than did managers ( 37.5 percent). Illness with a slow onset usually is associated with the provider role in contrast to the manager role that is associated with an acute onset. If the woman has had previous positive experiences with caregiving roles, it will facilitate her assuming the provider role. For these women this becomes very positive and personally valued.

\section{Caregiving Burden}

"It is not marriage, parenthood, the climacteric or empty nest, but 'parent-caring' that is becoming a major source of life- stress" (Neugarten, 1979, p. 890). Family members usually assume a caregiving role without an understanding of what is involved or what the consequences of that long-term role are (Archbold, 1982a). Families must usually "make it" through trial and error as there are as yet no training programs or classes to prepare for parent caregiving. The term, "caregiver burden," is now used widely to refer to the physical, psychological or emotional, social, and financial problems that can be experienced by family members caring for impaired older adults (George and Gwyther, 1986).

Providing care for the elderly comes with a personal cost. In Archbold's study (1982b) the care providers identified experiences of 
decreased freedom, lack of privacy, constant daily irritation and guilt. The care managers identified invasions of personal time, career interruptions and financial burdens. In a study on family caregiving, Lerner, et al., (1991) explored the egocentric bias between siblings. A priority focus was on the costs and contributions in caregiving. While the caregiving siblings label their siblings as responsive as they themselves were in the caregiving process, they perceived them as contributing less, altering their caregiving with more freedom, feeling less satisfaction and being resistant to do more. Thus, even when adult children are receiving help from siblings, there are often issues of an interpersonal nature that contribute to the complexity of the caregiving role.

Another way to consider caregiver burden is to view it from the emotional and structural perspectives. There are many painful emotional reactions. Many researchers have found emotional stress ranked first before physical and financial (Cantor, 1983; Danis, 1978; Horowitz, 1978; Robinson and Thurnher, 1979). Mental health symptoms such as depression, anxiety, sleeplessness and feelings of helplessness are common. The individual often feels emotionally exhausted. Grief is a heavy burden which may be more devastating as a response to chronic illness than in the accompanying death (Springer and Brubaker, 1984). In some situations, stress can lead to passive neglect of the elderly being left alone, or active neglect of both a verbal and emotional nature.

In general, research on family caregiving supports or assumes a positive correlation between increased frailty or impairment of the 
elderly individual and caregiver stress (Bowers, 1987). Robinson and Thurnher (1979) reported a study which looked at late-life parent-child relationships. They found stress resulted in these relationships in two primary ways: first, through coping with perceived mental deterioration of the parent, and second, when the caretaking relationship was experienced as confining. This responsibility infringed on their lifestyle or if in retirement, their hoped-for lifestyle. An interesting sidelight, these individuals were not giving financial assistance to their parents who were using social security (SS), Medicare, and Medicaid.

The amount of strain a caregiver feels is closely tied to the bond he or she feels with the elderly individual (Cantor, 1983). The more caregivers feel that family members have a responsibility toward family and that family involvement is viewed as a positive value, the more likely they are to feel strain. "Family members in the caretaker role of the patient have demonstrated role strain with those having close bonds exhibiting more perceived stress" (Ward, 1986, p. 47). Both Pearlin, Mullan, Semple and Skaff (1990) and Archbold, Stewart, Greenlick and Horvath (1990), have called our attention to the influence of the early caregiver-care receiver relationship upon the later caregiving situation.

While most of the research has focused upon the principal caregiver, there are many effects on the family system. The family is affected by interference with its lifestyle, life space, socialization, vacations, future plans, and income. The caregiver's time is diverted from other family members and there may be negative effects on his/her health (Brody, 1985). Danis (1978) reported the most frequent response his 
subjects gave when asked about the effect of their relative's iliness concerned their restricted mobility and time away from their own families. Archbold (1982a) found marital conflicts arose. Sibling conflicts were often rekindled due to perceived inequities in contributions which then often stood in the way of any mutual cooperation.

As the review has captured, the stress, burden, and responsibilities are evident in caregiving of the "frail" elderly at home. However, one crucial point remains. The nature of the care receiver's illness and functioning status greatly affects the reciprocity within the family caregiving system. An alert mind with a very ill body is a much different scenario than a strong body with minimal to no cognitive ability. Family caregivers to Alzheimer's individuals often comment that it is like a long funeral. The family member is often physically quite functional, but the mind can't remember and all the past history and shared memory is gone. The relationship is gone but the responsibility continues.

\section{DEMENTIA}

Symptoms of memory loss and a decrease in the ability to think and reason in adults are symptoms associated with the diagnosis of dementia. The cause of dementia of the Alzheimer's type is unknown but the progressive and irreversible brain damage is well documented. The patient often begins with gradual memory loss and ends as a completely dependent individual. This process may take anywhere from seven to 15 years (Lyman, 1989). The family caregivers find themselves with many new and often diffuse responsibilities. Somewhere on this caregiving 
continuum they begin the awesome task of diagnosis, trying to interact with the often confusing and hierarchical health care team. They must face the progressive changes in their $i 11$ family member and the demands in care these changes precipitate. They also face feelings these $A D$ changes bring, such as denial of the illness, fear of injury with combativeness or abuse and embarrassment which often occurs with behavior changes.

Families often have trouble obtaining a correct diagnosis and then appropriate and helpful information relevant to their caregiving needs. In a study of Alzheimer's families' experiences, Chenoweth and Spencer (1986) found only 16 percent reported receiving specific help for dealing with personality changes and behavior problems. Fifty-four percent of the families reported the health team focused on the hopeless nature of the disease and if they did offer explanations, they were too brief. Inadequate understanding of Alzheimer's can aggravate the already overwhelming problems of caregiving (Dieckmann, Zarit, Zarit and Gatz, 1988). While a few families report the strengthening of family ties as they respond to the challenges of caregiving with an Alzheimer's patient, many families find the need for constant physical care and/or supervision a major problem (Chenoweth and Spencer, 1986). Rabins, Mace and Lucas (1982) reported chronic fatigue, depression and anger in $A D$ caregivers. It is also common to hear of feelings of isolation as they are unable to leave the house or friends stop visiting. In a study of different caregiver types, Quayhagen and Quayhagen (1988) found wife caregivers more stressed by frequent disruptive (dangerous and embarrassing) acts than husband or offspring caregivers. The offspring 
were most stressed by having to bathe their parent and the parent's inability to stay alone. Repetitive questions from the $A D$ care receiver were stressful for all groups. As the disease unpredictably progresses, the care receiver's behavior typically changes, resulting in increased likelihood of assaultive behaviors, wandering and incontinence. With such changes, the caregivers must constantly modify their plans and adjust to new problems. Yet the national profile confirms a low use of formal care by caregivers (Stone, Cafferata and Sangi 1987). In a sample of 209 caregivers, Colerick and George (1986) found caregiver characteristics and caregiver well-being were more important predictors of institutionalization than were patient characteristics. Probability of institutionalization was more than doubled if the caregiver used psychotropic drugs while two factors significantly reduced the probability; 1) the relationship of the caregiver and care receiver and 2) the caregiver's need for caregiving assistance. Spouses are the last to relinquish care often due to their belief in the central role the patient plays in their life. This gives them internal empowerment as a caregiver. It is important to note in this discussion that female patients are at much greater risk for institutionalization. Greene and Monahan (1987) studied the effects of caregiver support and education on institutionalization of the care receiver. One pertinent finding is, while support and education can decrease the likelihood of placement, Alzheimer's was the only disease to predict formal care. Regardless of the cause of placement, it is widely supported that formal care is viewed as a last resort. 
FORMAL CARE

"One of the most unhappy times in the life of any human being comes when he must make the decision to institutionalize a parent" (Cath, 1972, p. 25). In the past, placement of a loved one in a nursing home was viewed by society as neglectful and families themselves felt a sense of failure. Even though people continue to hold negative stereotypes, the research conducted in the last decade does not provide support for this viewpoint. For a detailed survey of formal institutions see reviews by Horowitz (1985a).

Nowadays, entry of a family member into formal care can mean a shift of responsibilities, not a loss of the relationship. This change in site of caregiving does exact a price for family members. The disruption of the family relationships and the obvious change in the physical environment can contribute to a great sense of loss and grief (Greenfield, 1984). Tobin and Kulys (1981) have reported patients with feelings of abandonment and family members with feelings of guilt. The attitudes of family members can greatly influence the positive adjustment to a nursing home. Strong family relationships can continue and Miller (1986) notes affection may even increase. Shuttlesworth et al. (1982) have noted the quality of care in nursing homes appears to be better for those patients whose family members remain involved.

Involvement, in nursing home language, often means the assignment or delegation of "tasks." Litwak (1981), and Litwak, Messeri and Silverstein (1990) have proposed a "theory of shared functions" whereby staff would be primarily responsible for the technical tasks and family would handle nontechnical tasks. While in actuality, the technical 
tasks appear to have been assigned to formal care staff, Shuttlesworth et al. (1982) found great ambiguity between families and institutions in the responsibility for nontechnical tasks. A critical aspect of formal care centers around the staff-family relationship. Both families and staff have learning needs. Hirst and Metcalf (1986) in a study of families with dementia patients found families needed and desired information around the disease process, information to help them know their place within the formal care hierarchy and how to deal with their emotional responses. Nurses were also discovered to have learning needs in the areas of cognitive knowledge about the aging process, pathophysiology, assessment of the dementia patient and finaliy, knowledge of family dynamics. Brower (1981) would add that the attitude of the nurse has a critical influence on the type of care he/she delivers. It is the view of Bowers $(1987,1988)$ that effective collaboration between staff and families comes from a shared perspective and understanding of the invisible work of caregiving rather than a splitting of tasks.

Finally, policies often influence the level of care and behavior of staff. In a study of facility policies and family relationships, Montgomery (1982) concluded that policies that view family members as clients rather than as servants wi1l have the most positive influence on family relationships. 
DEMENTIA, FAMILY CAREGIVERS ANO FORMÁL CARE

In discussions of institutions and caregiving, the family indeed, often remains the "forgotten client" Pratt et al. (1987b), in exploring this notion, has highlighted the often older age and at-risk health status of caregivers to dementia patients. This becomes an important issue if caregiving activity has the potential to contribute to the overall health of a caregiving individual and provide growth producing experiences for not only the individual but the family as well.

Families who have been providing home care to a relative with dementia are signaling the formal care institution of an established commitment. These families often experience a strong desire to continue home care but as research by Worcester and Quayhagen (1983) has documented, the potential for nursing home admission increases as the psychological and behavioral problems of the care receiver increase. Family attitudes toward institutions are not commonly assessed at the time of transition to formal care but Deimling and Poulshock (1985) have identified their significance in family decision making. If caregiving is on a continuum, then increased awareness of the influence of attitude toward formal care for families of dementia patients will contribute to our better understanding when the shift in the caregiving site occurs. There is no way to project the course of Alzheimer's Disease, and thus, the demands and burdens for caregivers vary greatly over time. Just as individuals and families differ in their desire and ability to provide caregiving, so do their responsibilities and resources. Though one is not able to project a picture of each individual caregiver, through research there emerges a description of caregivers in general. 
Recent studies have given us insights into the special risk for negative outcomes that face families who care for their family members with Alzheimer's Disease (Gwyther and George, 1986). In a study comparing family caregivers of dementia patients to a community sample of non-caregivers, George and Gwyther (1986) found large differences in mental health indices. The caregivers had nearly three times as many stress symptoms, had lower levels of life satisfaction and a substantially higher rate of use of psychotropic drugs. They also reported less participation in social activities except attendance at church. For example, the cormunity sample reported twice as much time spent in relaxation activities. Pratt et al. (1987b) in a study comparing Alzheimer's caregivers at home to those in formal care found the institutionalized residents' mental status was significantly more likely to be rated as poor by family caregivers. Those caregiving in institutions were not only more likely to rate their health status as fair to poor but they were also significantly more likely to note the negative effect of caregiving upon their health status. Their issues of burdens were significantly more focused on concerns around finances to cover care, worrying about being able to continue in a caregiving role yet desiring to leave the caregiving to others and finally the sense they should be doing more. These findings certainly describe feelings of guilt but one also notes a sense of ambivalence. Is it possible that with their family member becoming more severely cognitively impaired and their personal health status in jeopardy, these family caregivers still feel a sense of failure upon turning to formal care? Although formal care may solve some of the family's problems, being on the roller 
coaster associated with dementia caregiving, new needs will most certainly surface.

In a recent study of family caregivers to Alzheimer's patients, Morgan (1988) reported not only do caregivers wait until almost the last minute to institutionalize, feeling guilt and a sense of failure for doing so but afterwards they express guilt for having waited so long to place their family member. Caregivers also have been known to try a return to home care if a little stability or slight improvement is noted in their family member. They reported little success with this coping strategy. Other caregivers shared their approach of moving between one formal care site and another, always in search of that elusive something.

Family caregivers -- when we hear these words, what image comes to mind? Too often no distinction is made in the type of caregiver, yet this is an extremely significant variable in the formula of care for the dementia patient. Another point to reflect upon in comparing types of caregivers, is that the comparisons presented are often an aggregate rather than an individual profile.

It is difficult to find research that focuses upon spouse and adult children caregivers for institutionalized dementia patients. In a study by George and Gwyther (1986) comparing caregivers of dementia patients to a random cormunity sample, 41 percent of the caregivers were providing care to an institutionalized family member. While the lowest level of well being was noted in at home caregivers, the caregivers to institutionalized patients continued to experience mental health and social participation problems. The data did not allow a comparison of 
the spouse and adult children caregivers of institutionalized patients. However, in their overall comparison of spouse and adult children, the spouse caregivers exhibited lower levels of well being in the dimensions of physical health, mental health, financial resources and social participation than the adult child caregivers. These findings contrast with Robinson (1983) and Zarit et al. (1980) who found no significant differences in caregiving burden between spouses and adult child caregivers. The later studies, however, did not include caregivers to the institutionalized family member.

Husbands and wives caregiving for dementia patients at home may experience similar degrees of burden but the female reports more symptoms of depression (Fitting, Rabins, Lucas and Eastham, 1986). More women than men reported a deterioration in their marital relationship but over 25 percent of the men stated an improved relationship with their wife after they assumed the caregiving role. It is important to explore the effect of institutionalization on depression and this spousal relationship. If depression results from a sense of hopelessness or powerlessness that accompanies dementia caregiving, then these spouses may find a different role after institutionalization. Men, who are often at loose ends upon retirement, may find that spouse caregiving provides them with responsibilities or a new "job." Institutionalization will impact this caregiving experience for the male caregiver. These issues reflect on the importance for us to explore the subjective experiences of husband and wife caregivers which will not be captured by objective measures. Much remains to be discovered about spouses and adult child caregivers, dementia and institutions. 
In exploring gender differences of adult child caregivers it was previously documented that daughters most often assume the caregiving role. Horowitz (1985b), in a study of adult children who were primary caregivers to their frail elderly parents found when sons did take on this role they tended to provide less extensive support, were less likely to help with hands-on type assistance, and had less stressful caregiving experiences independent of their involvement. Of significance, over 90 percent of both sons and daughters cited providing their parents with emotional support was their most common role. The common behaviors included talking to the parent and giving advice.

If institutionalization occurs, the relationship between the adult child and the parent can be continued or even enhanced. This strengthening of family relationships results from decreased strains on the family due to parents' acute needs, often the physical and mental improvement of the parent and the involvement of the parent with other residents in the institution (Smith and Bengtson, 1979). These parent-child interactions imply a reciprocity not likely for caregivers of Alzheimer's patients where memory has failed and behavior is very unpredictable. The influence of dementia should be integrated into future caregiving research on gender differences.

Institutionalization of a parent is indeed a traumatic event but this experience may provide a family with the opportunity for learning and growth (Smith and Bengtson, 1979). Caring for an elderly parent or spouse may be considered a developmental task. Spouse caregivers who achieve integrity after admitting their spouse to formal care must accept the past as it was, respond to the present with acceptance, and 
recognize that their current involvement will be controlled by the policies and procedures of the formal care facility (Brubaker, 1986). For both types of caregivers, the work of transitioning to formal care is influenced by the response of the formal care facility. Finally, the quality of nursing care has been shown to improve with greater family involvement (Dobrof, 1981; Harel, 1981). There is no dispute that families remain the "forgotten client" as identified by Pratt (1987b).

\section{Division of Labor and Formal Care}

In a major policy-oriented work, Litwak (1985) analyzed the basic differences between primary groups and formal organizations. Because of their basic structures, primary groups, such as the family, can best manage unpredictable events and nonuniform tasks with many contingencies. By contrast, formal organizations can best manage the uniform services often referred to as technical tasks or tasks requiring technical knowledge and expertise. The key variable is the amount of technical knowledge required. If technical expertise is not necessary, the lower cost, increased time available, greater flexibility and higher level of internalized motivation of the individuals make the family particularly appropriate for caregiving tasks. If however, technical expertise is required, the structure of the formal organization is cheaper, faster, more flexible and able to provide more motivated individuals (Litwak, et al., 1990). In other words, the structure of the group should match the structure of the task, thus the primary group matches tasks not requiring technical knowledge and the formal organization matches technical tasks. This does nat, however, mean that family and staff should perform separate tasks. Litwak et al. (1990) 
note that there is a functional division of labor between the roles played by staff and family, and the highest quality of care requires contributions from both of these two sources of caregiving.

Much of the past discussion of families and institutions has been embedded in the language of "tasks." First, they were discussed, then identified and finally attempts were made to delegate tasks, often technical ones, to staff and non-technical ones to family or as a shared function. However, Albert (1991) in an exploration of dimensions of caregiving, noted that typologies for categorizing caregiving tasks reflect the perspective of the service need rather than that of the caregiver's understanding of the domain. Ambiguity in the subdivision of these tasks may hinder the staff's ability to integrate families into patient care (Rubin and Shuttlesworth, 1983). In their 1983 study, Rubin and Shuttlesworth identified five broad problem categories: personalizing care; monitoring and ensuring the provision of care; meeting clothing needs; grooming and providing reading materials. Meaningful family involvement resulted from agreement in task assignments but these assignments must often be reviewed and encouraged by both staff and families.

Most research that has looked at relations between family caregivers and paid staff conceptualizes this issue in terms of the assignment or delegation of tasks. Studies in this tradition use quantitative checklists to gather ratings from both staff and family concerning who should do various tasks. When family or staff over or underestimate either their own involvement and responsibilities or those of the other role, stress and problems are likely to occur. More 
recently, Schwartz and Vogel (1990) found significant agreement between these groups. In areas such as "personal care" and "activities," however, the responsibility was still assumed by staff, even though the family was willing to share in these tasks. Thus a major theme in the literature to date has been the appropriate division of labor between family and staff, assessed in terms of which task should be assigned to which caregivers.

Bowers $(1987,1988)$ has provided the most prominent critique of this task assignment approach based on her qualitative investigation of the family's caregiving experiences. Her intensive interviews with family caregivers concerning their experiences and feelings, demonstrated the limits of a task-assignment approach. Family caregivers did not relate their caregiving in terms of tasks but rather described their care by its purpose. Specifically, caregivers for institutionalized family members do not want their family member to feel like a burden or nuisance for staff (Bowers, 1988). At a broader level, these family caregivers believed that the most important purpose of their involvement in formal care was to preserve the older individual's identity. Families expected staff to provide care in a way that was not only high in technical expertise, but also sensitive, nurturent and individualized in many ways. The staff's ability to deliver care that met these "emotional needs" depended on contacts with the family. Family perceptions of good quality care were thus based on a collaborative process involving shared perspective and understanding of the work of caregiving rather than an assignment of separate tasks. 
A discussion of family caregiving which incorporates relationships, interactions, and reciprocity must also recognize the ethical concerns these situations create. Pratt et al. (1987a) conducted a content analysis identifying ethical concerns in an open-ended question asking respondents to share any additional information that would help the researchers understand their caregiver experiences. The sample included spouses and adult children in both home and formal care settings. The most frequent (42 percent) concern was family obligations in caregiving followed by conflicts between caregiving and other commitments ( 29 percent), ethics in financing health care for dementia patients (13 percent), standards of professional and family care (13 percent) and the patients' roles or responsibilities in planning care (3 percent). These moral and ethical dilemmas impact not only the caregivers, care receivers and their families but the health care system and society as well.

Thus, as the review of literature has highlighted, family caregiving by its nature, is a private, sometimes painful and often difficult area to study. Research must be designed to address the gaps or increase the knowledge base. However, sensitivity must be shown to families at this vulnerable time in their life.

\section{SUMMARY}

Literature was reviewed from several perspectives and organized into five areas: (1) the elderly; (2) families and family caregiving; (3) dementia; (4) formal care; and (5) dementia, family caregiving, and formal care. It is evident that families do become caregivers to their 
elderly family member. In doing so, they experience burden and stress that affect their health and well-being. Dementia, in its often gradual and unpredictable course, carries family members into caregiving which often ends in institutionalization. This shift in caregiving site is often the caregiver's last resort and his/her new role is confusing at best. Minimal research has been devoted to family caregiving to dementia patients in formal care. Special attention should be directed to the distinctive experiences of caregiving spouses and adult children as they transition into formal care. 


\section{CHAPTER III}

\section{METHODOLOGY}

Since there is not a large developed literature around families and formal care and the goals of this study were exploratory, a qualitative approach was designed and implemented. Thus, grounding the study in the world and experiences of the caregivers is not only appropriate for increased knowledge, but practical for exploring new areas. For the researcher using the qualitative method, there are many rich sources of data available. In this study, data will come from caregiver interviews, which were facilitated through focus group discussion and one-on-one interviews. This approach will be discussed later.

The access to the focus group transcripts was provided through the author's participation as a team member in a family caregiving grant, "Caregivers for Elderly Alzheimer's Victims: A Comparison of Caregiving in the Home and in Institutions" (Morgan, 1989). Although this research project integrated both quantitative and qualitative data in its design, the qualitative data on families and formal care were offered to this author for use in the present study.

In order to address the purpose of this study, two specific bodies of data were investigated. First, tapes of an existing series of 30 focus groups with 179 caregivers who were either providing care at home or in formal care settings were analyzed. This data set allowed an analysis of the caregiver's perception of home versus formal caregiving 
and a preliminary analysis of the families' early perception of formal care. Second, ten follow-up interviews were conducted with caregivers who were initially involved in the focus group discussion while caregiving at home and who had since placed their family member in formal care. The shift from home to formal care allowed for an exploration of a caregiving transition. Knowledge was gained around the caregiver's life after the decision to institutionalize, the experience of the move, consequences of the move, and the relationship between families and formal care. Thus, this interview data set provides an in-depth exploration of perceptions, meanings, and feelings as families, specifically spouses and adult children, make the transition into formal caregiving facilities. If knowledge is to be generated which contributes to the understanding of family caregiving in formal care settings, one must explore what caregivers do and how they feel in this time of transition. These issues were not specifically addressed in the original focus group study.

This section will review the procedures used to generate the sample, the questions and procedures used to collect the data, and the process applied to the qualitative analysis of the data. Each area is presented separately.

\section{DATA COLLECTION AND ANALYSIS}

As noted previously, the intent of the present analysis of the focus group data was to help guide the direction and depth of the interview study. Thus, these two data sets will intentionally be presented separately. 


\section{Focus Groups}

Participants. The sample was recruited from a metropolitan area, through mailings to the Alzheimer's Disease Association contact list, in-person visits to local support groups, and contacts with formal care settings associated with the Oregon Association of Homes for Aging. One hundred and seventy-nine caregiving individuals participated in focus group discussions, resulting in 30 focus groups in 18 different sites. The caregiving subgroups included 76 spouses, 45 caregiving at home and 31 in formal care, and 103 adult children, 32 caregiving at home and 71 in formal care. (See Table I.)

TABLE I

FOCUS GROUP PARTICIPANTS

\section{Residence}

\begin{tabular}{ccccc} 
Relationship & $\begin{array}{l}\text { Home-Based } \\
\text { Care }\end{array}$ & & $\begin{array}{l}\text { Formal Care } \\
\text { Setting }\end{array}$ & Totals \\
\cline { 1 - 1 } Spouses & $N=45$ & & $N=31$ & $N=76$ \\
Children & $N=32$ & & $N=71$ & $N=103$ \\
TOTAL & $N=77$ & $N=102$ & $N=179$
\end{tabular}

Small focus group discussioris were conducted, consisting of four to nine participants per group. In the larger data collection sessions, it was sometimes possible to break the participants into smaller groups that reflected the basic design categories in the study, of home, formal, spouse, and adult child. This resulted in groups such as children in formal care settings or spouses at home. In smaller sessions, or where the participants were from a variety of design categories, focus 
groups were conducted with a mix of caregivers from the different design categories.

Two specific aspects of the qualitative data will be covered in this section. First, there is a description of the focus group approach. Second, there is a description of the question guides.

Focus Groups. Each group was led by a member of the project staff. All group leaders took a largely non-directive stance toward the discussions, as opposed to directing the discussion (Morgan, 1988, Krueger, 1988). The non-directive approach in this study was based on a set of questions that encouraged the participants to discuss their caregiving experiences among themselves. (See Appendix A.) When the discussion slowed, the leader would either move the group on to the next question, or would repeat the original question and ask for further information. This approach treats the research participants as informants on their own experiences, rather than as respondents to a pre-defined set of specific questions. Given the centrality of the caregiving experience to these participants, very little direction from the group leaders was necessary to create active discussions.

In keeping with the non-directive approach taken to group leadership, the questions posed to the group were highly general. Two basic questions were asked in every group:

1. What kinds of things make your caregiving either easier or harder for you?

2. How does the kind of caregiving that people do at home differ from the kind of caregiving that people do when their family member is in a formal care facility such as a nursing home? 
Coding and Analysis. A purpose of the focus group study was to compare quantitative data with qualitative data. This objective drove the actual coding process. Thus the original qualitative codes were developed to parallel the quantitative data concepts of social networks and social support, involvement, and burden and well-being. Each of the thirty transcripts was then coded by one of the members of the research team. Coders were randomly assigned to transcripts. The one exception was that no one ever coded a discussion where he or she had been the leader, in order to avoid importing implicit knowledge or unconscious assumptions that would not have been available to another coder. All coding was done in The Ethnograph software package (Seide1, 1988).

The coded transcripts were tabulated to show who the caregivers mentioned in a positive or negative fashion. For the original focus group purposes, only mentions of formal care staff were noted. By sorting and collecting all transcript segments that involved mentions of formal care staff, it was possible to determine which staff caregivers were mentioned, which staff behaviors generated these mentions, and how the caregivers arrived at positive and negative evaluations of staff. These data are integrated into the findings presented in Chapter 6. While these focus group findings called attention to the broad issues in family-formal care staff interactions, the purpose of the individual interviews was to take the family caregiver from the decision for placement through the actual transition into formal care. In continuing with a qualitative approach, the focus group findings were used to facilitate the early development of the interview guide. 
Individual Interviews

The additional interviews explored in depth what that transition was like, what they had experienced in interacting with staff, and how caregiving in formal care settings was different from caregiving at home. These more struccured individual interviews allowed the researcher to explore in-depth the issues that had been uncovered in the focus group discussions.

Two specific aspects of the qualitative data will be covered in this section. First, there is a description of the interview approach. Second there is a description of the question guides.

Participants. The participants in the follow-up study were recruited, in a purposive fashion, from individuals in the original study. They were selected from those caregivers who were providing caregiving at home at that time and had since placed their family member into formal care. Ten one-on-one interviewees were the target population. This decision was based upon the limited number of caregivers available in this category, i.e., 45 spouses and 32 adult children.

The confidential list of focus group participants was available to the author as a member of the focus group study team. The guidelines for the study participation were identified. First, the care receiver had been moved to formal care. Second, the caregiver was reachable by address and phone. Third, the caregivers were healthy enough themselves to participate. Fourth, each was willing to participate.

A protocol for contacting potential participants was established. Potential participants were contacted by phone. A brief, discreet and professional discussion determined their eligibility. By discreet and 
professional, it was meant sensitivity was used when asking about the health and well-being of both the care receiver and the care giver. If it was discovered the care receiver had died, sympathy was extended and a reminder of appreciation for their past participation was offered. The main premise was to avoid abrupt dismissal of anyone who was now not eligible.

After explaining the current research study, the researcher invited eligible individuals to participate. They were told a one- to two-hour interview would take place. The interview would be tape recorded and they could stop the interview at any time if they became uncomfortable. They were advised about the informed consent (see appendix B) and told it would be reviewed prior to beginning the interview and their signature obtained. It was also noted, a copy of the informed consent would be left with them for their own records. They were assured that what they said would be kept confidential and that their name or identity would never be used in publications or public discussions. Also, the transcripts of the interview tapes would include first names only and no formal care facility or health care staff would be identified. The complete list of the participants, their addresses, and phone numbers would be kept in a locked file, separate from the transcripts. They were informed that selected research examples from the tapes could be quoted in scholarly papers or presentations but where these quotes might involve sufficient detail to permit potential identification, appropriate "modifications" of the identifying information would be made. 
Upon agreeing to participate, if it seemed advisable, the participants were offered a day or two to think it over. They were also given the researcher's phone number in case they needed to reschedule or cancel. The participants were allowed to choose the interview day, time, and place.

Twenty-nine potential caregivers were contacted over a span of nine months. The reasons for non-participation of 19 of the 29 included: death of the care giver (1), death of the care receiver (5), still caregiving at home (5), the care receiver had actually been deceased at the time of the focus group participation (4), the caregiver had moved out of state (3), and the diagnosis of Alzheimer's Disease was now in question (1). It is important to note that all caregivers who met the criteria were willing to participate in the study. The final one-on-one interview sample consisted of twelve participants contacted through ten interviews. Two adult children-spouse teams desired to share the interview, thus give not only a couple's perspective but also the caregivers in-law perspective as well. There were six spouses, three male and three female. There were four adult children, three daughters, one son, plus one daughter-in-law and one son-in-law. Special effort was made to ensure the inclusion of the male caregiver. Nine of the ten caregivers chose their home as the site for the interview. One daughter caregiver chose an extended lunch time, away from the office for her interview. Only one interview time had to be rescheduled, due to caregiver-extended family conflict in schedule. There were no objections to being taped. 
The researcher, as a health care professional, realized the persona) nature of caregiving and was prepared to take sensitive measures to provide support to the participants if needed. If the researcher is a member of a profession, Fowler (1988) suggests that the value system of the profession be recognized as first priority and the role values, as a researcher, be second. To this end, the participants in this study were allowed to withdraw from the study or limit an area of discussion at any time. Also, other options included allowing time for crying or quiet reflections, allowing the participant to not discuss a certain topic, or just taking a time out with the tape recorder off. Although there were times of tears and sadness, the participants noted an acceptable level of comfort with the interview and on a few occasions, even noted how positive they felt about the whole process.

Interviews. These interviews were conducted with caregivers who were providing care at home at the time of participation in the focus group and had since placed their family member in formal care. In general, the semi-structured interviews explored in depth what that transition was like, how caregiving in formal care was different from caregiving at home, and what they had experienced in their relationships with formal care staff.

Qualitative methods by their nature employ unstructured or semi-structured interviews. Balancing the interview between flexibility and consistency is often a challenge (May, 1989). Consistency here refers to asking the important questions guided by the earlier research rather than the same questions to each informant. Other balances are between facts and feelings and depth and breadth. The end point is "to 
get the story and attend to the needs of the story te!lers themselves" (May, 1989, p. 181).

The beginning interview guide was designed to move from a broad base through a more structured section and end with a specific focus. The diagram in Figure 1 demonstrates the proposed plan.

$$
\begin{aligned}
& 2 \text { or } 3 \text { broadest issues } \\
& 4 \text { or } 5 \text { middle range areas } \\
& 6 \text { or } 8 \text { most } \\
& \text { specific } \\
& \text { topics }
\end{aligned}
$$

Figure 1. Follow-up Interview Guide.

This approach was chosen partly because of access to the earlier focus group analysis, but mainly because of the all-consuming intensity of recent life events. Interview strategies included at least two ways of asking questions or probes for channeling directions. (See Appendix $C$ for the follow-up interview guide.)

The interview began by discussing a biography around the move issues, i.e., the beginning of the shift to formal care. Questions to be posed include: "How about those days after you decided it was time to move (name of relative) to formal care?" or "How about those first days after the move to the nursing home?" This approach allowed the researcher to see what the caregiver identifies first, the events surrounding the transition or the feelings involved. The caregivers obviously had complete freedom to share their own experiences in their own words. After seeing where the caregiver first takes you, a move 
into the opposite direction will allow for the perception of events and feelings to be elicited. Next was the move into a discussion of the formal care decision, how it was made, how it feels now, and how realistic earlier thoughts on formal care decision-making seems now. Having explored the decisions and feelings involved in the transition, the next area for discussion involved formal care. The specific areas for developing insights centered on family perceptions of and interactions with formal care staff. The more general topics included contact with staff, involvement in caregiving, what makes it easier and what makes it harder to participate, perception of roles of different staff, and the staff-family relationship.

Realizing that home care and the caregiving decisions were not made in isolation, the next area incorporated family. This area is intentionally last, due to either its potentially emotional nature or its ability to dominate the caregivers past experiences. Thus, the most specific topics will incorporate discussions of perceptions of the family's caregiver role in formal care: does a family member's caring change after formal care? What happens to the caregiver-care receiver relationship after formal care and their perception of why home caregivers were reluctant to participate in focus group discussions of formal care. Finally, every interview concluded with the caregivers being asked to summarize, in their own words, the difference between caregiving at home and in formal care.

To summarize, the interviews explored in depth what the transition was like, what had been experienced in interacting with formal care staff, the influences of and effects of placement upon the family and 
how caregiving in formal care settings was different from caregiving at home.

Coding and analysis. The tapes of all the interviews were converted into transcripts by a professional typist. Each interview became a separate transcript. The typist used a format which presents the transcript with narrative on the left two-thirds of the page and the right one-third is left open for coding.

Prior to the actual coding, the analysis strategy was developed. As noted earlier, a modified version of the grounded theory method (Strauss and Corbin, 1990), was being used for the qualitative analysis. A complete grounded theory approach was not possible, as this approach requires the researchers to develop the analysis as they move in and out of the field. In this case, the overall design integrates two sources of data, and preliminary analysis of the focus group data informed the collection of the individual interview data. This analysis of the completed data set proceeded in three phases. Phase 1 was open coding, Phase 2 was concept development, and Phase 3 combined concept refinement and theory development.

a. Phase 1: Open Coding. The goal of the open coding phase was to begin the process by capturing and summarizing the material of interest. Open coding means a minimum of interpretation, concentrating on working directly with the content of the transcripts (Strauss and Corbin, 1990). An editing approach will help with formulating theoretical interpretations of the data. The first step was to take a transcript and find material, i.e., subject matter, that represents a discrete incident or event and label it in the margin as representing a phenomenon. There 
was no attempt to analyze or reach any conclusions or develop bigger abstractions at this time. For initial theme noting, each passage was treated as self-contained, i.e., "What do I see here?" With the use of a journal and the techniques of memoing, notes about comonalities and emergent ideas from the transcripts were captured and recorded. The result was six transcripts, with a full "open coding" set, including four focus group transcripts ( 3 formal care only and 1 mixed home-formal care but all representing both spouse and adult child) and one adult child and one spouse interview transcript.

b. Phase 2: Concept Development. The goal of the concept development phase was the sorting and categorizing of key aspects of the data. The open coding was transferred to the computer. These open codes were used rather than full transcripts to locate key concepts. This approach created a compendium of, in essence, what is relevant and interesting in the data. Thus, this results in the ability to crystalize out some organizing themes, bigger principles and clearer categories as well as to organize into a category system. Two preliminary strategies for concept formation were pursued: straight categorization of open codes, and sorting codes by the events involved in the transition process, i.e., decisions, placement, and formal care. The process of doing the coding and applying these different approaches to concept development was used to generate the list of core concepts.

After the initial efforts at concept formation, an expert in qualitative research (Margaret Imle, PhD.), was brought in on a consultation basis to review the developed core concepts and provide reflection on the next step of application. 
c. Phase 3: Concept Refinement and Theory Development. The goal of this phase was to test concepts by summarizing transcripts in terms of concepts and to discover connections between concepts. The tentative concepts were applied to a set of five fresh transcripts and passages of interest were marked. This process was more interpretative and less mechanical. As this process was undertaken, notes were kept on ideas, insights, questions and problems. This process, called memoing (Strauss and Corbin, 1990), allowed the researcher to not lose sight of important ideas and insights but also to not interrupt the actual analysis procedure in progress. As a result, the initial list of concepts was refined: expanding the content of those that were too narrow while restricting the content of those that were too broad, and dividing those that were too diverse while collapsing those that overlapped. As a sense of core concepts stabilized, the effort shifted to building theory in terms of relations among concepts. To prepare for presenting the overall results, these relationships were first sumarized in a tentative outline. Next was a return to the final set of transcripts, making certain each transcript had been examined. This process gave the concepts a final test and allowed them to be polished accordingly, i.e., further refining understanding of their interrelationships and revising the outline accordingly.

In Chapters IV-VI, the three research questions provide the approach for presenting the analysis and what emerged as the major findings. Quotes will be used where they can enhance the discussion. The next section is the fruit of these efforts, the results. 


\section{CHAPTER IV}

\section{REACHING THE END: DECISIONS}

Although there have been several discoveries and insights into the $A D$ process, the caregiving family continues to encounter challenges as the disease process leaves its effects upon the family member. They face many unknowns and decision points in their course of caregiving. They must relate and respond to not only the ill family member, but also factor in extended family members, the health care system, support resources, economic issues, and social-legal guidelines. Somehow, they find the time and energy for these constantly changing demands and make decisions as to what takes priority at this caregiving moment. This life of the caregiver has been well documented in such popular publications such as The 36 Hour Day (Mace and Rabins, 1981). However, there comes a time when, influenced by this around the clock toil, the caregivers perceive the outcome as no longer functional and responsible. Recognizing a turning point, the caregiver then enters into a decision process that results in placement of the care receiver in formal care. This move involves the transition from caregiving at home to caregiving in formal care which results not only in an environmental change for the care receiver but a role shift for the caregiver.

Transition is the conceptual framework underlying this research project. If another name for transition is change, then the changes in 
the caregiving role that these caregivers are experiencing at this time of move to formal placement constitutes a transition.

Bridges' (1980) transition framework is organized and practical but it hasn't been applied to the caregiving situation and thus there are reasons, as outlined earlier, to explore its fit. There will be an attempt to use it as a conceptual framework and one of the goals at the conclusion of this project will be to assess how appropriate a conceptual framework it truly is. Clearly, Bridges' 1980 model is an adequate organizing framework for presenting the material but is it a conceptually rich framework which helps us better understand transition to formal caregiving.

As detailed in Chapter II, Bridges (1980) identified three passages in the transition process; endings, the neutral zone, and the new beginnings. This first passage, defined as endings, is a time one finds themselves letting go of something. There is no set order in how endings happen or any commonality in response between individuals who experience a similar transition. Often endings are perceived with something going wrong. Bridges (1980) notes of endings, "They are ordeals, and sometimes they challenge so basically our sense of who we are that we believe they will be the end of us" (p.110). Even though the change this ending brings may be either unforseen or undesired, it must be dealt with in order to move on with what comes next.

Although a decision may signal the end of one thing and the beginning of another, in these $A D$ caregiving situations, that is not the case. While the site has changed, a caregiving role continues. Thus, in the decision for formal care placement there is simultaneously both 
termination and a continuation. It is within this understanding that the following three chapters are organized within a data oriented presentation. The focus of Chapter IV is on what happens around making the decision, and what it's like, in the home, at the end. The next chapter, Chapter V, addresses what happens in the move to formal care and to caregivers familiar with caregiving at home who are now trying to adjust to continuing caregiving in formal care. The last data chapter, Chapter VI, focuses on the caregiver's adaptation to the new way of life and development of the relationship with the staff who are in essence now the primary caregivers. Thus the findings will be organized into a data oriented presentation around three issues: endings-decisions, placement and the new beginning.

The focus of this chapter is centered on what happens around making the placement decision, the decisions that end the ability to caregive at home and to start the next caregiving role. It is important to note that decision-making is initiated in the ending phase. To decide has all kinds of future implications that affect how a decision gets made, when it gets made and what that end is like.

As the family members lived their caregivers role, they became aware of the many decisions they made along the way. However, they have also discovered that not to decide is to decide. On occasion, they made a decision in advance with anticipation and foresight, and yet, when they got there they chose to discard that decision through circumstances or they realized their thinking was changed. They may have thought something wouldn't be a problem only to find it is more than they could bear. They could anticipate a certain situation would be the straw that 
would break their back and when they got to that point they were a lot stronger than they thought they would be. Therefore, many of these decisions do not result in the transition to formal care. It will be useful to be able to identify key issues and their influence upon the families' struggle with the difficult turning points and decisions in their caregiving roles.

\section{FINDINGS}

The reader is reminded that the findings in this chapter relied mostly on analysis of the individual interviews. Although the initial purpose, as outlined above, was to organize the findings into the three identified areas, an important finding emerged. Family and surviving were revealed by the family caregivers as two themes that were of consistent and intense influence throughout the entire process from early caregiving, through transition, and into the adjustment period after placement in formal care. Therefore, they are appropriately integrated into the discussion of the findings in Chapter VII.

The family members in this study identified five specific themes that were crucial in their decision to place their care receiver in formal care. There was no specific theme, by itself, that caused the move; however, family members related an additive influence when changes began to mount. The five themes, in order of their influence as identified by family members include: event, health care system, caregiver-care receiver relationship, support, and options and availability. The order of influence was judged by the amount of time 
devoted to the topics in the interview and caregivers' perceptions of the importance in their caregiving decisions.

\section{Event}

To what extent was the decision driven by events? The easiest way to imagine this happening is through a crisis-type event. These, in fact, proved to be relatively rare. But there were a number of other things that caregivers spoke of as events that were the turning point in their decision-making. Often these were related to the progression of AD. To understand why these kinds of events were such a turning point needs to be seen against what caregivers mentioned more often than crises, a sense of exhaustion. As exhausted as these caregivers became, it does not take much of an event to become a turning point.

The obvious kind of crisis event one would think of is a situation that immediately disables either the care receiver or the caregiver. If the care receiver is involved, there is most likely a quick move to acute care and then a shift to a more continual level of care. If the crisis takes the caregiver out of the picture, formal care is the conmon replacement. These kind of crises were relatively rare. (Three of the ten interviewed caregivers experienced health crises, two in the care receiver and one in a caregiver.) The care receivers were much more likely to suffer the physical illness or need for immediate hospitalization, however, when the caregiver did suddenly become $i 11$, the situation became complex and the return to the caregiver role was extremely uncertain.

As the disease process took its toll on the caregiver, the sleepless nights and frequent need to reshuffle caregiving priorities 
resulted in extreme burnout. The one commonality that affected spouse and adult children and male as well as female caregivers was exhaustion, both physical and emotional. It is important that nine of the ten caregivers interviewed mentioned their physical exhaustion and three of these nine also spoke directly and poignantly of their emotional exhaustion. However, it must be stressed these numbers over-simplify the situation and in no way capture the complexity of this issue. As an example, the two adult children, who tried to resume home caregiving after a care receiver's physical crisis, were able to continue cnly briefly. It was as if their short time without the care receiver at home let them see how exhausted they had become.

Turning Points. The turning points that were consistently and intensely described by caregivers in the move to formal care included; issues of safety, dealing with incontinence and the AD progression. Interestingly, safety was identified more often by the female spouse caregivers and incontinence by male spouse caregivers. Caregivers often spoke of comparing the care receivers' needs versus their ability to deliver the care. In the home caregiving environment there was always an issue of care receiver independence versus safety. As the disease progressed, the safety issue assumed increasing importance and priority. Adult children struggled most with this issue as they had always related to their parent as an independent adult. It was as if, by making the decision to keep the parent safe by decreasing his or her independence through placement, the children were the cause of their parent's loss. It was a difficult adult child caregiving dilemma. A daughter in a focus group shared: 
It just kind of gets to the point where you have to come to that conclusion for their own good you have to do this. In our case I think we let her have her independence as long as we felt she could have it. Maybe longer than she should have, but it did work out all right, too, to let her have that. (Focus Group \# 6)

Dealing with incontinence was often the first reason presented in the caregiver's placement description,

We1l, I think what really brought the thing to a head was her incontinence. A full bladder, bowel just got to be-I was up all night and, not all night, I was up late at night and things just got, oh I don't know. (Interview \#3, husband)

She had to go to the bathroom and it was in five minutes then she started again and "I 've got to go to the bathroom." - . That was it, so she had to go and then she went out again but many times she confused the bathroom with the front room. - . here she was sitting on that little table, you see over there, that golden leaf table. She was sitting there and one time she confused right in the middle of the carpet because she didn't make it. Actually she intended to she thought the toilet was there and wanted to sit down, you know. (Interview \#8, husband)

Male spouse caregivers consistently detailed the great challenges they faced in an attempt to deal with incontinence, bathing and dressing their wives. As the actual physical caregiving demands increased other challenges emerged. Families shared concerns about, not only their actual physical issues of delivering personal care, but also how they struggled greatly with a lack of knowledge to make clinical judgments in order to deliver professional care 24 hours daily.

The findings would not be complete without the acknowledgement of the influence of the $A D$ progression upon the placement decision. Family caregivers are often able to deal with dressing, redressing and early memory losses; however, when the serious behavior changes begin, the demands on the caregiving role intensify. The caregivers realize the care receiver is requiring a level of $A D$ care they can no longer 
provide. This is captured in the following focus group dialogue from a daughter:

But we have, we have tried everything first, and like I said I think there comes a time when you realize that they just need more care than you can give them. They need professional care ... (Focus Group \#22)

For the caregivers who experienced an $A D$ crisis, it was not so much that the $A D$ event was making a difference but the ongoing aspects of caregiving that were somehow shading into a new series of events that were the end. It was more an outcome of caregiving and an outcome of the disease process rather than a direct cause of the decision-making.

In summary, although identified as an event, there was usually no particular crisis that precluded any other option and forced a decision. There was a combination of a predisposing factor of exhaustion matched with a turning point event such as issues of care receiver safety, incontinence, and $A D$ progression. There is not a clear way these events influence decision making. In other words, caregivers will continue to work through that 36-hour day and fight off the placement until some turning point event changes their way of thinking around the decision issue. As the caregivers' struggle with these decisions this may be the time they have to consider reaching out to professionals for help.

\section{Health Care System (HCS)}

Although HCS was second in their order of importance, the caregivers were more clear in their descriptions of this theme. In reality, caregivers do not get to the turning point toward formal care without previous encounters with the health care system. In fact, all caregivers had a HCS story. In essence, why the "event" steered things 
the way it did often had to do with their prior contact with the health care system. Past interactions and perceptions surround the importance they place on the HCS as they approach decisions.

Families were clear on this issue, the HCS was viewed as either positive or negative. There was virtually no in-between. When families talked about the HCS in positive terms, they first shared examples of how it helped influence the decision in a way they felt good about. They might identify a particular service that was helpful at a particular time or a suggestion for a resource that, when they followed up, proved usefur. In essence, this often allowed them to decide to continue with caregiving at home for a while longer.

Second, family members spoke of the HCS as providing direct help for themselves as the caregiver. When they shared this information, it took on a personal tone and was often identified within the framework of an interaction or relationship. Even if the decision needed to favor the move to formal care, they gave clues to feeling supported, respected, and cared about as individuals themselves. The following is a quote from a daughter caring for her mother:

I don't know where I'd been without the doctor... I would call her anytime and she would call me back and never be... I was never even charged for it. She just worked with me, you know. When Mom went into the nursing home, I sent her a great big bouquet of flowers and said, "Thank you for being a wonderful doctor." Because I would have been lost without her. (Interview \# 4)

The majority of the HCS discussion, however, revealed negative experiences and perceptions. The major themes included misdiagnosis, medication mismanagement, indifference, and professionals with limited $A D$ knowledge base. These experiences played out in two major ways, they 
prolonged the decision to access formal care and once the decision for placement was made, they influenced the families' initial ability to develop a level of trust within the formal care facility. Families' perceptions revealed much sensitivity in their interactions with the HCS as noted in the examples that follow:

Well within hours of the operation (hip), they didn't watch her and she got out of bed somehow, dragging all that packing and her catheter and everything else and then fell right out of bed so then she had to have another operation on the other hip. (Interview \#6, son)

We were really quite unhappy with the emergency situation there at $X$ hospital because not only did it keep us waiting and before we went in, but then when we did get in, we sat there again because they had other emergency. . . . So were it was like we were there like five or six hours just to get the arm set. And I knew she'd fallen backwards. . . But they never x-rayed anything except her arm and he fixed the arm and then sent us home. . . . that even getting her up from the bed to the portable potty she would just scream she was in so much pain. . . We talked to the doctor and she said, "If you can bring her in to see me in my office, then we'll go from there." So we did this and she said, "Lets put her into the hospital, "because she had fractures of the vertebrae. (Interview \#4, daughter)

And then the second time they sent her home with the wrong medication for her, she has seizures. Her seizure medication wasn't correct. I asked the nurse, I said, "How come she's going home on such a low seizure medication?" . . . I said, "Gee, that doesn't sound right." But I thought I'm no medical person, but it just didn't sound right. So we took her home on three a day and within a week, she had one of her major seizures .. So they called the ambulance and we took her to the hospital . . They called me at work and said. "Can you come down?" and I talked to the social worker and she said, "I think this is the time where it will be-we can work it to get your mom into a nursing home." (Interview $\# 5$, daughter)

And I never dreamed that this one doctor, when he, he put him on a drug holiday, took away all, everything, which I understand is of usefuT, but the point is that $X$ (husband), has Parkinson's too. And he took away all of his meds. Well, in three or four days, he couldn't walk, couldn't get out of bed and so I didn't know that. Suddenly the nursing home called me and told me that he was, the condition that he was 
in and that the doctor had agreed to put him back on his med. So at that point, this is about two weeks after he'd been there, at that point, I discovered that everything else was gone too you know. And I was really kind of angry and so I just started raising heck with (laugh) everybody. (Interview \#7, wife)

As obvious in the information shared by families, if the health care system in general was not the best place to turn for sensitive and consistent help, families must develop other avenues to turn to in their caregiving journey.

\section{Caregiver-Care Receiver Relationship}

In the earliest stages of the caregiving relationship, the care receivers are in essence a source of the efforts that are necessary to meet the job. Initially they have periods of independence that are sufficient for meeting their needs or they access their necessary support network. Slowly, and over time, the family member who was initially providing occasional support becomes the caregiver and there is a major shift in the responsibility. Caregivers described strong influences from the previous caregiver-care receiver relationship, the known health care wishes of the care receiver, and knowledge of previous caregiving experiences by the care receiver.

The previous relationship between these two individuals exerts a powerful influence on the continuing caregiving-care receiving relationship. Family members identified two directions of influence: one, within the actual one-on-one relationship, and two, within the influence on caregiving decisions. Caregiver perceptions of how they as mother-daughter or husband-wife interacted in the past provided insight 
into the current caregiving interactions. Three mother-daughter pairs

are presented for comparison of this point.

We will pay for a milkshake or get her a pop or some kind of a treat and sit there and visit. I sit there and talk to her when she doesn't make any sense at all, but I pretend like we are having a nice visit arid so on and so forth. ... I brush her hair and put combs in it, try to keep it out of her face. I have arranged for a beautician to groom her hair like on every other Wednesday or whatever so that she, because I'm sure she remembers how good that feels and that makes her feel better. . . . I just hug her and get her and take her outside because she enjoys that. . . So my going out there so often is because of the closeness I feel with her. Since I'm the only family that's here I want to give her as many hugs as I can, make her feel like she still has family. I'm doing it for her and not really for the home or can help the home in any way. It's just my closeness for her. (Interview \# 4)

She would always behave for me. .. I think it was because I was the only daughter and I'd always been very close to my mother growing up. - . I knew my mother very, very, very well. I knew what she liked and I knew what she didn't like. i.. We just sort of knew each other very closely. (Interview \# 2)

I wheel her out to the courtyard. They have a beautiful courtyard and nobody uses it, at least when I'm there. And then we have absolute privacy. And I do her nails or I sing to her because I've been taking voice lessons. So I sing to her or read poetry because she always loved poetry. ... And so then I'd read her these little poems that she was just-were dear to her that she'd memorized in her childhood. . . . And people just don't understand. But for me, it's almost like this is one of the specialist times for us because, well, quite honestly, my mother was a very unhappy person. She was bitter and sullen and ah, she was kind of disapproving in general of . . including me. Especially me, or at least I felt it maybe more than other people (laugh), she can't tell me now that I'm doing stuff wrong. All she can be is just a sweet little bundle of love you know, and I can hug her and kiss her and tell I love her and all this stuff that I always wanted to do. It's sort of like I'm making up for lost time. And I'm trying to manage something that was broken. (Interview \# 5)

Another important influence of past relationships is in its ability to affect the caregiving decisions. If the caregiving pair had an open, trusting communication style, then caregiving issues were freely raised 
and a variety of options were explored. If, however, the family member had a closed or mistrustful relationship, not only were options not explored but significant caregiving issues were never raised for discussion, let alone exploration.

Often the care receiver had shared his/her wishes on specific forms of treatment, placement in a nursing home and/or the right to life or death procedures. Families struggled greatly with these issues. Although they realized the care receivers lack of recognition of the actual caregiving environment or situations, they struggled with "knowing" as they made the painful placement decision. Caregivers implied the decisions would most likely have remained the same but this specific issue greatly increased their caregiving stress.

Well, she is dead in a way, in many respects, there is a death that's taken place and it's sort of like dealing with a residue and being respectful as you can. It's beyond the point I would want for myself. It's beyond the point where she would have wanted for herself; she had no choice in the matter. (Interview \#6, son)

He always had a thing about going to any, you know, he had this idea that, "I go to a nursing home, that's the final thing. That's the end." And he would say this too. .. Well, (laugh) guilty, but very relieved at the same time because I just felt like I was at the end of my rope. I was nervous, high-strung, and not good for him, you know. (Interview \#7, wife)

Because this isn't any kind of a life that he's leading and you know, because I know he wouldn't want to live like this or if he was to have a heart attack or whatever and die, maybe that's all for the best because why drag on like this. (Interview \# 10, wife)

Past family caregiving experiences had the ability to influence the present caregiving situation. It was not unusual that the care receiver had been a caregiver to a parent or extended family member in their past. Aware of the family history, the caregiver made the decision they 
should carry on with that caregiving style. Stressors often occurred as the earlier generation, the care receiver, set a standard under different circumstances that this caregiver could not live up to in the present.

One might expect to find that an adult child who has accepted this caregiving role in the family may also have a previous caregiving history. However, the magnitude of the findings in this study were surprising. Three of the four adult children had also provided caregiving at home for their other parent. What they shared was not their disappointment at the loss of a parent, as they already had that experience, but their inability to succeed this time in their caregiving at home. Because of this history, these caregivers found themselves deciding to delay placement until the last moment and perceived a much greater level of exhaustion, emotional stress and sense of failure with placement.

It wasn't something I had ever wanted. I had intended to take care of her. My father died at home and that's ideal. He didn't have to go to a hospital or a nursing home. At the end he had a lot of things. I was putting formula down his tube and having to put that in and out and so forth. We managed, but at that time I was 10 years younger too and you notice it. (Intervi ew \#2, daughter)

I felt like I was committing her to a death camp, because, and $X$ (husband) reassured me that it wasn't that at all. She was being placed in a facility where she'd get the kind of skilled care that she needed. But I really felt like I was committing her to something worse. (Interview \#4, daughter)

In summary, the previous caregiver-care receiver relationships have the power to exert influence upon the present caregiving situations. Although, because of a shared history, caregivers desire to 
continue in a home caregiving role they often find themselves facing increased stress with these difficult decisions.

\section{Support}

Early in their caregiving role families find themselves needing to turn to others for help, assistance and advice. As they $\log$ in the many weeks, months, and years of caregiving they become quite articulate as to what works best for them. Caregivers highlighted three sources of resources to meet the challenges they faced: (1) informal, (2) formal, and (3) self.

In their informal sources, families identified the positive influence of the extended family network. Some of the specific examples included actual caregiving help with the care receiver, providing words of encouragement and support, and affirming decisions made by the caregiver. When family members got involved in the actual caregiving situation, it provided not only a brief relief for the caregiver but a bonus benefit in the family members' better understanding of the care receiver's decline and what the caregiver was experiencing on a daily basis. Thus these family members were often able to be more understanding of the formal care decision.

I think contacting your family and getting everybody to agree, you know, they don't pay for it but keeping them aware of what's going on, what things are really like. I used to get them once in a while to come over and give me a few hours respite. And that was more valuable-what they learned here taking care of him was more valuable than any time I got away. The girls used to trade off Sundays. Sunday afternoon was mom's afternoon out and they (laugh) they learned a few things. (Interview \#7, wife) 
Some caregivers noted an interesting contrast in their current friend network. By this time in the AD process, their friends have mostly disappeared. A male spouse shared in a focus group discussion:

The worst part of what is going to happen is the phone stopped ringing. Friends no longer call. This is the worst part because you see we are pretty much aware that with Alzhimers, actually you suffer more. You suffer more. She is dying inch by inch practically. You see it over a period of time. And this is where you need the most support. (Focus Group \#21)

The drastic changes in the care receiver's behaviors have made social interactions difficult and friends have stopped coming or are at least less available now.

And when they came in, they came this way towards $x$ (husband). He was sitting like you are, he would have been facing them. M. and her sister both spoke to me, 'how are you?' and so on and so forth. They looked at $X$ and you know they didn't know what to do. They walked off.... Years ago, they would have patted his shoulder, and said 'how are you?', 'good to see you' and probably would have given him a hug, but they walked off. (Interview \#1, wi fe)

But not many friends, you know. They bail out fast. (Interview \#6, son)

The caregivers' formal supports included specific individuals within the health care system, home health services, respite resources, and support groups. It is important to note the contrast here between the HSC as a general agency which was alluded to earlier and professional individuals within the system who really made a difference for the caregivers and their decisions. By far, the most frequently mentioned helpful individual around transition information was a social worker. One might be inclined to think that is their job. That was exactly the caregivers' point, it is! According to these families, they were successful in providing a needed and respected level of support at 
a critical time. On a rare occasion the caregiver had a supportive relationship with a physician and was not hesitant to turn to him/her for help and guidance at the time of transition.

For those families who found the physical care becoming too demanding, home health services were cited as a resource that helped them continue to maintain for a while longer. This quote by an adult daughter demonstrates the point:

And so we decided, well, we would find people to come into the home that were willing to do it on a 24-hour basis for less money. So that's how we started the 24-hour caregiving, seven days a week. That was to take some of the pressure off of me and also to free up some of my evenings where I wouldn't be quite so involved. (Interview \# 4, daughter)

However, later in her discussion she outlined the amount of time and energy it took to find the right person for her mother and this job. So, this support also came with an energy cost and in the end this was factored into the decision for placement.

Often families are at the burnout point from being up day and night or needing to work and having to caregive all night. For these families it isn't so much the physical care but their level of exhaustion. Respite care often provided a resource that worked to extend their caregiving. While upon reflection respite was recognized as an important support, the decision to seek respite was noted as very difficult to initiate because it required the caregivers to look inward and admit some increased vulnerability.

Support groups were noted as being helpful for many families throughout the whole $A D$ process. However, during the time of decisionmaking and placement, the major level of support was provided in two directions; first, in the caregiving role and second, for the caregiver 
as an individual. In the caregiving role, the group helped not only during the decision-making time but with insights and clues at the actual time of placement. Through the group's sharing of their experiences and feelings around making the decision, the actual placement, and some early adjustments, caregivers were provided with additional resources for coping with their own feelings. Although this support didn't make the decision to move and the move itself less painful, caregivers were aware that others, too, had walked in their shoes and survived. Details of these findings will be presented in a later section on the caregivers after the move.

Interestingly, the caregivers identified themselves as a third source of support in the difficult decisions they were making. They cited their gut feelings, their intuition and their common sense as major points of influence. Often deciding that they had "gone the limit", they perceived these abilities as a sense of empowerment. It was their right to do what they were doing and decide what they were deciding. A large hurdle in arriving at self support was dealing with the absence of validation of their caregiving efforts by the care receiver. By the time they were at this decision-point the $A D$ process has robbed the care receiver of the ability to provide reciprocal feedback.

It is interesting to note that of the ten separate interviews, only two, one adult daughter and the other a female spouse, mentioned God or religion in their discussion. An adult son, shared an interesting philosophical perspective, 
I mean (laugh) it's a human problem now and you can keep that out of it because no amount of faith is going to change this one hellish job. (Interview \#6)

In summary, the caregivers identified the key sources of support as formal, informal, and self. Overall, individuals in the health care system were perceived as a negative source of support and tend to prolong the decision to access formal care. Family members, home health, and respite services provided significant and positive support and reinforced their decision to continue in their caregiving at home. However, noticeable by its minimal reference in the discussions was the care receivers' ability to exert any active influence on either these support systems or the resulting decisions.

\section{Options and Availability}

As caregivers realized they were closing in on the time of placement, their major focus included: identifying the type of care that would be needed, becoming acquainted with individual facilities, and dealing with the availability of a desired site. They identified pre-planning, beliefs and values, and realities as the key issues influencing their decision.

Pre-planning was best described as making visits to several formal care facilities and then making a decision to place their care receivers name on a waiting list. On hindsight, many of the caregivers identified how they had flirted with the issues of pre-planning but had not taken any initiative to follow through. This was an extremely difficult process for the caregiver to undertake which they described very poignantly as, Irying to visit but resisting the move. 
The beliefs and yalues of the caregiving spouse and child are the key elements involved in the dichotomy between resisting and deciding to making the move. They described very basic family-personal values, as well as their own individual philosophy. The myth of abandonment was clearly refuted. Caregivers noted, "you make commitments and follow through." "You go the limit." "Its a child's responsibility to their parent." "I am caregiving because I love my mother, not because I feel obligated."

Families arrive at the placement decision by considering the realities, which they labeled the practical issues. The absolute first reality is an open space in the facility at their care receiver's level of need. Three of the caregivers who were on waiting lists found the facility unavailable at their actual time of need. Two of these individuals found it necessary to seek another facility while the third caregiver found herself resorting to temporary facilities while waiting for the next opening at her original choice.

Well first, I had his name in at $X$ (home 1), and then also at the $X$ (home 2) and so when it became time, I contacted them and they said they didn't have a place right then, but they would let me know when they would. (After a period of hospitalization-So the only place I could get him was at $X$ (home 2) and so you know, that's about 20 miles or so from here, so I just couldn't keep him there any longer than I needed to and so then I contacted the $X$ (home 3 ) again and they said well they didn't have any place right then, but there was a man that was real sick so there could be an opening soon. So (husband) was out at $X$ (home 2) for two weeks and then we got him in at $X$ (home 3 ) where he's been ever since. And I'm real happy with the place. (Interview \#10, wife)

When she was in the hospital, we were making all these phone calls trying to find homes that would take her. They don't have any space even on an emergency basis to take a patient. (Interview \#4, daughter) 
And so, then they'd give me names and you know by the time he was ready to come out, the place would be gone...

(Interview \# 7, wife)

A second reality, closeness in distance to the facility, emerged as a very important feature for both spouse and adult children. For the spouse it was mostly the need to assume increased driving demands, but for the adult child, It was now having to work another responsibility into their daily or weekly schedule.

Then it was zeroing in on a home in a proximity and the doctor and that's very difficult to do to zero in on one area really narrows it down. (Interview \#4, daughter)

A lot of them in the neighborhood, right down here on (name of street) street, there's three of them. They own all of those. - . I have a very heavy job. And I bring work home most of the time. (Interview \#7, wife)

What I liked about it is it's so close to home, that my dad could drive there to visit. Because he still gets confused driving. At that time, he was still getting confused. He just moved to $X$ two years ago but he never quite got the road straight. And it's confusing out here. (Interview \#5, daughter)

Although families alluded to the financial impact of formal care decisions, at the practical level, their discussion was centered on identifying the best vs the cheapest for their care receiver. They became quite savvy at recognizing what the caregiving facility should offer to be the most appropriate place for their care receiver. New and "outside attractive" didn't always mean the best. A male spouse shared:

There was one place, a very lovely place. "How about security?" "No, we're always right here." The nurse was back in this room, the clients were sitting out here to walk right off. A very high class-looking place. But there was no security at all. Silly, if anybody wandered away. (Interview \#3, husband) 
One I thought was a good place, it was a new, modern home. They added an new section which was really, really nice and clean and everything there. But (sigh) then I soon found out that they overlooked my wife so much that she was just like a zombie, just like a zombie. (Interview \# 8, husband)

As alluded to above, what kind of an impression the facility makes is factored into the decision. The caregivers described their debate here as between facility features and human care. Facility features incorporated the appearance, smells, sounds, levels of care, and organization. Human care was described simply and insightfuily by a caregiver as the difference between sales people and individuals who demonstrate caring. As evidenced by these caregivers comments, a caring attitude on first impression, was quite influential.

- . but they just seem real human there. That's one of the reasons I picked that place. (Interview \# 5, daughter)

- . finally found $X$ (nursing home) and these people are just absolutely superior. I have never found my wife dirty. They are constantiy around these patients. They are-they do an excellent job. I'm very happy for her. (Interview 8, husband)

The actual details of formal staff behaviors and facility features are explored in chapter VI.

Finally, as families reviewed their options to finalize the placement decision, their beliefs and values, the amount of preparation they had invested and certainiy the realities that presented themselves strongly influenced the actual formal care choice. Although these choices incorporated caregivers' best thinking at the time, they were quick to point out if the original option wasn't available and it was time to make the decision, they choose the next best option. 
Summary

As noted above, the journey to formal care took many different paths. The five themes explored under the concept of reaching the end: making decisions, suggests how complicated and contingent this decision-making process was. The themes, presented in order of importance to the caregiver were: events, the health care system, caregiver-care receiver relationships, support, and options and availability. While the event could be a crisis, most often it was a turning point event that signaled the end. The one commonality caregivers experienced was exhaustion. The male caregiver was more likely to make a decision for placement as a result of a turning point event around an incontinence problem while the female spouse caregiver was triggered by an AD safety issue. The HCS most often was a negative influence and prolonged the placement decision. With the caregiver-care receiver relationship and support, the influences of past experiences were extremely powerful. Finally, even if the family had decided to place their care receiver on a waiting list, it was rare that an opening existed at the time of crisis or turning point. Any one of these factors can tip the decision either way and all of them can change almost overnight in ways that are unpredictable. Thus, by themselves they may not predict placement but in combination there was a profound effect leading to placement. However, it is worth noting, once the decision had been made and the transition to formal care had occurred, there was little likelihood of a return to caregiving at home. 


\section{CHAPTER $V$}

\section{MAKING THE TRANSITION: PLACEMENT}

The theme of this chapter is: what happens during the move to formal care? This is the time that's partly adjusting to not doing caregiving at home and partially getting used to the new environment as well as coping with the immediate consequences of the move. In this time of transition, both of these processes are going on at the same time.

The reader is reminded that the neutral zone is the second passage of the transition process. As noted by Bridges (1980), "The neutral zone is not an important part of the transition process -- it is only a temporary state of loss to be endured" (p.112). The label "neutral" should not be taken at face value. Although it is meant to reflect a "time out" concept for the individual, it is not reflective of what is going on inside. During this time the individual experiences confusion, feeling disconnected, isolated, lost, empty and emotionally unconnected to the present.

\section{FINDINGS}

What is it like going between home and an established routine within formal care? This is deceptive because the care receiver is in one place or the other but the caregiver's mind is torn between the two, a very emotional and draining time. The caregivers describe this time 
period as anything but neutral as they shared their feelings and emotions.

The move to formal care is a time bounded shift. As the caregivers noted, something indeed has happened. Basically the shift results in three changes: 1) moving the care receiver to another setting, 2) relinquishment of some level of day-to-day care, and 3) confrontation of a new caregiving environment. The caregivers suddenly need to try to make sense of what is going on, especially in the immediate past in their home caregiving role. A great deal of reinterpretation results and they must now try to project a whole new future on this side of the transition. NOW is seen in a different light and NOW means something else. A real paradox happens at this time: the caregivers are "trying to hold on while letting go."

The pivotal piece in the development of the caregivers' transition to formal care is their recognition of the differences between caregiving at home and caregiving in the formal care facility. Immediately, family caregivers noted shifts in three major areas: control, involvement, and personal reorganization.

\section{Control}

Overwhelmingly, the family caregivers sensed a change in control. They reflected, while at home, that the decisions and responsibility were solely in their hands, theirs alone. Now there are others who certainly dominate, if not control, the responsibility and decision-making. Female spouse caregivers often noted how this reaffirmed a previous loss of decision-making ability as the AD process had earlier robbed them of their couple shared decision-making. As 
several spouse and adult child caregivers noted, they were on new turf now and this also contributed to the issue of control. Finally, in seeking placement, caregivers had recognized the need for professional services and they anticipated, as this relationship evolved, control would be an early, if not constant issue. As an adult daughter shared:

Oh yes. And I certainly (sigh) you know, I'm trying to control what these doctors do. - . I just really haven't agreed with what they were doing. (Interview \#7)

\section{Involvement}

Discussion of changes in caregiving involvement brought an intensity to the interviews. Caregivers reflected changes first in purpose and then later in the actual caregiving activities. The major shift in purpose became one of changing their caregiving activities from total responsibility and care to one of monitoring. Monitoring served two functions, to maintain their relationship with the resident and to provide an access for their newly self-delegated responsibility of evaluating the care by the formal care staff. Family members also saw their evaluation of staff as a way to deal with their loss of control issue. Initially, they perceived this staff evaluation would inciude the level of professional care staff was delivering and staff's ability to personalize care. Professional care evaluation included such areas as equipment, staff's $A D$ knowledge, and the physical caregiving skill level of the staff. In exploring the initial concerns regarding the issue of personalization, caregivers quickly noted the staff's lack of personal knowledge of the resident, shared an awareness that there would 
be little things that could no longer be done for their resident and that, overall, there would be less flexibility in the daily schedule.

The first question caregivers asked themselves as they reflected on their continued role, was; do I want to continue to? If so, how? Their responses ranged from no desire to continue to desiring some degree of participation, often desiring to help with feedings. Caregivers operationalized their approach to caregiving participation via a visiting schedule. Visiting behaviors soon involved strategies and were a result of two sub issues, frequency and sharing. Some caregivers could only manage visiting once a week while others made a daily commitment. Spouses were more likely to take this on as a daily responsibility, choosing to do this by themselves. Adult children were more likely to share visiting with siblings and extended family as a two or three times a week activity.

\section{Personal Reorganization}

Almost immediately, caregivers experienced a shift in personal reorganization. They had gone from total and constant physical care responsibility to having actual time for themselves. Although initially dealing with their physical and emotional exhaustion, they soon discovered a change not only from within themselves but in the environment at home. No longer a slave to a routine, most caregivers quickly felt a freedom to come and go. They remembered they could enjoy a life outside the day-to-day caregiving. Within this freedom to make other choices, they emphasized their option to continue to care for and love their resident. The changes, at home, ranged from feeling very lost and lonely to pure enjoyment of the quiet and relaxed atmosphere. 
Regardless of the direction of their personal reorganization, caregivers stressed the accompanying intense feelings and emotions. As a son-in-law noted,

It just seems like when her mother went into that care facility, we were given our lives back. (Interview \#4)

The common caregiver phrases emerging with placement were, "The moment has arrived" and "It's time." The key point stressed by these caregivers was emphasizing the actual transition to formal care, doing it vs the earlier deciding. However, the overwhelming message one received was the perception of the abrupt and traumatic end of their caregiving at home. Immediately, the caregivers identified the differences between caregiving at home and caregiving in formal care in the areas of control, involvement and personal reorganization. Shortly after placement the caregivers realized changes were also occurring in the relationship with their care receiver. The reader is reminded, that focus of this chapter is on the immediate consequences of placement. Long term issues that were faced by the caregiving family, the care receivers, and the formal care staff are discussed in detail in Chapter VI. It is important to note that with the placement in formal care, the care receiver will hereafter be referred to as the resident.

Consequences. Immediately there were reactions and responses by caregivers to this change in the caregiving site. The caregiving role and relationship had been massively transformed and there were real consequences for the caregiver-resident relationship, the resident, and the caregiver based on this transition.

Within the caregiver-resident relationship, what kept their role as caregiver alive was the continued commitment to promoting, maintaining, 
and preserving the integrity of the resident. Although the AD process had robbed them of any reciprocity from the resident in this relationship, the importance of the resident to them remained the centrality of their caregiving role. This finding supports the earlier work of Bowers (1987) and her concept of protective care. Most stressful for the caregiver, within this context, was the resident's inability to recognize how hard they were working to remain involved in their resident's caregiving. Dialogue from three male spouse caregivers iliustrate:

- well I can remember when she was in the nursing home, I'd take her hand, hold her hand, and held her hand an awfuil lot and give her a kiss and $i$ says $X$ would you like to give me a kiss?... it's a tough situation when you lose a person, that the mind is gone and that's the way it is with these people... I says, "X," I have to leave now, she showed absolutely no emotion at all about it. (Interview \#9)

- . And like I said, I go for a walk with her or go out, but not that it makes any difference, my wife, I don't think she knows. She just simply doesn't. And very, very, very, very few times that maybe . . . all of a sudden her eyes went open and she came to her full senses "Oh my man," she said and was gone just like that again. As soon as I squeezed her and hugged her and oh, that moment everything was gone again. She was right back in her own world again. (Interview \#8)

Well pretty much the same. I go out in the afternoon-Sunday afternoon. She's up, sitting in the chair, and she recognizes me in a way. I don't know she recognizes me. And we usually take a little walk. I'm there for an hour, an hour and a half, and I come home. She welcomes me in a sense when I come, she doesn't really miss me when I leave. She acts like I'm just going around the corner and I'll be back in a few minutes anyway. (Interview 3)

The consequences of the move to formal care for the resident are often difficult to detect and decipher. First, the caregiver was in the best position to evaluate the effects of the transition, having the past history and baseline for the most recent resident behaviors. However, 
the caregiver was in a time of great personal stress and may not have been the most reliable judge at this time. Secondly, any decline in the resident could result from the progression of the $A D$ process, be it a response to the change in the caregiving environment, a change in the physical caregiver, or from all three. Caregivers cited behavior changes and physical changes. Whether pacing, swearing, zombie-like, or aggressive behaviors were described, all were recalled as changes since admission and represented extreme trauma for the family caregivers. It would, however, be impossible, and impractical, to isolate the cause and effect. Finally, as noted earlier, there was the lack of reciprocity from the resident. The caregiver was unable to rely on the verbal feedback or the mood of the resident as a barometer to the quality of care being given by these new caregiving individuals, the staff.

The caregivers were able to identify four personal consequences in this early time of transition. They described feelings, responsibilities for self, other residents, and role shifts. Their discussion was usually direct and to the point, yet they shared the intensity of feeling and emotion that accompanied this experience.

a. Feelings. Almost immediately, caregivers noted an intense roller coaster type effect. They had experienced the ups and downs of caregiving in the past but these current feelings were intense. Most often their first mention was of guilt, as these interview excerpts reveal.

So my main reason was lack of sleep, that was -- otherwise I would have taken care of my wife much longer because I still feel so goddarn guilty about this whole thing, you wouldn't believe it. I feel so guilty that I put her in a nursing home, that many times I can't sleep because I always think God, what does my wife think of me." . . . this tremendous 
pressure is gone, but on the other hand, the guilt feeling has not left me yet. I still have a guilty feeling I let my wife down for some reason or the other -- that is still there, even after two years ... my brain tells me I did the right thing; and heart tells me hey, couldn't you have done a little bit more? Couldn't you have done, just maybe you could have done this? (Interview \# 8, husband)

So putting her out of my life was a very difficult thing. I hungered too long but since $X$ care center is close to the house, I think we can still be a part of it, but it's difficult. It's even difficult to go down there because the guilt still comes in, but I did ah, still wish I could have kept her at home. (Interview \# 6, son)

Then there's the guilt too -- part of it is guilt like I really should be coming more often but I know I can't and I don't have to, but, I should but, she doesn't know the difference but, I still should you know. So you have this stuff going on and the pressure builds up if you don't get there. (Interview \# 5, daughter)

However, the best example of the ambivalence and intensity of these feelings was summed up in this quote by an adult son, "In the guilt, I feel relief" (Interview \#6). This son had noted, early in the interview, his intense feelings toward the placement decision. However, since he had made it past that hurdle he now thought her death would be the ultimate loss.

I don't know if it will be a relief for us or it will be a horrendous challenge. I'm frightened of her death in a way. When I first put her in, I thought well, she'll be well taken care of, I can still be part of this process and all, and there's a great relief within the guilt, but I don't know. I sometimes think her death will probably be worse now than if she died right here at home, which would have been preferable. Because that's what I was holding out for was I was thinking she would die here where I thought the most noble kind of death and dignified death would be here at home. (Interview \#6)

b. Responsibility for self. When the caregivers turned to sharing a realization of their need to assume some responsibility for themselves, they spoke most often of time and new stressors. Adult 
children now needed to find a way to work in visiting during an aiready hectic schedule. Spouses, however, often found themselves either with time on their hands or filled the days by spending most of it at the nursing home. Mostly the stress referred to dealing with their physical and emotional exhaustion, the suddenness in the caregiving site change, and the felt need to recognize and respond to the caregiving role changes. However, there was at least one spouse caregiver who noted the stress brought on by the void left in his life at home.

I go out once a week. I can hardly stand that. And so leaving; not getting, not being with her, but leaving. Just like turning the blade on the lawn, you know . . Y You know, I have everything -- all the other activities, but I don't have to take care of her which gives me time which lets me look out the window when I should be doing something ... I just don't have the drive to use it (freedom) half the time now. But I waste it, unfortunately .. I don't have nobody to talk to. (Interview \# 3, husband)

c. Other residents. A clear majority of the caregivers were unprepared for the feelings they would experience when they were confronted with a ward or unit of $A D$ residents. Some found the behaviors engulfing, as everywhere they looked they saw the variety, intensity and complexity of Alzheimer's symptoms. Others were saddened to realize the behaviors they observed represented the future symptoms their resident might exhibit. Often, as described, it was an overwhelming beginning experience.

d. Role shift. The role shift brought a recognition and redefinition of the caregiving responsibilities. As caregivers shared earlier, their first job was to recognize the differences from caregiving at home. Initially, the caregiver's emphasis was on recognition of their perceived new responsibilities. After they had a 
period of time to interact with the staff, their focus shifted to the development of new strategies which allowed them to remain involved in the formal caregiving role. An in depth discussion of the interaction with staff is the major focus of Chapter VI.

In summary, the care receiver became a resident in formal care. However, for the caregivers, they found themselves torn between dealing with the loss of caregiving at home while trying to respond to issues in the new caregiving site. The caregivers early on recognized two important themes within this transition: first, how caregiving in formal care differed from caregiving at home and second, what were the consequences of this move to formal care. The caregivers identified differences between home and formal care in the areas of control, involvement, and personal reorganization. Although aware of consequences for the resident and their resident-caregiver relationship, caregivers focused mostly on their personal consequences of feelings, role shifts, other residents, and responsibilities for self. As we listen to the caregivers one recognizes they have made the transition to formal care. With this transition came new responsibilities, especially the need to deal with formal care staff. The development of these relationships between family caregivers and formal care staff is the central topic of the next chapter. 


\section{CHAPTER VI}

\section{THE MOVE BEYOND}

The purpose of this chapter is to explore the caregivers' adaptation to a new way of life. These individuals described themselves as in the process of developing a relationship with the staff who now are, in essence, the primary caregivers.

Bridges (1980) called this third passage in the transition process, "New Beginnings." In this phase the individual launches into a new activity. As Bridges shares, "New beginnings are accessible to everyone and everyone has trouble with them" (p.141). The outcome from this time period depends on an internal or inner realignment rather than external changes. It's during this time that the individual struggles with letting go of the old way of doing things. As the individual emerges from this experience he/she may be described as changed, renewed or refocused.

This chapter will present the findings from analysis of the caregivers' discussion of their formal caregiving perceptions and experiences. As outlined in Chapter III, the data from the interviews and the focus group discussions were merged. However the major portion of the formal caregiving data originated within the focus group discussions.

In acknowledging the caregiver's complete transition to formal care it is critical that one considers the longer term transformations. The concept of the move beyond incorporates a recognition that relation- 
ships take time to develop and that the families' caregiving role transition evolves through perception and evaluation of shared experiences with staff. In this over-time process in formal care, family caregivers identified three major themes: caregiver-staff relationships, factors influencing the nature of the formal caregiving relationship and caregiver evaluation of quality of care. Although some of the sub-areas will not be new issues, they have by now taken on increased intensity and meaning.

\section{CAREGIVER-STAFF RELATIONSHIP}

The big theme and what really matters most to the family caregivers is the relationship with the formal care staff. As explored earlier, relationship development involves time, energy and commitment from the family caregivers. However, adding to the complexity in this situation, caregivers identified a two-step process they negotiated. First, is a recognition of the change in their caregiving role. Second, is the establishment of a relationship with the formal care staff.

The caregivers' roles and relationships have been greatly transformed and there are also real consequences for the caregiver-care receiver relationship based on this transition. In this new. relationship, recognition and redefinition of the new caregiving responsibilities must occur. What keeps their role as caregiver alive is their continued comitment to promoting, maintaining and preserving the integrity of the care receiver. Thus, as they begin in the formal caregiving process, the caregiver's focus is on promotion and 
construction of the role rather than the caregiver-care receiver relationship.

It is obvious that over time, the resident will continue to decline. Now, the caregivers finds themselves needing to decide if this is a result of the disease process, or a change in environment and staff. The caregivers are challenged because not only do they have a lack of resident reciprocity, they also have no validation of poor staff care if they perceive this is the situation.

Reflecting on their continued involvement in formal care, caregivers discovered a need to refocus. As they recognized their responsibilities in this changed caregiving role, it was extremely clear a new relationship had been forged. As noted in Figure 2 when caregiving at home, there was a relationship between the caregiver and the care receiver. Since the transition to formal care, the caregiving relationship has been modified to include the addition of staff. It has now become a critical responsibility of the caregivers to assess the staff as well as their resident.
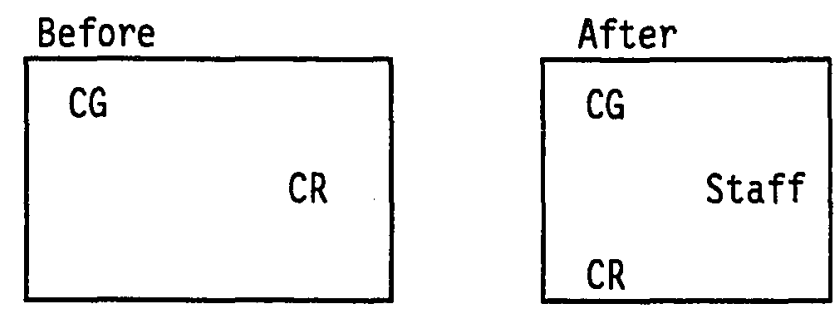

Figure 2. Caregiver-Care Receiver Relationship Before and After Placement.

This caregiver relationship with the staff takes time to plan and carry out. Maybe this is why even though formal caregiving may not be as physically draining as home caregiving, it continues to be as 
emotionally draining. Comments from an adult son caregiver provide an example:

There a few of them, a few people over a period of time who have made me feel really good about coming in, but whether it's my nature or what, I feel sometimes that I'm the one that has to break the ice, provide the humor to make everyone feel good. (Interview \#6)

Aides

Although staff relationship was the central theme in exploring the move to formal care, the details of the discussions centered on the caregivers perceptions of and relationships with the aides.

Table II shows a breakdown of how in the focus group discussiors, family caregivers' 142 mentions of formal care staff were divided between positive and negative references to different categories of staff. Two themes are particularly notable in these data. First, over half of all the mentions involved nurses aides. Second, the mentions of aides were much more positive than any of the other groups. Indeed, the 25 percent negative rate for mentions of aides may be an overestimate, as over half of these mentions involved problems that were due to aides carrying out institutional policies and procedures.

The major reason for this emphasis on aides was that aides were the ones that family members consistently found providing the direct care to their family member. One spouse (Focus Group \#10) shared, "Only the aides take care of the patient. The nurse doesn't do a thing but administer medicine, that's all." An important reason why family members discussed aides so positively was an identification issue. It was the aides who now substituted for the tasks that family members used to do. In addition the aides were the ones who really knew their family 
TABLE II

POSITIVE AND NEGATIVE MENTIONS OF FORMAL CARE STAFF

BY FAMILY CAREGIVERS IN GROUP INTERVIEWS ( $N=179)$

\begin{tabular}{|c|c|c|c|c|}
\hline & $\begin{array}{l}\text { Aides } \\
\text { Staff }\end{array}$ & $\begin{array}{l}\text { Nursing } \\
\text { Staff }\end{array}$ & $\begin{array}{l}\text { Administrative } \\
\text { Staff }\end{array}$ & $\begin{array}{l}\text { Facility } \\
\text { In General }\end{array}$ \\
\hline $\begin{array}{l}\text { Positive Statements } \\
\text { Negative Statements } \\
\text { ('Frequency) }\end{array}$ & $\begin{array}{l}75.3 \% \\
24.7 \% \\
(77)\end{array}$ & $\begin{array}{l}36.7 \% \\
63.3 \% \\
(30)\end{array}$ & $\begin{array}{l}28.6 \% \\
71.4 \% \\
(14)\end{array}$ & $\begin{array}{l}38.1 \% \\
61.9 \% \\
(21)\end{array}$ \\
\hline
\end{tabular}

members' needs in technical and personal terms. These points were nicely illustrated in an individual interview ( \#6) with an adult son:

Now rarely do you get personalized observations out of a nurse ... it's the aides... and I sometimes think why aren't the nurses more this way? But the aides do the hard work and you see the difference and you have so much respect for them because this is the person you care about and this is the person who is dressing them, undressing them, taking them to the bathroom, feeding them, bathing them. The most intimate things are being done by these people.

In particular, other than occasional mentions of frustration with nurses' low level of direct invoivement and doctor's almost complete absence from the setting, discussions of interactions with staff was predominantly about interactions with aides. This combination of consistent contact with aides and a shared understanding of the kind of caregiving the aides do lead family members to emphasize their contact with aides and to talk about these contacts in a highly positive manner. Thus, in the family members' discussions about what staff were involved in providing care in nursing homes, it was the aides who played the central role. While it is important to know who the major staff players are, it is also critical to explore what it is in this new relationship that makes it work and what hinders its best function. 
In summary, development of the relationship with the formal care staff was identified by family as the most important adjustment in their transition to the formal caregiving role. Perceiving a need to refocus, the family caregivers recognize the caregiver-care receiver relationship was modified to incorporate the formal care staff. The aide was the staff member family most consistently and positively identified. This perception results from not only a personal identification with the aides caregiving but also they are the ones the family member constantly finds taking direct care of their resident.

FACTORS INFLUENCING THE NATURE OF THE FORMAL CAREGIVING RELATIONSHIP

The second theme family members identified in their adjustment to formal care explored the factors that influence the nature of the formal caregiving relationship. Caregivers' bring all their previous health care system experiences with them. As noted in the earlier pre-placement discussions of health care organizations, these perceptions and experiences had been good or bad, no in-between. The important factors caregivers' identified that affect the nature of the formal caregiving relationship included: monitoring, trust, staff behaviors and family behaviors.

\section{Monitoring}

The caregivers monitoring behaviors become a key strategy in the overall development of the caregiver-staff relationship. Monitoring also becomes the crucial link in the development of trust. However, it is also a critical behavior which provides caregivers the opportunities to make observations, form perceptions and provide reciprocity to staff. 
Caregivers were very open in sharing their monitoring goal. Simply put, they monitor to "keep good homes good." They know staff are aware of which families stay involved with their residents. Early on, they themselves became aware of those residents who had no visitors. However, to monitor was not just to show up; it involved developing strategies. Much energy was put into timing visits and observing staff interaction with other residents. Caregivers pointed out it was important to vary not only the days but the time of day they visited. They became sophisticated enough to be able to evaluate the difference between daily shift staffing and weekend staffing.

I just have a hell of a nice relationship with these people. I have a lot of confidence in them. Now with the swing shift, I'm not so sure. I'm -- I don't know. I don't uh, I was in there several times in the evenings and I don't think it is quite as efficient as it is on the day shift, but no complaints. (Interview \#8, husband)

They're understaffed. A lot of times I go on weekends, and they don't show up, they don't go to work. That means they're - short handed. (Focus Group \#1, wife)

There was no secret to how these family perceptions were made. Family caregivers not only observe staff interactions and behaviors with their family member but they monitor staff's treatment of other patients as a barometer for how their family member will be treated when they are not present. This was also a consistent theme in the interviews.

But I think they treat other patients pretty well, I think. You're right, that gives you an indication of how they are to my mother when I'm not there. There's this one older fellow that's just demanding constantly and kind of like a broken record, 'Nurse, nurse, give me my, I want my, nurse, nurse.' I mean it goes on 24 hours a day. But they never really lose patience with him and they don't ignore him either so that makes me feel good. (Interview $\# 5$, daughter)

And they handle other situations like last Sunday in the day room, they gave a lady a glass of milk which she managed to 
drop on the floor. I was leaving the dayroom but I was so curious as to what they would do. No problem. Nice. (Interview \#3, spouse)

Oh yea, because you know, during the time that you're in there, you notice if they were gently treated and with lots of patients, there wasn't any yelling at anybody. (Interview \#9, husband)

Thus, through observation of staff with other residents,

particularly those who appeared without family, the caregivers developed a sense of what was happening when their resident needed help and they were not there. As noted earlier, this monitoring strategy was a key link in the development of trust.

\section{Trust}

A first on the road to the formal caregiving relationship is the development of trust. Without an ability to trust, there is no chance for a positive caregiver-staff relationship to develop. Caregivers were quick to note the importance of including both the facility and the staff within their level of trust. Repeated interactions, again over time, are the cornerstone for the development of trust. Most often the validating experience was finding that a requested caregiving behavior had been carried out by the staff.

Yeah, they do and they're very good about you know, when he was up and around, they' 11 say ..- they would call me and say 'We found $X$ on the floor, he had fallen or whatever, and we wanted you to know that he did and that he seems to be okay and everything. (Interview \#10, wife)

The nurses would call me if there was any change. He would even fall out of his chair, go to sleep and fall out of the chair right in front of the nurses desk and they would call me and tell me, He took a tumble out of his chair but he, she said we checked him very carefully and he's alright. If I didn't happen to be there or they would call me at night if he was more disturbed than usual and let me know. (Focus Group $\# 10$, wife) 
But they always contacted me. It didn't seem to be any problem. I'd say, 'Okay, fine. Thank you.' And that was about it. (Interview \#9, husband)

-. I was making suggestions like I thought I'd like to hang a mobile over her bed because I said, "She lies on her back in bed so much." "Great idea, we'll have a hook put up above her bed, and you can bring that in." And I did. ... And I said 'Do you think you could walk her?' "Oh we're trying to walk her, you know," so they were receptive to my ideas and like we were going to be a team even though I'm not there. (Interview \#5, daughter)

Thus, when monitoring shows desirable staff behaviors, the result is a positive outcome, the development of trust. What this commentary is also conveying is that family caregivers are making observations and forming perceptions of staff behaviors.

\section{Staff Behaviors}

Within the exploration of the formal caregiving relationship and the dynamics of their interaction with staff, caregivers devoted considerable attention to the influence of staff behaviors. Just as family caregivers were clear about who was doing the care, they also knew what they wanted them to be doing.

Two categories of behaviors were particularly prominent in the caregivers' viewpoint. While some discussion focused on behaviors that reflected the staff's relationship with the resident, their major emphasis was given to behaviors indicative of the staff's relationship with them as caregivers.

It's notable that the family's priority in the staff-resident relationship was similar to what Bowers (1988) found under her heading of preserving the identity of the resident, treating the resident as a person rather than an object of care. What this amounted to was family 
caregiver's thinking of quality care as involving an inseparable combination of technical quality and respect for the resident. As evidence of high quality care, family caregivers wanted to see the staff develop a personal and/or professionally sensitive relationship with the resident.

Especially here, the gals in that special care unit, they do know. That's why Mom has adjusted there. They don't force her to do anything. If she doesn't want to do it, she doesn't do $i t$. They just leave her alone, and come back five minutes later as if they've never mentioned it and say, "Let's do this." and she'1l do it. Before, in the other places, you either get dressed now or I don't have time to come back, and you do this now and they make an issue out of it, and so you have an upset patient. (Focus Group \#6, daughter)

A dialogue about the aides from focus group \#6:

A: They're so tolerant. That the only thing that makes all this workable. (daughter)

B: And they also touch and that's so important. And brush with the hand, pat on the hand. (daughter)

Or hug. (wife)

D: And a very positive attitude. (son-in-law)

B: That would be hard to be a caregiver daily. I just thank God for these people... (daughter)

During an interview (\#6), an adult son shared:

We11, I don't know what their cormitment is to 1 ife and what their background is -- whether it's a religious background or they just have all this compassion for people. ... And one of them gets sick with back problems and another one is off sick at times and you see the place really changing. So certain people have just kind of a unique quality.

Turning to staff-caregiver relationships, these emerged as not only a personal but a sensitive and priority area for their discussion. Family members were quick to point out that it takes both family and 
staff working together to develop a relationship. A daughter shared in her interview:

Its funny, they're individuals of course. Some of them are just ever so kind and helpful and communicative and some of them are just put offish completely. They just -- its like you're invading their territory or something you know, 'and we sure hope you leave pretty soon so we can get back to business.' Others of them make you feel like you could be their best friend. And you're both in this together and they just want to do what's the best thing for your mother. (Interview \#5, daughter)

Another daughter shared this staff response at the time of her mother's death:

She made it clear to everyone that if she was to die, she wanted someone to put her eyebrows on .. . she stayed up with her in the next room, and that night when she died, she got up and she put her eyebrows on before she called us. And when we got there was a rosebud on her bed. (Focus group, \#13)

Other caregivers shared:

If they had understanding for the family. That's the biggest thing. (Focus group, \#1, daughter)

I felt that they were concerned about me as well as him. (Focus group, \#10, wife)

You see, one of the little aides put her arm around my shoulder--a little Cambodian girl who I think is just great. (Focus group, \#3, husband)

The caregiving relationship is enhanced when staff recognize the caregivers by name and when they share about the resident's activities, appearances and behaviors. A particularly powerful sharing can occur when staff validate caregivers' past experiences. As staff and caregivers discussed caregiving experiences, caregivers could receive reassurances that many of the problems they experienced were encountered by the staff as well.

We had always had a good relationship, and I was disturbed when I had her at home that it was completely deteriorated to, 
you know, having her be angry at me all the time. But I know some of these people who take care of her at the home said that she can get angry at them sometimes, . . . I think that it surprises some of them out there because they think she looks like such a sweet little old lady, but she can be a little witch. (Focus group \#15, daughter)

Well, I find that it's much easier to be one of the good guys now instead of one of the bad guys! (Laughter) She gives them so much problem that I know she used to get angry at me, and now I'm the one that she can smile at. I can enjoy it more, and she can enjoy me. (Focus group \#6, daughter)

Although family caregivers realized their new team role is likely to be secondary to that of staff, they often were very knowledgeable about the disease process in general and certainly their resident in particular. They were aware of the past history with medications or aspects of the environment such as noise level or patient's personal reactions such as being overstimulated by TV or rock music, now being played by staff. Thus, the caregiver had a baseline for observing the resident's response to institutionalization and often their evaluation influenced whether the resident stayed or moved to another facility. After all, family members seek formal care to get better care. The team relationship is facilitated if staff view the family's behavior in this process as interest in the resident rather than a desire to harass or threaten staff.

Here, anytime I have said anything to them that might help, they say, "Thanks for telling me that. We' 11 try that." -. I think that's another reason why I've appreciated this place is that they do take a suggestion as if they're interested to hear them. (Focus group, \#6, daughter)

\section{Family Behaviors}

As noted above, family caregivers recognized they bring not only desires but responsibilities to this developing relationship. 
Caregivers often shared how they felt a need to actively influence the relationship with staff. Here too, they initiated purposeful strategies.

We've come to the conclusion now that the purpose of the visit is to show the staff that you care. (Focus group, \#21, daughter)

As a common strategy, they provided care to their family member in ways that they hoped would provide role modeling for the staff. Since role modeling implies a presence with the resident, the interrelationships between strategies of monitoring, visiting, role modeling and trust begins to be obvious. Family caregivers were also aware of the importance of communication, thus they intentionally gave positive feedback to staff as a way of influencing staff to provide higher quality of care for their family member. All of the above activities were ways in which the caregivers actively participated in not only observing but molding staff's behavior to create the best quality of care for their patient.

And I did not get through to anybody that this wasn't just a stick lying here that they were treating until I got this little nurse and I was asking her questions, and she said, "She can't hear." So I said, "How old is your grandmother?" And the nurse looked at me, "Oh, well, she's -- whatever --" I said, "She's like your grandmother," and then she started treating her like a person. (Focus Group \#8, daughter-in-law)

Thus, role modeling was a common strategy used by caregivers to help promote the family caregiver-staff relationship. Family members expect sensitive and professional behaviors toward not only the resident but themseives as well. They share a willingness to reciprocate in a staff relationship that is already positive and a desire to make contributions to improve those that need help. In summary, family 
members identified monitoring, trust, staff behaviors and family behaviors as the important factors that influence the nature of the formal caregiving relationship. Monitoring as a strategy is a key link in the development of trust. Trust is critical to the development of the caregiver-staff relationship. While family expect staff behaviors that provide for a sensitive relationship with the resident, their major focus was on the staff behaviors that influence a supportive relationship with themselves as caregivers. Recognizing they have responsibilities, family members often use role modeling to help promote the family caregiver-staff relationship.

\section{FAMILY CAREGIVER EVALUATION OF QUALITY OF CARE}

The final theme in the adjustment to formal care centered on the caregivers' exploration of the quality of care issue. Family caregivers spoke with one voice on this issue, they expect quality of care. When they were the single caregivers at home, they provided the resident with loving and competent care. Now, with a team of caregivers, there is no excuse for anything less.

How do family caregivers go about evaluating for quality of care? To be clear about what is desired in a relationship is one piece of the puzzle. However, it is often difficult to know how to evaluate the factors involved in the actual caregiving. Family caregivers identified three areas that they included in their evaluation: the quality of care for their resident, staff knowledge, and the organization of the formal care facility. Quality of care, they were quick to point out, equated to respect for their resident. 


\section{Quality of Care}

In the family caregiver's evaluation of care, there was very little identification, let alone discussion of caregiving tasks. When specific tasks did come up, the caregivers discussed activities such as dressing and toileting in ways that were most meaningful to them. For example, dressing involved providing their resident with clothes that matched and were not soiled, and toileting needed to be accomplished in a way that protected modesty and privacy. Just as Bowers (1987, 1988) discovered, family caregivers are more likely to relate their caregiving experiences in terms of the meaning that experiences have for them rather than the specific tasks that comprise their caregiving activities.

Family caregivers identified their emotional involvement, love, and personal motivation that provided the basis for their care at home and that they continued to bring to the formal setting. As explored in his

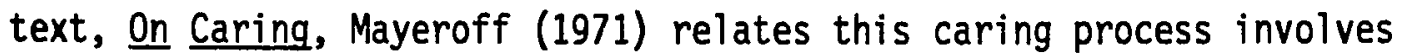
time and patience. The caregiver's vision of caring was not a passive result but one in which they were an active participant. At this time, in the adjustment to formal caregiving the vision of caring continues, as on a continuum. Changes in their role and the resident occur and will continue to do so, just as it did while caregiving at home. A key concept within the caring process is the idea of not only being with someone but also being for them as well. ". . in caring for another person we can be said to be basically with him in his world, in contrast to simply knowing about him from outside" (Mayeroff, 1971, p. 32). Thus, quality of care for these family caregivers is influenced from at least two perspectives. First, as a continuation of their past shared 
caregiver-care receiver comitment. Second, in response to their personal relationship loss within the $A D$ process, they will struggle to be for their resident and not just with them.

Staff must do their care in a heavily restrictive organizational setting. Quality of care for a nursing home makes smooth functioning of the organization a high priority. This was often at odds with the fact that staff must do their care in a heavily restrictive organizational setting. Quality of care for a nursing home makes smooth functioning of the organization a high priority, while for family members it means emotional, bonded care between caregivers and residents. The difference in these two perspectives leaves a lot of room for misunderstanding. Aides are often caught in the middle, as they are the employees in the organization who not only provide the majority of the direct care for the resident, but also have the most contact with the family.

Family comments are captured in the dialogue from focus group \# 15:

A: Most of the aides I've met are really good, and it makes me so mad. The facility will say, "Oh, we'll hire if we can just get them." and they don't. That's just a bunch of bull. (Daughter)

B: They've got good ones down there. You know, the ones that stay, they're alright, but they have some who come in extra... would just lay around and wouldn't - - there's something to do all the time in a nursing home in order to keep it -. and you've just got to keep ahead of your work. (Husband)

A: But you know, one I talked with where my mother is, she's really a good little gal. She's been a nurse's aide for about ten years, and she said if she complained really, they would just tell her to leave. If she left that facility, she would have to start at minimum at another one . . They are not appreciated. Makes me mad! And if you complain, like if my mother, if I think something's not fair that's happening to her, if I complain, it would be the aides that get hell, and that isn't the 
point. It's because there aren't enough of them. (Daughter)

In an interview an adult son disclosed:

And know that when you go there, that one person you enjoyed so much as the caregiver may be gone tomorrow and you're constantly going to be retraining yourself to that new person that comes on and you're going to be fatigued by it because you're thinking, "Oh God, now I've got to deal with this one." and you look at all the problems you're going to have there. We11, so you deal with it. You don't have a fixed situation. It's always in transition. The turnover rate is horrendous. (Interview \# 6)

You look at the staff here, there's an incredible turnover. Why? They're overworked and underpaid. That's simple. This is an incredibly labor intensive business, particularly when you're talking Alzheimer's. (Husband, Focus Group \#14)

Thus, caregivers who identified the quality of care they desired for their resident often found themselves in a system that had a different definition. While they expected quality from all staff, an aide who was skilled and knowledgeable was often a key link to the caregivers positive perception of care.

Knowledge base. Family caregivers bring a great deal of knowledge about $A D$ and their resident as an individual with this disease to the placement. They have been in interaction with heal th team members, support groups, and formal organizations. Also, they often seek printed resources and access professionals, such as lawyers, on their own. When family caregivers began to interpret and evaluate staff members, they identified with the physical or "bed and body" work of the aides because that is what they used to do. While they expected all staff to have a knowledge base about dementia, it was crucial that staff also be trained in appropriate professional behaviors.

There just wasn't the knowledge then. Now when there is the knowledge out there and it can be obtained, now I do blame 
them. I do blame aides in nursing homes that don't understand various forms of dementia. I do blame the hospital workers who don't understand and react the wrong way. (Focus Group $\# 27$, wife)

As family caregivers seek a quality of care for their resident, they are not only evaluating individuals but the facility. Thus, the setting and it's guidelines exert a controlling influence overall.

Organization of the formal care facility. There were a number of things that affected caregivers' perception of the quality of care but an underlying theme that kept coming up repeatedly was the organizational setting and the ways the organizational setting influenced the staffs' ability to deliver care. This was particularly important in the staff's ability to deliver care in ways that made the caregiver feel there was a high quality of care delivered in that facility.

Earlier the discussion acknowledged the caregiver-staff relationship that develops over time. The emphasis the caregiver places on the aides was also explored. However, caregivers also recognized the demands of staff caregiving in a heavily restrictive organizational setting. There is too much work to be done within their quality of care guidelines, and there is too little pay to reward a staff member for that level of care. Staff who attempt this level of care may not only go unrecognized, but it may even cause problems for themselves within this system. However, family caregivers sense that this quality of care is how they provided care at home and upon turning to formal care this is how they expect the system to provide care for their resident. This is why we see the caregivers involved, to provide for the quality dimension and their desire to get as much out of the staff as they can. 
In an attempt to look more closely at the organization of the nursing home and the caregiving role it is useful to recall the discussion of caregiving tasks in Chapter II. Litwak et. al. (1990), in his task specific theory, linked technical tasks with the formal organization and non-technical tasks with the family suggesting that nursing homes and the caregiving families are currently at a state of imbalance. It is assumed that while the goals of both groups are complementary, their structures are in conflict and herein lies the basic problem. When routinization is a major focus, the description sounds more like a machine or an assembly line product rather than a process that incorporates human beings that have the ability to be caring, sensitive and respectful. However, to support an optimal family-staff relationship, the interaction processes between family and staff could assume as much importance in accomplishing the task as the actual task completion.

Thus, at an optimal organizational level, staff caregiving delivered in a caring way could be valued by both the family and the formal organization without having to incur additional expense. Basically, this is a process-relationship issue and not a focus on the actual task. In the long run, this approach is also responsive to the issue of family as the "forgotten clients."

While there was an attempt above, to discuss both quality care and organizations separately, the exploration of quality care within a formal care organization is considerably more realistic and practical. At the same time as caregivers see staffs' work being invalidated in the nursing home and they see no respect for adding that caring or respect 
dimension that they really want, they recognize quite fuliy that to the extent that the aides add a caring dimension, it detracts from the ability to meet the technical demands of the rest of the facility. Still, as far as caregivers are concerned, that is what quality of care consists of. Thus, they end up seeing that the person doing the job that they most empathize with is when they are most aware that the demands of the system and the rewards of the system are completely out of line with what they see that person is doing. The caregivers seem to be saying, that these staff are as unrecognized and stressed in their caregiver roles in this system as I was unrecognized and stressed in my caregiver role at home when I was the only one.

Over all, on a broad level, families still want to see some clear sign of respect for the resident. Their care comes out of years of commitment and obligations and technically excellent care is not a substitute for the bonded family care they gave at home.

With the focus on working together as important as preoccupation with tasks and structure, the formal organization and the family could identify their contributions to a mutually identified optimal caregiving outcome. Competence is certainly necessary from the family's point of view, but mere competence is not enough. The bottom line wolild be not only what these two groups do but how it is done.

Thus what really matters from the family's point of view and the involvement of the family in formal caregiving organizations is centered within the organizational structure. As caregivers make the move toward this new beginning, issues of where they fit, how the formal care facility is organized, how they comprehend or fail to comprehend 
important agendas, and how they find a place in or fail to find a place within that organizational structure are crucial.

In sumary, in exploring their formal caregiving experiences, family caregivers do make a new beginning. They are able, over time, to refocus their caregiving relationship with their resident to incorporate the staff. They plan strategies, such as visiting, role modeling and monitoring. It is through these techniques that they arrive at the ability to develop trust.

In their discussions, family caregivers most often reflected on their relationship with the staff, identified factors that affect the nature of this relationship, and shared insights into how they evaluated this new caregiving relationship. The aides are the central staff individual for family members. Family caregivers expect a quality of care for their resident even though they all must function within a restrictive, formal care organization. This quality of care, however, involved a recognition of themselves as caregivers as well as a recognition of their resident as an individual. As noted earlier, the challenge for the staff and the formal care organization is to also care about the residents rather than only take competent care of them. 


\section{CHAPTER VII}

\section{DISCUSSION}

The past three chapters have moved with family caregivers and their $A D$ residents through the decisions that ended their caregiving at home, into the formal care placement and left them as they were developing their relationship with formal care staff. One of the things that Chapter I highlighted as an issue underlying all of the various phases of the transition would be potential issues in spouse-adult child differences. Beyond that, other areas that showed a consistent relevance were family and surviving. Within family, the important dyad of caregiver-care receiver relationship will be shown to play an integral role in better understanding family caregivers' experiences around the transition to formal care. The overall discussion will move from family, which is at a social, interactive and support level to surviving, which is at the individual level. An important and relevant reminder: The choice of a qualitative approach provides a window through which one can peer into the individual world of the caregivers. Thus, the type of caregiver provides a first clue to differences in caregiving issues.

\section{SPOUSE-ADULT CHILD}

A key objective of each research question and one theme that has been looked at explicitly but separately within each of the chapters is 
the difference between spouse caregivers and adult child caregivers. The first point of discussion is to look at the broader issues of that comparison not just at a specific point and time, since overall there are some systematic similarities and differences.

Both spouse and adult child caregivers experienced tremendous exhaustion with their caregiving experience. However, their reasons for placement seem to differ. Spouses, who tend to push themselves to the very end, find themselves most vulnerable to a physical crisis or an $A D$ turning point event, such as safety for the females and incontinence for the males. Adult children are more likely to be vulnerable to an $A D$ behavioral change or caregiving issue, like the need for respite or home health help. In the spouse relationship there is more equity and one continues with the caregiving stresses and $A D$ changes, because the central hub of their life revolves around this relationship. With the adult child who is exhausted, trying to work and continue with family responsibilities, the changes in the parent causes a much different stress, in that while a significant responsibility, it is not their only one and may not even be the central one. In the parent-child relationship, most often the holding on as long as possible has to do with a reversal in the dependent-independent relationship. It is hard to recognize your parent as the dependent one, as these caregivers share:

So putting her out of my life was a very difficult thing. - . but inside you can feel that feeling of abandonment. I abandoned her and I didn't want to. As I say, I wish she could have died. (Interview \#6, son)

. . I felt like no one else was going to look after them. By God, somebody's got to look after them. (Interview \#5, daughter) 
There is a difference in how spouses and adult children behave around the placement decision. Spouse often assumed the responsibility for making the placement decision and then just informed their kids and extended family. This is not to say that spouses don't discuss more general activities, but they perceive their offspring are too busy to be intimately involved. While these spouses most often spoke of positive relationships with their children, they identified limited involvement in the actual caregiving itself. However, this limited level of involvement was most often initiated by the spouse caregiver as they labeled their kids as families who were involved in parenting young children, both parents working or a single mother supporting the grandchildren. While some of the caregiving spouse's behaviors may come from their exhaustion level, or a desperate desire not to have to relive the many experiences by retelling them, the more common response was they don't want to burden or bother these already too busy adult children with other responsibilities. These behaviors also represented the spouse's attempt to remain an independent caregiver and not show dependency needs to their children. Examples from a male spouse caregiver and a female spouse caregiver provide some insight:

It was my decision but however, two of -- I called and talked with -- I have two sons anyway. - . they were involved but not in the decision. I'm, I just said, told them beforehand, I said, "Well, the time will come I probably have to place mom in a nursing home." And their response was, "Dad, you did all you can" and that was that. (Interview \#8, husband)

Well, they realized that I couldn't handle it anymore and that I needed to get away from it and they of course are busy with their families and everything and they couldn't really give me too much support and you know, taking care of him or anything like that. So they, you know, well especially when he started becoming combative and everything. They thought that was the thing I should do. (Interview \#10, wife) 
Adult children turn to their siblings or the remaining parent with more of a discussion-type decision. This process is not to imply that the decision comes easy or is unanimous. These behaviors are strongly tied up in the dependency-independency role shifts that placement will bring but may also of necessity be influenced by wishes of the other parent, siblings, and extended family. In contrast to the caregiving spouse who, in the past, has shared decisions one-on-one with the spouse, the adult child has no history or experience of being in a position of decision-making for a parent. For the adult children, it is as if they've lost the relationship with the parents but find themselves with the responsibility. This interesting dialogue is between an adult daughter and her husband:

Well, the only thing is that it's just a body of the person that you have grown up with and through the years. It is no longer that person. (son-in-law)

No, that's the memory that stays with you. (daughter)

I know, but that's what it becomes. I mean, all the sudden out of a clear blue sky, that person that you knew is no longer there and it's just that their body is there and it's a whole different personality. (son-in-law)

Well, they are worse than a child, worse than anything. (Interview \#4, daughter and son-in-law)

With both the AD process and placement, spouses shared a great sense of loss. This seemed to be the case with both a short-term relationship of married just 3 years ago, as well as a long-term one going on 49 years together. There was this huge void in their days and evenings, in their heart and their life in general. The caregivers had often become so involved with the caregiving, it had become their whole existence. The spouse misses not only the intimacy and relationship 
with their spouse but after placement often find themseives physically alone too.

Well, it's very lonely. ... just something you've got to keep doing. You know, you've got to hang in there and of course, my bad times are at night. . . We were always real close and everything. (Interview \#10, wi fe)

- . the car went bad and everything went wrong. I just wanted some comfort from $X$. I wanted him to say it was gonna be allright. He simply isn't there. - . We used to think we knew what we were going to do, that we'd be here. Sure, one of us would go, but we would be here together. (Interview $\# 1$, wife)

Yeah, my wife and I, we are together since we are teenagers. All of our lives and both kids are from us and that's it. . . she doesn't show any emotion or anything like that. (Interview \# 8, husband)

We11, I was lonesome of course. I mean that was the main thing, but I was relieved. ... I mean we would go into the front room and sit down and she'd ask me who I was and I said, "Well, I'm your husband." . . . she didn't even recognize this house as her home, and we planned it and had it built, landscaped it and all of that. (Interview \#9, husband)

With an adult child who is already juggling many responsibilities, there is more a bewilderment process with behavioral changes in the $A D$ progression and certainly guilt with placement. The children say while you expect to lose a parent eventually and the process is painful, with the severe behavioral changes there comes a role reversal in their dependent-independent relationship. When they take away their parents' independence with placement, they feel guilt. This is true even when absolutely necessary for the severest of safety issues. Another issue for the adult child is the need for placement often signals a progression in the disease process. Thus, it may be easier to verbalize the guilt with placement than think about the finality of the loss of the parent. 
Another caregiver difference occurs shortly after placement, in the early transition time. The differences in spouse and adult child behaviors might be described as the adult child being more reactive vs the spouse being more accepting. While having an idea of what they desired in a formal care facility prior to transition, after the placement, both caregivers set out to evaluate the quality of care. The spouses often spoke of the facility as an acceptable place, thus appearing to be abla to shift pre-placement priorities in order to be able to feel an acceptance with the facility. It was not possible to capture how much of this was tied up in other issues such as the exhaustion level or the desire to find a facility that was close. Certainly clues were given to suggest these issues were relevant. Discussion from these spouse caregivers provides for reflection:

There were times when I thought maybe the care could be better. There were times when I noticed that her hands were, that her fingers were dirty and all, perhaps whatever she had been doing with her hands, they didn't keep her clean in that direction or something like that. But I imagine they took the best care that they could. (Interview \# 9, husband)

- . he's always -- most of the time he's shaved every day and clean and since he's been bedridden mostly, I'm not real sure about his teeth being brushed. . . . But I really feel that they do a good job on their patients. Like I say, they are caring, they try. (Interview \# 10, wife)

An adult child was more likely to move a parent to a different facility rather than look for compromise. This difference was more evident with the focus group discussions than in the individual interviews. Indeed, this adult child response is most likely tied up in the role shift response which was explored in Chapter $V$. The parent is now in a dependent role and the child, in an attempt to respond to this new and increased responsibility, leaves few stones unturned in pursuit of 
quality of care. On occasion adult children noted the amount of stress they put their parent under, as well as themselves, when making several facility changes. Again, the heavy influence of the role reversal is evident in the guilt with placement, the concern with responsibility to get quality care and the guilt with the toll on their parent for making facility changes. However, after the initial placement evaluation and responses just discussed, there did not seem to be notable differences within the development of the relationship with formal care staff. These issues were discussed in Chapter VI.

This decision brings the caregivers to a shift in their life after placement. To compare the different worlds of the spouse and the adult child after placement is like comparing a major transition with an overall reorganization. This involves a reorganization for the adult child who moves from a 36-hour day to maybe 12 hours per week. However, the spouse experiences a major transition where their investment of energy is not that much different but there is a question of where it occurs and what they are doing. For the spouse, there is not only a difference in performance of the caregiving role, but they are still locked into that role. The emotional investment continues for both caregivers. These emotions and interactions involved in being a spouse or adult child are clearly tied to family relations.

\section{FAMILY}

The discussion above points to another theme which has operated in many ways throughout these chapters, and that is family. Family is often presented and explored at a social or support level; however, the 
findings have shown it was not so much an issue of a broader support network as an intense involvement within family relationships and a number of different elements of family. The most fundamental linkage of family is the caregiver-care receiver dyad, but a variety of more extended issues will also be explored.

While families are linked by marriage and birth, there are other variables which enhance this relationship, such as communication, interactions, and sharing a history or reminiscence. What one cannot assume is a poor commitment, lack of attention or neglect will be the outcome from a caregiver who has had a previously poor relationship with the care receiver. Again, this is a very personal and individual caregiving situation.

The caregiving decisions are often made within this family context, even if only as imagined by the caregiver. The caregiver's own sense of self, self worth, accomplishment, and meaning is often not just lodged within the caregiver-care receiver relationship, and not just within their own self-image but also within their ties to that broader family. The responsibilities, the conflicts and that sense of reflected appraisal, i.e., who we are, is done through an imaginary kind of sense of how acceptable our actions would be to our significant others. Even if the impressions are not directly coming out of their family's feedback, it is coming out of the caregiver's imaginings of what they think the family would feel about what they are doing.

One of the issues that has not been recognized as a family theme, both here and in the literature, is the caregiver-care receiver relationship. Basically a family issue, this relationship is often not 
seen as falling into that side of things but indeed, it is yet another element in the whole question of family relationships. As noted in Chapter II, both Pearlin (1990) and Archbold, et al. (1990) have called attention to the importance of the caregiver-care receiver relationship.

Reflecting the influence of the $A D$ process, the most poignant influence on the caregiver-care receiver relationship is the loss of their past history. All of the interactions and memories gathered over the years are absent for one individual and painfully present for the other. Although all caregivers spoke to this issue, it was especially difficult for spouses from long-term relationships. So, it is not surprising to hear the caregivers speak of loss of the person as well as the reciprocity within the relationship.

Oh well, you've lost the person's -- she doesn't seem to have love anymore. ... it's a tough situation when you lose a person, that the mind is gone and that's the way it is with these people. (Interview \#9, husband)

Some caregivers experienced another phenomenon that linked the closely shared memories, history and placement decision. It was as if when they placed the care receiver in formal care they sent all the memories along and ended up with a big void. Although by this time the reciprocity was already gone, it was as if the care receiver's physical presence represented the ties to the memories. Thus, the physical presence represented the remaining link to that previously shared relationship.

So putting her out of my life was a very difficult thing. I hungered too long, but since $X$ (facility) is close to the house, I think we can still be a part of it. . . . you know, it's a precious person you're trying to do the best for, but you can't. Can't do that forever. (Interview $\# 6$, son) 
In the caregiver-care receiver relationships, outward behaviors are not indicative of the relationship between the two. Similar behaviors may have different meanings and different behaviors may have similar meanings. The intensity and especially the individuality of the meaning of this relationship is captured in the comparison of the difference in these two adult daughters' relationships with their mothers. Both daughters described almost identical caregiving activities when visiting their mother in the nursing home: much touching, singing favorite songs, reading poetry and brushing their hair. However, the meaning of the behaviors was quite different for each daughter and obviously grounded in their previous relationship.

So my going out there so often is because of the closeness I feel with her. ... I want to at least give her as many hugs as I can make her feel like she still has family. (Interview \#4)

... and I can hug her and kiss her and tell her I love her and all this stuff that I always wanted to do. It's sort of like I'm making up for lost time. And I'm trying to manage something that was broken. (Interview \#5)

A common response, buried within the caregiver-care receiver relationship, was the worry that somehow the resident would suddenly have a brief touch-point with reality, recognize where they were and realize what the caregiver had done. Obviously, the caregivers live daily with the implications of their decisions, while the care receiver has no overall comprehension of the issues. The fear of this scenario is very real for many caregivers. The following caregiver example captures that description based on the care receiver's perception of a nursing home as where you put someone to die.

I still feel so goddarn guilty about this whole thing, you wouldn't believe it. . . I I always think, God, what does my 
wife think of me? . . . Then maybe she has that moment and she maybe realizes that she is in a nursing home, the she might think, 'What did my husband do to me?' I just can't get over that. (Interview \#8, husband)

Although not a point of lengthy discussion but important by its frequency of occurrence and highlighting by caregivers, is the influence of previous family caregiving-caregiver relationships upon this current caregiver-care receiver relationship. While it was noted that some of the care receivers had been caregivers in their earlier life, the most critical influence came within the great number of adult children who had provided caregiving already to another parent. The ability to provide caregiving at home, and successfully by their description, left them feeling they had failed this care receiver.

It wasn't something I had ever wanted. I had intended to take care of her. My father died at home and that's ideal. He didn't have to go to a hospital or nursing home. . . We managed. (Interview \# 2, daughter)

While the caregivers could share these insights, the topic was too painful to explore in more depth. Thus, it is important to gain insight into, not only the current caregiver-care receiver relationships, but other relationships both the caregiver and care receiver might have experienced in their past. This also suggests, if one is a caregiving type of individual, he or she may get several opportunities in some families.

\section{Extended Family}

Family members are also involved in sorting out their feelings at this time of transition. What the caregiver perceives and how he/she responds is very individualized. The feelings continue to be very 
intense. If the children or stepchildren agree with the placement decision, it becomes a very powerful reinforcer of a "good" decision.

But before I put $X$ (wife), $X$ has a daughter, $X$ 's my second wife. And she has a daughter that lives up in $X$ (city). And before I put $X$. in this home, she had come down and we had together inspected a couple of places and she was all in favor of the one that I had selected and when she comes down, she's very happy with what she sees. (Interview \# 3 , husband)

If, however, there is any conflict surrounding the placement, feelings often run deep and bitter, especially if the family has not shared any caregiving activities and are perceived now to be critiquing or evaluating the caregiving decision.

I thought I was accepted by everybody in this family. For 20 years I thought I was accepted But I found out that day I was simply not. . . . and I was gonna do this and I was gonna sign that and I was so upset, so tired, that I signed. ... But they changed so drastically. I suddenly was their step-mother and I suddenly couldn't be trusted. (Interview \# 1 , wife)

What also happens is, soon after placement, family members often come for a visit after a period of non-involvement and are shocked at the appearance and decline of their resident. They immediately infer that the resident's condition was influenced by the caregiver's lack of attention rather than the result of not only the disease process but their long absence from the resident. This is, unfortunately, true for both spouse and adult children.

... So they just went out to the nursing home. They have never been there before. It was Sunday. They went in. They couldn't find her. They couldn't find anyone to tell them where she was. And when they did locate her, it was just such a shock because she's lost a lot of weight... So, she had lost all this weight, she's tied in a wheelchair. It was a shock to them. (Interview \#4, daughter)

Focus group discussions revealed conflict as well as supportive functions within blended families. It was common to find divorced and 
remarried care receivers and caregivers as well as stepchildren, half-brothers and half-sisters within the wider caregiving unit. Examples of "our family" versus "their family" were often a key issue in both supportive and non-supportive families. The point of reality that this issue touches upon in the caregivers' day-to-day life and decision-making is the challenge of merging several different viewpoints. Open communication and shared perceptions becomes very challenging within these different relationships. Even within a close supportive caregiving system, different family members have different perceptions of a similar event.

I felt like I was committing her to a death camp because -And $X$ (husband), reassured me that it wasn't that at all. She was being placed in a facility where she'd get the kind of skilled care she needed. (Interview \#4, daughter and son-in-law)

However, there are times when siblings and in-laws can be sources of support with difficult decisions, helping to extend caregiving time at home and seeing caregiving stressors with clearer insights.

Mostly the fact that my brother just said he couldn't go on with it any more. He was so good for us; he was the only way we could get away. So he would fill in the duty like weekends and all when we would want to do something. . . Yeah, well he just, I think, was more realistic about it. He hadn't lived with her for 30 years. (Interview \#6, son)

I told him (caregiver's sibling), I says, ' $X$ (caregiver) is at the point now where she can smile, she can laugh, she is relaxed, we have conversations again, we go places and do things.' I says, 'I, for one, am not willing to go back to where we were.' . . It just seems like when her mother went into that care facility, we were given our lives back.

So I told him, 'Gee, $X$ (brother), I would really appreciate it if I take care of mom and dad Sunday if you wouldn't mind coming over Saturday night and doing dinner.' Well since I said that, he never missed dinner Saturday night. He was there every Saturday night with his wife, with his kids, or 
without them or whatever, but he was there. (Interview \# 5, daughter)

Paying for the nursing home costs, although rarely mentioned in the interviews, was identified in the focus groups as a probable source of conflict for families. The financial debate which emerged pitted parental entitlement to care versus taking the parents' savings and providing quality care for them as a responsible way to spend their hard-earned money. Obviously, one plan may leave the kids with some money and the other most likely won't. There was no closure on this debate and again, the outcome is a reminder of the complexity and individuality of the caregiving situation.

Finally, the issue of visiting by grandchildren demonstrated the intergenerational complexities of extended families' involvement in caregiving. This situation emerged as a dilemma for many families. Some saw only the opportunity for the two parties to be together, hoping to build memories for at least the younger generation. Other families saw the potential influence of the nursing home environment with its smells, noises, and above all the behaviors of the other residents as either frightening or inappropriate for the children. One wonders if this is not also reflective of how it seemed for the caregivers themselves, at least in the beginning. The individual most often caught in this situation was the adult child of the protective caregiving spouse. Because they had been sheltered along the way from the decision-making process, they often found this a difficult situation. They are caught in the web of their relationship with both parents, their relationship with their child, and most likely, their relationship with their spouse. 
... the oldest was just 15 , and she really had a hard time with that, and the little one, it affected her some, but not as much as the older one. And I think that's the only time that they've been to see $X$ (care receiver/grandfather). They ask about him, but they don't seem to want to go again. (Interview \#10, wi fe)

And my, it kind of bugs me but everybody's different. My sister-in-law doesn't want them to see my mother the way she is and that really kinds of bugs me. And that's her right, I guess as a parent, but I just don't see how she feels that's gonna hurt them to see their grandma. (Interview $\# 5$, daughter)

We've always done it here and you know, had usually a family dinner of some kind at least once a week and so we just kept right on when he was sick and we've never given it up. ... It's worth it for the children in the family. (Interview \#7, wife)

Most often, if the grandchildren had been involved with the grandparent during the home care, they remained involved. So, while these behaviors reflect the family focus, the stresses and struggles are felt most acutely by the intimately involved caregiving individual.

Beginning with family at a level in terms of the social level,or within their social integration and social environment, and then later moving to the individual level, is much like the caregiving experience itself. In the early AD process, family often overlook symptoms or change their responses and routines to compensate for changes in the $A D$ individual. Obviously, this results in changes within the caregiving environment, the caregiver-care receiver relationship and the family dynamics. Over time as stress and exhaustion increase, the result is an individual battle by the caregiver for survival.

Finally, the caregiver has been shown not only to be influenced by the relationship with the care receiver but also very affected by the extended family unit in which he finds himself a member. However, how 
he responds and reacts to these supports and stresses within this family milieu comes down to an individual level and personal survival.

\section{SURVIVAL}

Caregivers were quick to point out, if the earlier survival tactics were working, they continued with them over the long term. They found success in recognizing that as they continued to do a good job in their caregiving role, this positive feeling contributed to their positive perception of self. By now, they had become more sophisticated in their recognition of and avoidance of stressors.

-. I'd try not to go over there when they were trying to feed her or anything like that or I'd go in the afternoon. (Interview \#9, husband)

And there were just a lot of gurgling and moaning and yelling and it was just really gross. And I thought, my God, how can anybody eat when all you see is this and this is what you're hearing. . . What we do now is we just don't go over there during eating times, you know. We either go before or after because it was... it'd just gross me out. (Interview \#4, daughter)

The key to dealing with the intense roller coaster effects noted above was to be able to develop strategies. An important first step was to tell themselves it was an OK decision, that it was necessary and timely. In the early adjustments to formal care caregiving they often reviewed how severe the symptoms had become, how sudden the decline had occurred, or how bad the caregiving toll had increased. These insights seemed to help the caregivers accept the stress and guilt of placement. They also planned strategies which allowed themselves to combine a role and a responsibility, i.e., strategize around visiting.

Well I only, I would go about three times a week. I didn't go over there every day. Sometimes I'd go four and sometimes I 
would go three and sometimes it would be in the morning or ... I'd go in the afternoon. (Interview \#9, husband)

I have a lot of confidence in them. Now with the swing shift, I'm not so sure about that. I was in there several times in the evenings and I don't think it is quite as efficient as it is on the day shift, but no complaints. . . it isn't that you come every Wednesday at a certain time or every Sunday, but different shifts, different times, and you see a quality of care there consistently around the clock. (Interview \# 8, husband)

If they desired to visit often, they found ways to do this. If visiting was too intense an experience, they looked for signals that it was $O K$ to limit the frequency. The visit was a crucial signal in the caregivers repertoire. For some, it is such a painful a reminder of their loss, they visit only weekly.

... I go out once a week. I can hardly stand that. And so leaving; not getting, not being with her, but then leaving. Just like turning the blade on the lawn, you know. (Interview $\# 3$, husband)

For others, their loneliness and loss of that daily responsibility find them visiting every day. Don't count out visiting's function of monitoring which is accomplished by observing other resident's care, as well as the status of their own. Also, individuals cannot role model the care or demonstrate the commitment if they never visit.

Yeah, I don't feel good if I don't go see him, even if I drop in for a few minutes, I do. . . there isn't any tears or anything when I leave. But yet, I'm not glad to be leaving. I just feel good that I went to see him. (Interview \# 10, wife)

Lastly, it is through those visits over time that the caregiverstaff relationship winds its course.

Some caregivers noted a feeling of personal positiveness through now knowing their resident would be able to receive the necessary professional level of care they were unable to provide. 
- . so basically I thought perhaps that the nursing home would be a better place for her because they have the facilities, they have the personnel and I just thought it would be better. (Interview \#2, husband)

Others allowed themselves to react to the emotions in the way that felt best to them. Two of the male spouse caregivers provide an interesting contrast.

- . many times, I myself catch myself going 'don't cry, don't cry, don't cry.' I say but then they do come anyway. So when I talk to my sons about it, you know, but I don't think it really affects them that much as it does to me. (Interview \#8, husband)

Well, I suppose I just turn it off. Bottle it up is what is amounts to, I suppose. (Interview \#3, husband)

Often, a caregiver realized they would be unable to deal with a return to home caregiving and felt at peace with the decision.

- . And I just, you know, once I got away from that, I just felt there was no way I could get, go back to that. . . And (laugh) I guess I'm selfish but I was so tied in for so long, I just felt like whee (laugh). (Interview \# 7, wife)

Survival after placement emerges as a process. The caregiver must not only deal with the loss of the decision-making responsibility and the physical caregiving role, but now must integrate a stranger into this previously intimate and private relationship. Rather quickly, the physical care and the majority of the decisions get transferred to the formal care staff. However, the integrating of the caregiver into that previous one-on-one relationship is a process that requires time and testing. Often they begin by developing the ability to ask questions or make suggestions without threatening their resident's care by the staff. Caregivers didn't want to cause problems by being perceived as a trouble-maker for their resident. In other words, much energy goes into avoiding alienation of staff by family caregivers. Realizing this was a 
major change in their caregiving role, caregivers often recognize the need to allow some time for adjustments to occur.

After being involved in formal caregiving for awhile, two new survival features appeared in the caregivers' move beyond. First, their ability to turn to other residents for meaning in their caregiving and second, the personal self-growth some caregivers discovered in this transition experience. On occasion caregivers confided that the relationship with their resident became too much for a day or two. Often rather than quit going at all, the caregivers turned to other residents with whom they had developed a relationship for a much needed reciprocity. This scenario was described by an adult son:

- . you know she's totally out of it and then you can go and visit someone else. ... and it's sometimes a relief when I don't have to talk to my mother, you know. (Interview \#6)

Finally, as some of the caregivers described their adjustments to this new caregiving role, they realized it had become a springboard to personal self-growth. They had waged some tremendous personal battles and emerged not only with quality care for their resident, but a high level of self-esteem for themselves. The daughter, who, when she first placed her mother, had to leave part way through the visit to sit in her car and cry before she could return inside, provides a wonderful example. She did this for the first three weeks after placement. Her personal insights to this struggle was described this way:

I had to go back enough times to where I would get used to it or I'm not going back at all because it was just terrible for me. So anyway, we just kept going back and going back and going back until I could go in there and not get emotional. -. So I really feel good about that and I'm glad that I chose to keep going back as much as I possibly could where I 
could feel good about it because it's been very hard for me to do that. (Interview \#4, daughter)

Thus, as explored above, surviving can be viewed as a personal issue. However, it is tied up in family issues and spouse-child issues and spouse-child issues are all part of family. While these were the main relationships of the caregiving world at home, the major shift in the transition to formal care comes with the addition of the relationship with formal care staff.

All of the above leads up to the more individualistic issue of surviving. At some level, surviving sounds individualistic. At another level it is so tied in to all these other factors: the relationship with the care receiver, the relationship with the family, the relationship with formal staff. Thus, the individuals survival is an individual issue but it's bound up in this complex web of relationships that they are trying to guide themselves through during this difficult time in their lives.

\section{INDIVIDUALIZED EXPERIENCE}

A critical underpinning of these findings is that every caregiving unit, caregiving family and their care receiver/resident represent a unique and individual experience. Often they get labeled with a name like $A D$ and that frames a progression of symptoms. Also, once the care receiver is placed in a nursing home, it is assumed a homogenization of resident, spouse or adult children caregivers, and extended family member takes place. However, these findings, while windowing in on the difficult and complex interactions and decisions, also support the 
significant and touching ways these family members worked to manage the caregiving responsibilities they assumed.

The benefit of the qualitative approach allowed a glimpse into the real world of the caregiver and the journey from home to formal care. It is obvious from the findings that one cannot talk about the caregiver or care receiver/resident in isolation from one another. Caregiving is commonly treated as on a continuum or linear trajectory, such as might be implied by the phrase, caregiving career. Within this image, one can envision a stage or phase building on or coming after one another. Gubrium (1991) has offered a look at caregiving based on a broader view. Referred to as the "mosaic of care," it emphasizes the distinct and complex interpersonal experiences of caring.

However, a mosaic is something that is done on a wall or surface, and made out of pieces or things that are glued or fixed to that surface. Thus, although projecting a complicated pattern, the image projected is very static and very fixed. One can't really grasp it up close, but you have to back off to see how all the little pieces fit together into the larger whole. This would fit with looking more introspectively into the complexity of the caregiving experiences, however, the image remains fixed.

Thus, the author suggests the caregiving process of necessity begs for a kaleidoscopic view rather than a microscopic view. This kaleidoscope contains bits of something within, maybe bits of liquid, crystals or metal pieces. As you turn the kaleidoscope, the bits and pieces change and the pattern shifts and it's literally impossible to go back to the previous pattern once you have shifted. This image suggests 
interconnections, multiple patterns, pictures, reflections, motion and change. If one thinks about caregiving as patterns of connections and relationships that either help the caregivers move in the direction they need or create a tension that makes it difficult for them to travel on, there is much analogy to the kaleidoscope. As the events, relationships, Alzheimer's disease symptoms, experiences and the caregiver change within their relationship and interaction with one another, the new caregiving result will not be like it has been before. Thus, like similar behaviors meaning something different and different behaviors having similar meanings, each caregiving situation has unique and individual underpinnings.

It is important to assess the fit between the above findings and a framework for practical implementation in formal care. The following summary provides suggestions for professional staff in how they might make use of the findings in planning their caregiving services.

In summary, it is important to recognize these findings do support the caregiving literature's reference to overall physical and often emotional exhaustion in family cargivers. Although exhaustion was common for these caregivers, upon admission to formal care, sensitivity should be directed to the type of caregiver, spouse or adult child. While the spouses may have experienced turning point events around issues of incontinence or safety with their resident, adult children may have experienced a turning point event around behavior changes in their resident. The educated and insightful formal staff caregiver will not assume that spouse and adult children have only the above issue or that even if they do, that the intensity of the event and the significance of 
the placement decision is similar for each family experiencing this transition. The staff caregiver should ask each family caregiver about their individual experiences and reasons around placement.

In the early staff- family, caregiver interaction it would be helpful to know where the family caregivers are coming from, as well as what they desire in their formal caregiving experiences. Another valuable point of information for better formal care planning is knowing who was involved in making the placement decision. Did the spouse caregiver decide alone? If so, were the children informed and if so, how? If the caregiving adult child included other siblings in the decision-making, were there a broad range of concerns that emerged, directed toward the child caregiver or the formal facility? Might this caregiver need support in the interaction with family members in addition to making the transition to the formal caregiving role?

The key point in the above interactions is the over-time issue. The formal care staff-family caregiver relationship takes time to build. The above dialogue, as proposed, is enmeshed in the relationship that develops. If anything has been learned from these caregivers, it would be that these relationships take time and are a result of their perceptions, strategies, and trust.

The other key issue is the perceptions of the health care system that the family caregivers bring with them. As they clearly labeled these experiences as either good or bad, a clear question would be appropriate. "What has been your past experience with the health care system?" 
Since family caregivers gave a clue that they experience an overtime adjustment process, staff need to revisit the early identified issues for their continued relevance. Also, knowing that spouse often compromise on their initial placement goals while adult children may move their resident could be useful to the staff. The primary point is that family caregivers can and do change their expectations of the facility after placement.

The findings suggest the family caregivers experience some similarity in adjustment after the decision-making and initial placement evaluation. Thus, at this time there seems to be more commonality in the formal care staff-family caregiver relationship. Differences are more attributable to individual uniqueness than type of caregiver. Family caregivers had two key requests, to provide quality of care for their resident and to recognize them as an individual. Embedded in the quality of care issue is a responsibility for both family and staff. For the family member, it was to provide staff clues to the resident as a person and his/her past. For the staff it was to be receptive to the information provided.

It is not uncommon in caregiver literature to find quality of care issues, however, these findings do seem supportive of the "family as forgotten client" agenda. Family caregivers gave many clues to the feelings, approaches and survival tactics they experienced in their desire to remain involved in caregiving. Family caregivers experience a life after placement. While many must initially deal with feelings of guilt, it is a very personal issue in how they do this and how long it takes. Staff could benefit from the two findings dealing with survival 
tactics and caregivers personal development of self-growth after placement. Caregivers gave clues to visiting and interaction with other residents as clues to their survival tactics. Staff might look for patterns or other clues before they assume the family member who visits only once a week is disinterested or wishes to remain uninvolved. If the family caregiver chooses to reflect on their past caregiving struggles and decisions and to explore ideas about their new found time, staff can also be supportive in their process. A critical underpinning remains, while surviving sounds individualistic, at another level it is tied to the caregivers relationship with the resident, extended family and the staff. Therefore, it is incumbent upon staff to remember each caregiving situation is unique. Similar behaviors can have different meanings and different behaviors can have similar meanings.

Recognizing, therefore, each caregiving family as unique and individual begs for those health care professionals and the systems who interact with them to make a comitted effort to individualize their care. Recommendations which suggest direction on some of these issues are found in Chapter VIII, which follows. 


\section{CHAPTER VIII}

\section{CONCLUSIONS AND RECOMMENDATIONS}

This study has traveled into the world of family caregivers as they experience those final decisions that resulted in the transition of their care receiver into formal care. A return to the research proposal and critique of not only the questions, but the findings, introduces this chapter. An evaluation of Bridges' (1980) model applied to the study findings follows. After noting the limitations of the study, emphasis is placed on sharing what has been learned from this effort. Lastly, recommendations are offered toward the areas of policy, practice, family caregivers and future research.

\section{CRITIQUE}

In Chapter I, the big picture was explored and the following questions were posed: What do family caregivers of Alzheimer's patients experience as they shift their caregiving from home to formal care? How does caregiving in formal care differ from caregiving at home? And, how do family caregivers perceive the relationship that occurs between families and formal care staff? The close contact with the data has provided both a sense of what the answers are and a much more datadriven, grounded theory sense of what the questions are. Essentially, the original research questions were appropriate and facilitated the rich findings around the caregiver responses to the change in the 
caregiving site. Being aware of these findings, it is evident additional research designed to follow family caregivers during those last weeks of caregiving at home, through the turning points decisions, and into the first six months of formal care caregiving, would help to confirm and extend the findings. Exhaustion was an issue that proved to be of extreme influence, but was under-represented in the original questions. While there was an attempt to explore the difference in issues between spouse and adult children, it resulted in a "tip of the iceberg" outcome. Additional research questions should be directed toward increased understanding of the similarities and differences these family caregivers experience. While this research noted the uniqueness of sons, daughters, husbands and wives, additional research in this area would also be useful. Lastly, the focus on the concept of transition provided the hoped-for depth to capture the events surrounding the caregivers move from home to formal care.

Family caregivers providing caregiving at home are involved in constant and daily decisions. Into these experiences they bring past relationships and history, stereotypes from society, values from their family, family caregiving traditions, and previous interactions with the health care system and other informal sources of support. Arriving at the common state of physical and often emotional exhaustion, caregivers described a turning point event that signaled this was the time for the big decision that would put closure on their ability to provide caregiving at home. The major theme that has been used to organize and examine this material has been the whole notion of transition. 
As mentioned in Chapter I and incorporated in Chapters IV, V, and VI, many writers have worked with different applications of the transition concept. The specific framework that was applied here was Bridges (1980). In applying this model, one of the goals has been to assess how apt a conceptual framework it would prove to be. It was already recognized as an adequate organizing framework, but would it help further the understanding of the transition to formal care?. Often within transition, described as change, the role disappears and is replaced by some different role, or there may be a presence of a role versus the absence of a role. For example, in divorce, the role disappears. In caregiving, the disappearance would be analogous to the myth of abandonment. We know this is not true, in the transition to formal care, the role continues but is very highly modified.

\section{Evaluation of Bridges' Model}

In Bridges' (1980) model, there were the phases of ending, neutral zone and the new beginning. As applied to the findings of this study, the results are shown in Figure 3. In a general overview, the caregivers do reach an end, coupled with exhaustion, they do reach a turning point that results in the decision to make the move to formal care. In the next phase, the major point stressed by the caregivers, was, with this decision, there was action which resulted in placement. After a period of consequences and adjustment, the caregivers made a move beyond. As presented in Chapter VII, the themes of family and survival were influential in the total transition process. A closer look at Bridges' (1980) model in comparison to these findings is appropriate and 
necessary for a proper analysis. In the following section, each phase will be explored individually.

Ending. As noted in the findings, the changes in the caregiving role at home can come about slowly and gradualiy or abruptly. The concept of ending would still capture this event.

Bridges (1980) states, "Endings often seem devoid of meaning -much less positive meaning" (p. 91). The latter part of his statement certainly is true for the family caregivers; however, the earlier part is very much under-represented in most caregivers experiences. This ending had tremendous meaning for them. It is worth reflecting on the influence of the $A D$ process upon these feelings. The caregivers had already voiced a sense of their loss of a reciprocal relationship with the care receiver. However, when they reflected upon their great loss with the decision for formal care, they most often felt failure, guilt or both. They often summarized this as the loss of the relationship but not the responsibility. Bridges (1980) also related the difficulty with endings because ". . the impact of the transition upon us does not necessarily bear any relationship to the apparent importance of the event that triggered it off" (p. 19). With $A D$ it is hard to know where the placement decision ranks in this overall caregiving process. With some caregivers, the confirmation of the disease process may rank as the crucial point and the placement decision would not give the same signals as noted above.

Neutral Zone. The caregivers did provide testimony to the disruption and confusion that comes with this phase. Perhaps the best example is captured in the paradox noted earlier: Holding on While Letting Go. 
As noted by Bridges (1980), the neutral zone is characterized by inactivity and routines and/or rituals; this is also ". . only a temporary state of loss to be endured" (p. 112). Indeed, this played out as some of the early consequences adopted by the caregivers were 


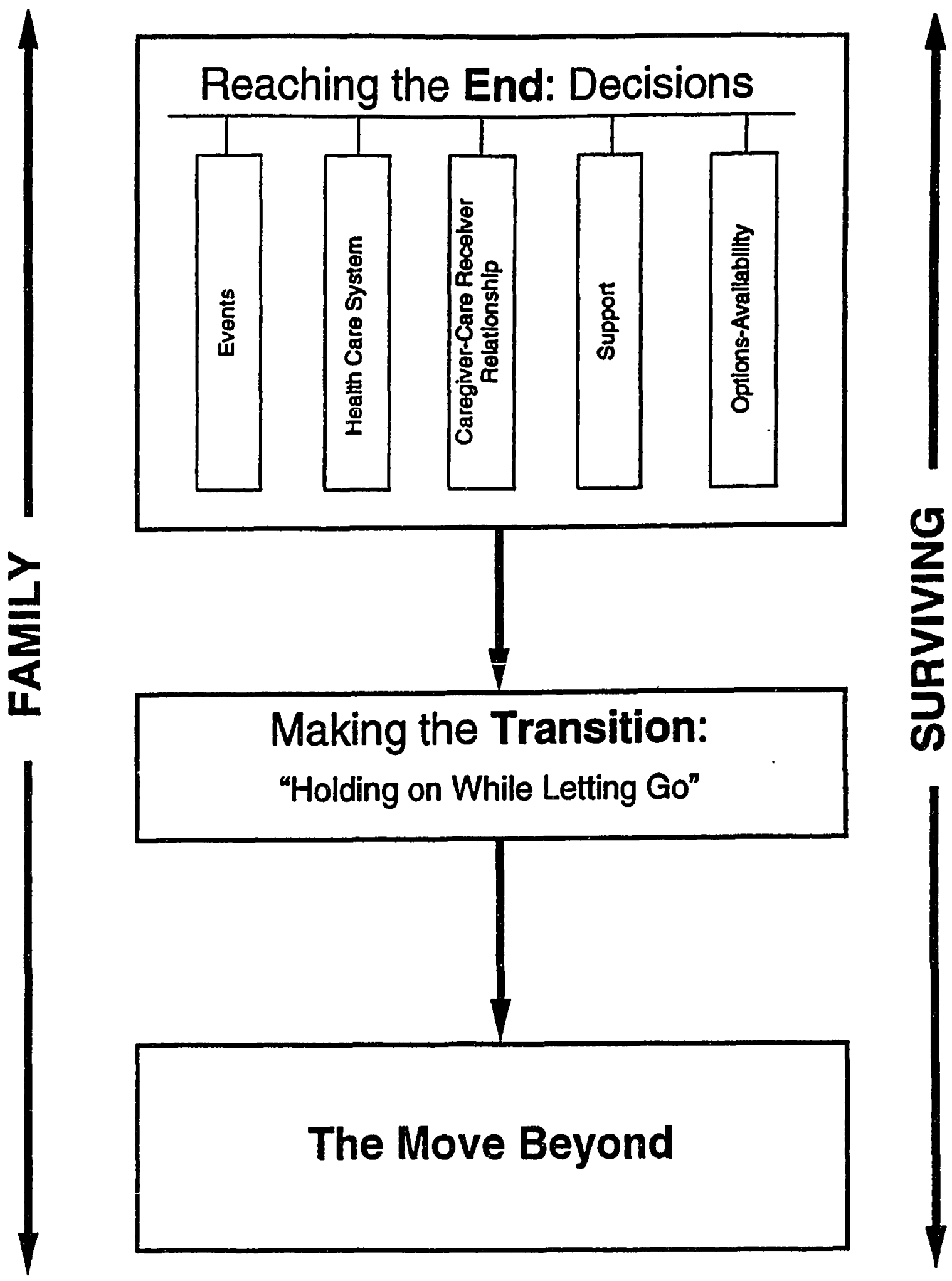

Figure 3. Bridges' Model of Transitions Applied to Caregiving. 
visiting and monitoring. However, these early routines and rituais lead rather quickly into the longer-term strategies of developing the relationship with the formal care staff.

A good analogy for this phase of the transition is like trying to distinguish between sunrise and sunset. We know when day is and when night is. We also know there is a sunset that occurs between day and night, but it is like the neutral zone, that period when it makes almost no sense to describe it as a day ending or as night beginning. It is a period that marks the occurrence of the transition and thus, belongs neither to what went before or what comes after.

New Beginning. In this phase there were to be faint, subtle inner signals that begin the process of change. In the early consequences noted above, there is testimony to the caregivers making a move to remain involved although the site has changed. Another strong clue is their common, unsolicited evaluation of the formal care facility, "its not perfect but it's OK." As also noted by several caregivers and reflected an earlier quote from an adult son, "In my guilt, I feel relief" (Interview \#6), the earlier evaluation is probably more reflective of the decision and the actual change in the caregiving site than that of the formal care facility itself. The model has also related that in this phase, the individual caregivers use any supports or indulgences that make things easier. Certainly the ongoing theme of surviving speaks very clearly to this caregiver behavior. It is also important to note that while often there has been a focus on quality care for their resident, the findings also pointed to caregivers' other 
major focus, the development of a positive relationship for themselves with staff.

In summary, it appears that Bridges' (1980) model is a conceptually rich framework that helps us understand the family caregivers' transition to formal care. It was as if there were two established phases of caregiving, each containing its own sets of tasks and dilemmas, with a period of flux in between. Bridges (1980), in essence, is right about this time; when someone must make such a large change within an on-going career or activity there is this period of indecision, confusion, and adaptation where the individual is simultaneously dealing with endings and beginnings.

Although not a major focus of this research, the caregiver taskapproach by Litwak (1981, 1985), and Litwak et al., 1990) was a significant part of the earlier caregiving discussion and deserves a follow-up exploration. In a major policy-oriented work, Litwak (1985) and Litwak et al. (1990) analyzed the basic differences between primary groups and formal organizations. Because of their basic structures, primary groups, such as the family, can best manage unpredictable events and nonuniform tasks with many contingencies. By contrast, formal organizations can best manage the uniform services referred to as technical tasks or tasks requiring technical knowledge and expertise. The key variable is the amount of technical knowledge required. If technical expertise is not necessary, the lower cost, increased time available, greater flexibility and higher level of internalized motivation of the individuals make the family particularly appropriate for caregiving tasks. If however, technical expertise is required, the 
structure of the formal organization is cheaper, faster, more flexible and able to provide more motivated individuals. (Litwak, et al., 1990). In other words, the structure of the group should match the structure of the task. Thus Litwak's (1981) "theory of shared functions" proposed staff would be primarily responsible for the technical tasks and family would handle non-technical tasks.

If the above theory keeps the technical tasks with the formal organization and the non-technical with the family, it suggests that nursing homes and caregiving families are currently at a state of imbalance. While the goals of both groups are complementary, the basic problem lies in the fact that their structures are in conflict. In formal care, routinization is a major emphasis which sounds more like a machine or an assembly line. When family caregivers discuss caregiving, the emphasis is on process with a focus on caring, sensitivity, and respect for the individual.

In assessing the fit between Litwak's (1981) theory and the actual formal care setting, caregivers revealed the above is not how they perceive it, not how they want it and not how it worked for them. The theory is too abstract and distanced from the reality that the caregivers experienced. Litwak (1981) may be a good point of departure for conceptualizing some of the issues but not as a basis for policy and practice. It is necessary to get much closer to the experience one is dealing with to see how the issues, such as roles, staff responsibilities, family expectations, and family-staff relationship, play out. Thus, beyond issue identification, this theory should not be assumed to provide a prescription for policy. 
Litwak's (1985) point of view is to emphasize a strict taskoriented division of labor. Families are given the task to provide emotional care and love and this task is to be provided in an unscheduled, non-technical way. The caregiving families in this study desired what might be described as a more integrated model. They don't desire to broaden their role in providing actual "hands-on care" but they also don't want the staff involved in a "hands-off" care. The family caregivers role prior to the transition to formal care was more than the implied non-technical and emotional tasks but they now desire to relinquish that role to the staff. Caregivers emphasized bringing the staff into the non-technical caring side.

An interesting contrast occurs when one views staff as handing residents in a routine way or more as an object, like with feeding, bathing and dressing (personal cormunication, J. Colling, June 1992). The family, however, views the need for residents to be approached with regard and respect. For example, it is not necessarily even the words that staff might use but a tone of the voice. So, in one approach the care is routine and object-focused while in the other it is sensitive and individualized. Thus, this is a situation where optimal care would result from a model that did some careful blending rather than relying on a strict division of labor. A narrow, compartmentalized division of labor is not the appropriate way to deliver care in a nursing home.

Thus, Litwak (1981) could be viewed as a good theory to orient future efforts but it is not a sound basis for policy or practice in and of itself. Using the orienting concepts out in the field, these family members revealed that this is a model that would, in essence violate the 
central tenets of Litwak's (1981) recommendations for how to organize this kind of care. The quality of care desired by caregivers could result from placing as much importance on the way the task is performed as on completion of the task, at the organizational level, family value staff caregiving delivered in a sensitive and respectful way. Thus, the highest quality of care requires contributions from both of these two sources of caregiving.

\section{Limitations}

It is important in this final reflection to make note of the limitations of the study. Indeed, there are only 10 one-on-one interviews. Also, all of these caregivers are Caucasian and live in the metropolitan area. However, since this is not a representative sample and is a qualitative design, there is not an expectation that the explicit details of the results will generalize to any particular population. Instead, the more important goal from qualitative work, such as this, is to suggest the kinds of theoretical conclusions and potentially testable hypotheses that these results point to, which can then be evaluated in more generalizable frameworks.

\section{What was Learned}

Each family is individual; however, if the range of themes that were identified in this study are applied, it will provide valuable clues about each family in order to see where they are in their lives as caregivers. While we have seen these individuals in all their richness, there is no need to claim that every one is so completely unique they must be studied as an $\mathrm{N}$ of one. Instead, broader themes and principles 
were involved, and if the researcher or clinician starts by looking at those factors, they will project a good idea of where the individual finds himself.

Family turned out to be a very key issue at this point. It was one of those things that seemed like a minor issue in the beginning and turned out to be what everything was tied to. Why did the issue of family end up getting so much more attention? Several findings seem to touch on the answer. First, with AD there is a slow, gradual development of the caregiver responsibility. The caregiver and care receiver bring a shared history and a shared relationship into this experience. Within this "cast of characters" there is an intimate and personal nature imbedded in the relationships between spouses, parent-child, siblings and extended family. Thus, caregivers can often do the things they do because of the help from the family. At the same time, they often feel pressured to continue because of their perceptions of what the family will think.

Thus, when family caregivers approach decision making, particularly the decisions that end home-based caregiving leading to placement, it is helpful to consider what is involved. These decisions take place in a personal, social, and biographical context as captured in the individual themes of family and surviving. They must wrestle with the caregiving issues per se, the caregiver needs, their ability to continue to caregive and when that final move to formal care must be executed. The magnitude of the range of these bigger issues is always going to be involved in the specific decisions. 
Another point learned from this study centered on the influence of crisis within the decision making process. While the literature often flags the importance of crises, the findings of this study, while not negotiating this, also call attention to the crucial nature of events. The kinds of events turn out to be more like turning points rather than crises. An important difference is that a turning point changes one's understanding of the situation rather than confronts one with a radical shift in caregiving tasks.

The findings called attention to an issue that was not unimportant but relatively straightforward, the Health Care System. By the time the family caregivers were beginning to seriously consider the placement decision, they not only had several experiences but a definite perception of this system as either positive or negative. The perceptions of these past interactions were not only powerful in the placement decision but they continued to significantly influence the early relationships with the formal care staff and facility.

If one was looking for support as a major issue, the findings did not confirm this. It turns out support was a limited notion and may not have that much to do with what is going on at this point in the caregiver's life. Although there was a tremendous amount of attention to family, not all of that family attention was supportive by any means. The question of what is going on in close relationships, not just in exchange of receiving support to meet stress, but what is happening in terms of who people are most intimately tied to and who their actions in the world most depend on and most affect was observed. Although obvious in the caregivers' discussions, this is different from support. So, 
from the outside, if we look at the literature, support seems to be the issue, but when we listen to the caregivers and hear about their world, it isn't support; rather, it is those crucial, intimate ties that are very much at this point in their lives, in the family.

An exploration of family caregiving would not be complete without reference here to the worlds of the spouse and adult child. For both, caregiving is physically, and often emotionally, exhausting. Spouses tend to hang on until the last possible moment. This is embedded in their relationship with the care receiver. While the loss is overwhelming, it reflects the earlier commitment this generation made to each other and have carried out over a lifetime. Adult children, while also feeling a sense of loss, do expect to lose a parent. For them, having the care and responsibility for a parent is only one of many responsibilities they face daily. Often it is a safety issue or a need for an increased level of care that makes a change necessary. In making this painful decision, there is a role reversal of the dependent-independent role within the parent-child relationship.

Once in formal care, there was overall little difference in the roles assumed by spouse and adult children. Both identify quality of care for their resident and the establishment of a personal relationship with them by staff as their priority issues. Again, tapping into that shared history, their own caregiving experiences and expertise, and the strong influence of family, they chose to monitor and role model care in an attempt to help the staff get to know their resident as a person. They clearly realize the family caregiving role in formal care is dependent upon their development of a relationship with staff. The aide 
is the staff person most involved in this relationship. Aides are consistently identified by caregivers as most frequently involved in the intimate care of their resident and with whom the family can identify.

One caveat was uncovered here which also supports the application of Bridges' (1980) model. Family spend much more time on the turning point events, making that end decision phase and developing the relationship with formal care staff or the new beginning phase than they do in the neutral zone phase of the actual placement. Indeed, this placement phase is analogous to the idea of a brief "time out."

\section{RECOMMENDATIONS}

The lessons learned from this study have relevance for several different domains: at the level of theory development; the level of institutional policy; the level of clinical practice in formal care; the level of family caregiving behaviors; and the level of future research. Based upon the findings of this study, the following recommendations are offered within each of these domains.

\section{Theory Development}

1. Continue to consider different types of caregiver needs rather than a generic approach to caregiving;

2. consider further exploration of the concept of turning point events in contrast to crisis;

3. increase the research focus on the past caregiver-care receiver relationship's effect upon the current caregiving situation; and 
4. seek to integrate knowledge on the influences of variables of culture, ethnicity, gender, and family structure and lifestyle into future caregiving practices.

Certainly current literature and recent research often speak of the family caregiver as if it is a single entity. However, the findings of this study point to the importance of carefully recognizing the type of caregiver, is a spouse or adult child. These caregivers shared their different journeys to the placement decision and also how unique the early adjustment to formal care could be. There were also strong clues to possible gender differences, within the spouse group especially.

The discovery of the concept of turning point events in contrast to a crisis looms as a high need for further research. Indeed, much remains to be explored if indeed the majority of family caregivers are not experiencing an actual care receiver or caregiver crisis but instead are experiencing similar events around which the placement decision is made. Increased knowledge will not only help us better define and understand this concept it can then lead to increased individualized support and policy decisions for family caregivers.

The importance of better understanding the influence of the past care receiver-caregiver relationship on the current caregiving situation deserves increased attention. The analysis powerfully demonstrated that similar behaviors can have different meanings and different behaviors can have similar meanings. The current resident-caregiver interaction cannot be assumed to provide a clue to the past relationship.

Finally, it is imperative that variables of culture, ethnicity, family structure and lifestyle be incorporated into future family 
research. Tomorrow's family caregivers will often be single parents, married two or three times with children and step-children, multiracial, and homosexual. Increased knowledge will help us be more responsive to these families' needs. Plus, as we gain more knowledge in this area, we can begin to ask better questions.

\section{Institutional Policy}

1. Establish guidelines to enhance ways for families to increase their involvement in formal caregiving;

2. support policy development that rewards staff and facilities who contribute to a staff-family caregiving team; and

3. recommend policy that encourages family and staff recognition of the contribution that each other makes to the residents care.

At this time in formal care facilities, it seems, as family caregivers perceive it anyway, there are two parallel tracks for familyresident interaction and staff-resident interaction. It isn't that families cannot become involved, however, they perceive they must often take the initiative to make this happen. Another point family caregivers noted was the institutions lack of recognition for aides in general and exceptional aides in specific.

It must be remembered that the above recommendations result from the perceptions of family caregivers. Research to explore the perceptions of staff regarding family caregivers who remain involved in their resident's care should be undertaken prior to the actual development and implementation of institutional policy. 


\section{Clinical Practice and Formal Care}

1. Encourage the formal care staff to look for the level of exhaustion each new Alzheimer resident's caregiver brings with admission;

2. on admission, encourage staff to evaluate the caregiver's past experiences with the health care system;

3. encourage staff to recognize short-term as well as long-term family adjustments to formal care caregiving;

4. encourage staff to recognize their role and responsibility in the development of the caregiver-staff relationship; and

5. remind staff that family caregivers are moving from the role of sole or primary care provided to working as a team member.

It was clear, family caregivers bring not only their family history but their caregiver history with them into formal care. Since exhaustion is common to all caregivers, upon admission, a staff question sensitive to this issue would seem to be 1) insightful into past caregiving history as well as 2) supportive of their past individual role as a caregiver. Staff could use information shared at this time to further explore the family member's past experiences with the health care delivery system. Findings from this study strongly point to how important and useful this information can be for formal care staff.

Staff are aware that family caregivers as well as residents experience a change with placement. However, they may not realize how imbedded it is in making the roie change from primary care provider to working as a team member. Recognizing this knowledge and realizing they have a professional responsibility to the family, they would take the 
initiative to help family members make this transition to formal caregiving. These family caregivers described early as well as overtime adjustments and staff would be advised to share this information with families early on in the transition interactions with families.

\section{Family Caregivers' Behãviors}

1. Take responsibility to contribute to positive staff-family interaction;

2. continue to monitor to keep good homes good nursing and influence a positive level of care for their resident;

3. recognize there is a chance for a change in their personal life after placement of their resident, i.e., a move beyond; and

4. encourage individuals to recognize their own unique survival techniques and continue what works for them.

As noted earlier, families often found themselves taking the lead in initiating interactions which they felt contributed to positive staff-family relationships. These caregivers also support earlier research findings that their monitoring helps positively influence the quality of care their family member receives. They should be encouraged to monitor to keep good homes good.

One might question how families might access this information. Physician and nurse practitioner's offices could benefit by having this information to share with family caregivers as they are counseled regarding the transition to formal care. Support groups would also be an important place to begin. Caregivers should be strongly encouraged to first recognize they will experience changes and then second, to recognize what works for them as they maintain their desired level of 
involvement in their residents care. Through group discussion, caregivers would be exposed to a variety of different techniques and strategies.

\section{Future Research}

1. Design research that will follow the caregiver from home through the actual events, into placement and beyond, to capture the actual transition event and not have to rely on caregiver recall;

2. continue to explore the transition event for the richness and diversity of this experience for caregiving families and their resident;

3. capture the transition experience from the view of the extended family; and

4. repeat this study using a different cohort or generation of family with the focus on blended families and different family lifestyle variations.

It is obvious the findings in this research were based on caregiver recal1. A study which followed caregivers from home through the placement decision and transition process could extend these findings and help to increase the knowledge base around families involvement in formal caregiving. Since the findings support the importance of the transition concept and also families' significant ability to influence its outcome, it is important that future research include the extended family in the study of transition to formal caregiving.

Summary. The findings from this research have been well worth the efforts. As noted above, the experiences of spouse and adult child caregivers as they made the transition to formal care caregiving were explored in depth. The caregivers perceptions of the differences 
between caregiving at home and in formal care identified how hard it was to "hold on while letting go." Finally, an exploration of the major issue in formal care caregiving, that of adding the now-necessary relationship with staff, was initiated. Although a beginning, this area begs for further study. Thus, having met the goals outlined in Chapter I and II, these findings contribute to the knowledge base about the experiences of spouse and adult children caring for their Alzheimer's family member as they make the transition from caregiving at home to formal care. 


\section{REFERENCES}

Ahmed, B., \& Smith, S. (1992). How changes in components of growth affect the population aging of states. Journal of Gerontology, 47, S27-37.

Archbold, P., Stewart, B., Greenlick, M. \& Horvath, T. (1990). Mutuality and preparedness as predictors of caregiver role strain. Research in Nursing and Health, 13, 375-384.

Archbold, P. (1982a). All-consuming activity: The family as caregiver. Generations, Winter, 12-14.

Archbold, P. (1982b). An analysis of parentcaring by women. Home Health Services Quarterly, 30, 5-25.

Albert, S. (1991). Cognition of caregiving tasks: Multidimensional scaling of the caregiver task domain. The Gerontologist, 31 , 726-734.

Barusch, A. (1988). Problems and coping strategies of elderly spouse caregivers. The Gerontologist, 28, 677-685.

Bengtson, V. (1978). You and Your Aging Parents: Research Perspec tives on Intergenerational Interaction. In P.K. Regan (Ed.), You and Your Aging Parent. Los Angeles, CA: University of Southern California Press.

Bengtson, V. (1989). The problem of generations: Age group contacts, continuities, and social change. In V.L. Bengtson \& K.W. Schaie (Eds.), The Course of Later Life: Research and Reflections. New York: Springer.

Blieszner, R., \& Shifflett, P. (1990). The effects of Alzheimer's Disease on relationships between patients and caregivers. Family Relations, $\underline{39}, 57-62$.

Bowers, B. (1987). Intergenerational caregiving: Adult caregivers and their aging parents. Advances in Nursing Science, $\underline{9}, 20-31$.

Bowers, B. (1988). Family perceptions of care in a nursing home. The Gerontologist, 28, 361-368.

Bridges, W. (1980). Transitions: Making sense of life's change. Menlo Park, CA: Addison-Wesley Publishing Company. 
Brody, E. (1981). Women in the middle and family help to older people. The Gerontologist, 21. 471-480.

Brody, E. (1985). arent care as a normative family stress. The Gerontoloc : : $25,19-29$.

Brower, H. (1981). Social organization and nurses attitude toward older persons. Journal of Gerontology Nursing. Z, 293-298.

Brubaker, E. (1986). Caring for a dependent spouse. American Behavioral Scientist, $\underline{29}$, 485-496.

Cantor, M. (i980). The informal support system, its relevance in the lives of the elderly. In E. Borgotta and N. McCluskey (Eds.), Aging and Society, 111-146. Beverly Hills: Sage.

Cantor, î. (1983). Strain among caregivers: A study of experience in the United States. The Gerontologist, 23, 597-604.

Cath, S. (1972). The geriatric patient and his family: The institutionalization of a parent. Journal of Geriatric Psychiatry, 5, 25-46.

Chenoweth, B., \& Spencer. B. (1986). Dementia: The experience of fami ly caregivers. The Gerontologist, 26, 269-272.

Chick, N., \& Meleis, A. (1986). Transitions: A nursing concern. In P. Chinn (Ed.), Nursing research methodology. Rockvilie, MD: Aspen Publishers, Inc.

Colerick, E., \& George, L. (1986). Predictors of institutionalization among caregivers of patients with Alzheimer's disease. Journal of American Geriatrics Society, 34, 493-498.

Danis, B. (1978). Stress in individuals caring for ill elderly relatives. Paper presented at the meeting of the Gerontological Society, Dallas. (ERIC Document No. ED 170 668).

Deimling, G., \& Bass, D. (1986). Symptoms of mental impairment among elderly adults and their effects on family caregivers. Journal of Gerontology, 41, 778-784.

Deimling, G., \& Poulshock, S. (1985). The transition from family in-home care to institutional care. Research on Aging, 1, 563-575.

Dieckmann, L., Zarit, S., Zarit, J., \& Gatz, M. (1988). The Alzheimer's disease knowledge test. The Gerontologist, 28, 402407. 
Dobrof, R. (1981). Guide to practice. In R. Dobrof ? E. Litwak (Eds.), Maintenance of family ties of long-term care patients: Theory and quide to practice. Departinent of Health and Human Services Publication No. (ADM) 81-400. Washington, D. C.: United States Printing Office.

Emerson, R. W. (1965). The journals and miscellaneous notebooks of Raiph Waldo Emerson. Vol. 5. Cambridge, Mass.: Harvard University Press.

Fauerbach, M. (1984). Nursing and Family Perceptions of the Family's Care Task Responsibility in the Nursing Home. Unpublished Masters Thesis, University of Wisconsin, Madison, WI.

Feinstein, A., Gornick, M., \& Greenberg, J. (1984). The need for new approaches in long-term care. Presented at Conference on LongTerm Care Financing and Delivery Systems: Exploring Some Alternatives. Washington, D. C.: Health Care Financing Administration.

Fitting, M., Rabins, P., Lucas, M., \& Eastham, J. (1986). Caregivers for dementia patients: A comparison of husbands and wives. The Gerontologist, 26, 248-252.

Fowler, M. (1988). Ethical issues in nursing research: Issues in qual itative research. Western Journal of Nursing Research, 10, $110-111$.

George, L., \& Gwyther, L. (1986). Caregiver well-being: A multidimensional examination of family caregivers of demented adults. The Gerontologist, 26, 253-259.

George, L. K. (1984). The burden of caring. Duke University Center Reports on Advances in Research, $8,1-6$.

Glaser, B., Strauss, A. (1967). The discovery of grounded theory. New York: Aldine Publishing Company.

Golan, N. (1981). Passing through transitions. New York: MacMillan Publishing.

Greene, V., \& Monahan, D. (1987). The effect of a professionally guided caregiver support and education group on institutionalization of care receivers. The Gerontologist, 27 , 716-721.

Greenfield, W. (1984). Disruption and reintegration: Dealing with familial response to nursing home placement. Journal of Gerontological Social Work, 8, 15-21.

Gubrium, J. (1991). Mosaic of care: Frail elderly and their families in the real world. New York: Springer. 
Gwyther, L., \& George, L. (1986). Symposium: Caregivers for dementia patients: Complex determinants of well-being and burden. The Gerontologist, 26, 245-247.

Harel, Z. (1981). Quality of care, congruence, and well-being among institutional aged. The Gerontologist, 21, 523-531.

Hirst, S., \& Metcalf, B. (1986). Learning needs of caregivers. Journal of Gerontological Nursing, 12, 24-28.

Horowitz, A. (1978, November). Families who are: A study of natural support systems of the elderly. Paper presented at the meeting of the Gerontological Society, Dallas.

Horowitz, A. (1985a). Family caregiving to the frail elderly. In C. Eisdorfer (Ed.), Annual review of gerontology and geriatrics (Vol. 5). New York: Springer.

Horowitz, A. (1985b). Sons and Daughters as caregivers to older parents: Differences in role performance and consequences. The Gerontologist, 25, 612-617.

Johnson, C. \& Catalano, D. (1983). A longitudinal study of family support to impaired elderly. The Gerontologist, 23, 612-618.

Krueger, R. (1988). Focus groups: A practical quide for applied research. Newbury Park, CA: Sage.

Lerner, M., Somers, D., Reid, D., Chiriboga, D., \& Tierney, M. (1991). Adult children as caregivers: Egocentric biases in judgments of sibling contributions. The Gerontologist, $\underline{31}$, 746-754.

Leininger, M. (1985). Nature, rationale, and importance of qualitative research methods in nursing. In $M$. Leininger (Ed.), Qualitative Research Methods in Nursing. New York: Grune \& Stratton, Inc.

Levinson, D. (1978). The seasons of a man's life. New York: A. A. Knopff.

Litwak, E. (1981). Theoretical bases for practice. In R. Dobrof \& E. Litwak, E. (Eds.), Maintenance of family ties of longterm care patients: Theory and quide to practice. Department of Health and Human Services publication No. (Adm) 81-400. Washington, D. C.: United States Printing Office.

Litwak, E. (1985). Helping the elderly: The complementary roles of informal networks and formal systems. New York: Guilford Pressi 
Litwak, E., Messeri, P. \& Silverstein, M. (1990). The role of formal and informal groups in providing help to older people. In D. Unger \& M. Sussman (Eds.), Families in Community Interdisciplinary

Perspectives. New York: Haworth Press, Inc.

Lyman, K. (1989). Bringing the social back in: A critique of the biomedicalization of dementia. The Gerontologist, 29, 597-605.

Mace, N., \& Rabins, P. (1981). The 36-hour day. Baltimore, MD: John Hopkins University Press.

Maxwell, E., \& Maxwe11, R. (1986). Search and research in ethnology: Continuous comparative analysis. Behavioral Science Research.

May, K. (1989). Interview techniques in qualitative research: Concerns and challenges. In Morse, J. (Ed.), Qualitative nursing research: A contemporary dialogue. Rockvilie, MD: Aspen Publishers, Inc.

Mayeroff, M. (1971). On caring. New York: Harper \& Row.

McCracken, G. (1988). The long interview. (Sage University Paper Series on Qualitative Research Methods, Vol. 13). Beverly Hills, CA: Sage.

McGoldrick, M., \& Carter, E. (1982). The family life cycle. In F. Waish (Ed.), Normal family process. New York: Guilford Press.

Miller, S. (1986). Relationships in long-term care facilities. Generations, Summer, 65-68.

Montgomery, R. (1982). Impact of institutional care policies on family integration. The Gerontologist, 22, 54-58.

Morgan, D., \& Spanish, M. (1984). Focus groups: A new tool for qualitative research. Qualitative Sociology, $7,253-270$.

Morgan, D. (1988). Focus groups as qualitative research. Sage University Paper Series on Qualitative Research Methods (Vol. 16). Beverly Hills: Sage.

Morgan, D. (1989). Caregivers for elderly Alzheimer's victims: A comparison of caregiving in the home and in institutions. A final report to the Andrus Foundation, AARP. Portland, OR: Institute on Aging, Portland State University.

National Insitute of Health (NIH). (1981). NIH studies causes of Alzheimer's disease. Special report on aging. Washington, D. C.: NIH Publication No. 80-2135, pp 16-18. 
Neugarten, B. (1979). Time, age and the life cycle. American Journal of Psychiatry, 136, 887-893.

Ory, M., Williams, T., Emr, M., Lebowitz, B., Rabins, P., Salloway, J., Sluss-Radbaugh, T., Wolff, E., \& Zarit, S. (1985). Families, informal supports and Alzheimer's disease: Current research and future agendas. Research on Aging, I, 623-644.

Parkes, C. (1971). Psycho-social transactions: A field for study. Social Science \& Medicine, $5,101-115$.

Pearlin, L.I., Mullan, J.T., Semple, S.J., \& Skaff, M.M. (1990). Caregiving and the stress process: An overview of concepts and their measures. The Gerontologist, 30, 583-594.

Poulshock, S., \& Deimling, G. (1984). Families caring for elders in residence: Issues in the measurement of burden. Journal of Gerontology, 39, 230-239.

Pratt, C., Schmall, V., \& Wright, S. (1987a). Ethical concerns of family caregivers to dementia patients. The Gerontologist, 27 , 632-638.

Pratt, C., Schma11, V., Wright, S., \& Hare, J. (1987b). The forgotten client: Family caregivers to institutionalized dementia patients. In T. Brubaker (Ed.), Aging, health and family: Long term care. Beverly Hills: Sage Publications.

Quayhagen, M., \& Quayhagen, M. (1988). Alzheimer's stress: Coping with the caregiving role. The Gerontologist, 28, 391-396.

Rabins, P., Mace, N. \& Lucas, M. (1982). The impact of dementia on the family. Journal of the American Medical Associaiton, 248, 333-335.

Robinson, B. (1983). Validation of a caregiver strain index. Journal of Gerontology, 38, 344-348.

Robinson, B., \& Thurnher, M. (1979). Taking care of aged parents. The Gerontologist, $\underline{19}, 586-593$.

Rubin, A., \& Shuttlesworth, G. (1983). Engaging families as support resources in nursing home care: Ambiguity in the subdivision of tasks. The Gerontologist, 23 , 632-636.

Schwartz, A. \& Vogel, M. (1990). Nursing home staff and residents' families role expectations. The Gerontologist, $\underline{30}, 49-53$.

Seidel, J. (1988). The Ethnograph version 3.0 [computer program]. Littleton, CO: Qualis Research Associates. 
Shanas, E. (1979a). Social myth as hypothesis: The care of the family relations of old people. The Gerontologist, 19 , 3-9.

Shanas, E. (1979b). The family as a social support system in old age. The Gerontologist, 19, 169-174.

Shanas, E. (1980). Older people and their families: The new pioneers. Journal of Marriage and the Family, Feb, 15.

Shuttlesworth, G., Rubin, A., \& Duffy, M. (1982). Families versus institutions: Incongruent role expectations in the nursing home. The Gerontologist, 22, 200-208.

Silverman, P. (1978). Mutual help groups: A quide for mental health workers. Rockville, MD: National Institute of Mental Health.

Silverman, P. (1982). Transitions and models of intervention. Annais, AAPSS, 464, 174-187.

Smith, K., \& Bengtson, V. (1979). Positive consequences of institutionalization: Solidarity between elderly parents and their middle-aged children. The Gerontologist, 19, 438-447.

Springer, D., \& Brubaker, T. (1984). Family caregivers and dependent elderly. Beverly Hills, CA: Sage.

Stephens, M., Kinney, J., \& Ogrocki, M. (1991). Stressors and well-being among caregivers to older aduits with dementia: The in-home versus nursing home experience. The Gerontologist, 31 , 217-223.

Stern, P. (1985). Using grounded theory method in nursing research. In M. Leininger (Ed.), Qualitative Research Methods in Nursing. New York: Grune \& Stratton, Inc.

Stoller, E., \& Earl, L. (1983). Help with activities of everyday life: Sources of support for the noninstitutionalized elderly. The Gerontologist, 23, 64-70.

Stone, R., Cafferata, G., \& Sangl, J. (1987). Caregivers of the frail elderly: A national profile. The Gerontologist, 27, 616626.

Strauss, A., \& Corbin, J. (1990). Basics of Qualitative Research. Newbury Park, CA: Sage.

U.S. Bureau of the Census (1988). Projections of the population of the United States by age, sex, and race: 1988 to 2080. Current Population Reports, Series P-25, No. 1018. Washington DC: U.S. Government Printing Office. 
Tobin, S., \& Kulys, R. (1981). The family in the institutionalization of the elderly. Journal of Social Issues, 37, 145-157.

Treas, J. (1977). Family support systems for the aged: Some social and demographic considerations. The Gerontologist, 17, 486491.

Trol1, L. (1971). The family of later life: A decade review. Journal of Marriage and the Family, 33, 263-290.

Ward, C. (1986). The meaning of role strain. Advances in Nursing Science, $8,39-49$.

Worcester, M., \& Quayhagen, M. (1983). Correlates of caregiving satisfaction: Prerequisites to elder home care. Research in Nursing and Health, 6 , 61-67.

Zarit, S., Reever, K., \& Bach-Peterson, J. (1980). Relatives of the impaired alderly: Correlates of feelings of burden. The Gerontologist, 20, 649-655.

Zarit, S., Todd, P., \& Zarit, J. (1986). Subjective burden of husbands and wives as caregivers: A longitudinal study. The Gerontologist, 26, 260-266. 


\section{APPENDIX A}

FOCUS GROUP INTERVIEW 


\section{FOCUS GROUP INTERVIEW}

Site

Protocol:

Introduce self

Inform about process: Please state you name and who it is that you take care of and where that person is, whether at home, foster care, or formal care.

After everyone is finished, we will start with the questions. My job is to ask

the questions and then I will fade into the background. For the most part, this is your discussion and we want to learn from you.

1. What kinds of things make your caregiving either easier or harder for you?

2. How does the kind of caregiving that people do at home differ from the kind of caregiving that people do when their family member is in a formal care facility, such as a nursing home?

3. Thinking about placing your family member into a formal care facility, when is it time to make that move? What kinds of things do you consider in making that decision?

4. Who else could be helpful when someone is trying to make the decision about moving their family member to a formal care facility? What about doctors? Nurses?

5. What would you recommend to someone who has a family member who has just been diagnosed with Alzheimer's Disease?

6. What would you recommend to someone who is trying to decide about using a nursing home or foster care? 
APPENDIX B

INFORMED CONSENT 


\section{STATEMENT OF INFORMED CONSENT}

I, hereby agree to participate in a research project, "Family Caregivers for Alzheimer's Patients in Formal Care Settings,: conducted by Marie Duncan, RN, MS, a graduate student in the Urban Studies Doctoral Program, under the supervision of Professor David L. Morgan, Institute on Aging, Portland State University.

I understand that the study involves participating in a taperecorded discussion concerning my experience with caregiving after institutionalization of my family member.

I understand that there may be psychological risks associated with the discussion of a potentially stressful topic, such as my personal experiences with the decision to institutionalize an elderly family member. I also understand that there is some inconvenience associated with giving up an hour or two to participate in the research.

It has been explained $i \dot{u}$ ine that the purpose of the study is to learn how the decision to institutionalize a victim of Alzheimer's Disease and to continue in a caregiving role affects the involved family members. It has also been explained to me that the purpose of these sessions is to collect data for research and that I may not receive any direct benefit from participating in this study. My participation may, however, help to provide knowledge that will benefit others in the future.

Marie Duncan and Professor Morgan have offered to answer any questions I may have about the study and what is expected of me in the study. I have been assured that all information I give will be kept confidential and neither my name nor identity will be used for publication or public discussion purpose.

I understand that I am free to withdraw from participation in this study at any point without jeopardizing my relationship with Portland State University or any of the other groups and organizations associated with this study.

I have read and understand the foregoing information and agree to participate in this study.

Date Signature

If you experience problems that are the result of your participation in this study, please contact the Chair of the Human Subjects Review Committee, Office of Grants and Contracts, 303 Cramer Hall, Portland State University, 725-3417. 
APPENDIX C

FOLLOW-UP INTERVIEW GUIDE 
INTERVIEW GUIDE

First Name

AdC

Date

$\mathrm{Sp}$

Sp

I General Information

Tell me about the move of your family member (specify) in to formal care (name of facility if known).

I understand is in a formal care facility

-). Tell me about the move.

How long ago did this move take place?

How long has been at ?

How often do you see ?

When you do visit, can you give me an idea of that is like?

What kinds of things are you involved in now?

How often are you able to do these activities? 
II Staff: Perceptions and Interaction

What kind of contacts do you have with staff?

What is it like dealiniy with staff?

OR

How much input do you have into caregiving decisions?

What kinds of things (activities) do they want from you

$\mathrm{OR}$

Do they make any requests of you?

Are there things staff do that help you stay involved?

Are there some things staff do to help you feel good about your caregiving?

What kinds of things help you feel good about your caregiving?

Have you ever had any problems with the staff?

When you think of a staff member who is outstanding in the caregiving with good? , what is it that makes them so

There are lots of kinds of staff members who work at the nursing home. Who do you come in contact with most often?

What is the difference in the contact you have with nurses and aides?

$O R$

Is there a difference in the contacts you have between nurses and aides? 
Is there a difference in the kind of care each gives?

$O R$

Is it important to you which health team member provides the care?

Suppose you couldn't provide the amount of care you do now, what would happen?

If you weren't able to be there as often as you are now, what would happen?

\section{Family}

[Introduce by: One of the things you mentioned, or One of the areas I'm interested in is Family]

Were other family members involved in the move/decision to move?

Did this involvement change after the move to the nursing home?

If so, how (focus on involvement)?

\section{Exit}

[If the interview is short and factual, can ask for their summary/if interview is difficult, long, or angry, may already be able to summarize]

How would you say caregiving in formal care is different from caregiving at home?

As a family caregiver, what would you suggest I should share with family members who are reflecting on placement informal care? 
OR

When I reread the transcripts of the focus group, I heard family members saying they were afraid of this placement decision -- what would yo say to them?

What would you suggest I tell nursing home staff?

\section{OR}

I will be trying to create a list of do's and don'ts for staff -. from your perspective, what should be on that list?

Is there anything you wanted to share with me about caregiving that I haven't asked about? 